\title{
A robust and versatile nanobody platform for drug delivery
}

Zhuolun Shen ${ }^{1,7}$, Yufei Xiang ${ }^{1}$, Sandra Vegara ${ }^{2}$, Apeng Chen ${ }^{3,4}$, Zhengyun Xiao ${ }^{1}$, Ulises Santiago ${ }^{6}$, Changzhong $\mathrm{Jin}^{1}$, Zhe Sang ${ }^{1}$, Jiadi Luo ${ }^{5}$, Kong Chen $^{5}$, Dina Schneidman-Duhovny ${ }^{8}$, Carlos Camacho ${ }^{6}$, Guillermo Calero' ${ }^{2}$, Baoli $\mathrm{Hu}^{3,4,9}$, and $\mathrm{Yi} \mathrm{Shi}^{1}$

1. Department of Cell Biology, University of Pittsburgh, PA, USA

2. Department of Structural Biology, University of Pittsburgh, PA, USA

3. Department of Neurological Surgery, University of Pittsburgh, PA, USA

4. Pediatric Neurosurgery, UPMC Children's Hospital of Pittsburgh, PA, USA

5. Department of Medicine, University of Pittsburgh, PA, USA

6. Department of Computational and Systems Biology, University of Pittsburgh, PA, USA

7. School of Medicine, Tsinghua University, Beijing, China

8. School of Computer Science and Engineering, Institute of Life Sciences, University of Jerusalem, Israel

9. Molecular and Cellular Cancer Biology Program, UPMC Hillman Cancer Center, PA, USA

Correspondence should be addressed to Yi Shi (yi.shi@pitt.edu)

\section{Abstract}

Therapeutic and diagnostic efficacies of numerous small biomolecules and chemical compounds are hampered by the short half-lives. Here we report the development of a repertoire of diverse, high-affinity albumin-nanobodies ( $\mathrm{Nb}_{\mathrm{HSA}}$ ) to facilitate drug delivery. By integrating biophysics, and hybrid structural biology, we have systematically characterized the $\mathrm{Nb}_{\mathrm{HSA}}$ for albumin binding, mapped the epitopes, and resolved the architecture of a tetrameric $\mathrm{Nb}$-albumin complex. We employed quantitative proteomics for accurate, multiplex $\mathrm{Nb}$ pharmacokinetic analysis. Using a humanized albumin mouse model, we found that the $\mathrm{Nb}_{\mathrm{HSA}}$ has outstanding pharmacokinetics; the most stable $\mathrm{Nb}_{\mathrm{HSA}}$ has a 771 -fold $\mathrm{T}_{1 / 2}$ improvement compared with a control $\mathrm{Nb}$. Interestingly, the pharmacokinetics of $\mathrm{Nb}_{\mathrm{HSA}}$ is related to their biophysical and structural properties. To demonstrate the utility of $\mathrm{Nb}_{\mathrm{HSA}}$, we developed a highly stable $\mathrm{Nb}_{\mathrm{HSA}}-\mathrm{hlL}-2$ cytokine conjugate "Duraleukin" and confirmed its improved anticancer properties than hIL-2 alone. We envision that this high-quality $\mathrm{Nb}$ resource will advance research into novel biotherapeutics.

\section{Main text}

\section{Introduction}

Numerous chemical compounds and small biologics, such as hormones, cytokines, and coagulation factors, have limited therapeutic efficacy due to their poor in vivo stabilities. Different strategies have been implemented to address this challenge, including chemical modifications, conjugation with the antibody Fc domain, and targeting to human serum albumin (HSA). Human serum albumin (HSA) is an abundant serum protein with an exceptionally long half-life of $\sim$ three weeks ${ }^{1}$. Unlike small biomolecules $(<50 \mathrm{kDa})$ rapidly eliminated (e.g., from mins to a few hours) via glomerular filtration, HSA can be retained due to the relatively large size $(66.5 \mathrm{kDa})$. Importantly, HSA can bind with the neonatal Fc receptor (FcRn) at acidic $\mathrm{pH}$ and is continuously recycled via the FcRn-mediated transcytosis ${ }^{2,3}$. Because of its stable interaction with the FcRn, it can escape the endo-lysosomal degradation pathway and obtain outstanding serum stability. Interestingly, although HSA is highly abundant in the serum, its intracellular concentration is likely very low ${ }^{3,4}$.

The high in vivo solubility and stability of HSA make it an attractive endogenous carrier for drug delivery. Different HSA-based strategies, such as direct fusion to HSA, albumin-binding domains (ABDs) derived from gram-positive bacteria, and albumin nanoparticles, have been developed ${ }^{1,3,5}$. Despite the encouraging progress, however, successful applications of these methods towards robust bioengineering 

available under aCC-BY-NC-ND 4.0 International license.

and clinical uses remain limited ${ }^{6}$. The development of robust agents, ideally easily accessible to the research community, will help advance drug development.

Nanobodies (Nbs) are small antigen-binding fragments ( $15 \mathrm{kDa})$ derived from the camelid's heavy chain only antibodies (HcAbs) ${ }^{7}$. They are well known for the robust folds, excellent solubility, stability, and ease of bioengineering and manufacturing. Besides, they can efficiently penetrate tissues and are potentially low immunogenic for clinical applications due to the high sequence similarity with the human IgGs. Because of these characteristics, Nbs have emerged as a new class of antibodies for biomedical research and drug development ${ }^{8,9}$.

We have recently discovered an extensive repertoire of anti-HSA $\mathrm{Nbs}\left(\mathrm{Nb}_{\mathrm{HSA}}\right)$ by camelid immunization of recombinant HSA in conjugation to proteomic identifications $\left\{\right.$ Xiang et al., submitted ${ }^{10}$. We selectively produced a set of diverse $\mathrm{Nb}_{\mathrm{HSA}}$ sequences for systematic characterizations by multidisciplinary approaches, including biophysics, integrated proteomics, structural biology, and modeling. We then developed a strategy based on PRM (parallel reaction monitoring) mass spectrometry that enabled unbiased, parallel pharmacokinetic (PK) analysis of dozens of high-affinity $\mathrm{Nb}_{\mathrm{HSA}}$ in a humanized albumin mouse model. Our studies revealed that the $\mathrm{Nb}_{\mathrm{HSA}} \mathrm{PKs}$ are related to their binding kinetics at the acidic $\mathrm{pH}$ environment and their epitopes. To demonstrate the utility of our $\mathrm{Nb}_{\mathrm{HSA}}$, we conjugated high-affinity, crossspecies Nbs to a critical cytokine interleukin-2 (hlL-2), developed and characterized several stable $\mathrm{Nb}$ cytokine conjugates (Duraleukins), and have confirmed the improved antitumor efficacy of a Duraleukin than hIL-2 in a melanoma mouse model. We envision that this high-quality $\mathrm{Nb}$ resource and the hybrid proteomic technologies will find broad utility in biomedical applications.

\section{Results}

\section{Characterization of a highly diverse repertoire of high-quality $\mathrm{Nb}_{\mathrm{HSA}}$}

A collection of 71 recombinant His6-tagged Nbs with diverse sequences was produced from $E$. coli cells (Fig 1a, Table S1). The selected $\mathrm{Nb}_{\mathrm{HSA}}$ vary significantly on the CDR3 (complementarity-determining region 3) fingerprint regions, including amino acid compositions, sequence length, isoelectric points (pls), and hydrophobicity potentially spanning a large spectrum of physicochemical structural properties (Fig 1b). We performed enzyme-linked immunosorbent assay (ELISA) to assess their relative affinities and crossspecies selectivities. We ranked $\mathrm{Nb}_{\mathrm{HSA}}$ based on the ELISA affinities to different albumins, including HSA, cynomolgus monkey albumin, and mouse albumin. HSA is highly conserved with cynomolgus monkey albumin (92\% sequence identity) and is relatively conserved with mouse albumin (78\% sequence identity). As expected, greater than $75 \%\left(53 \mathrm{Nb}_{\mathrm{HSA}}\right)$ of $\mathrm{Nb}_{\mathrm{HSA}}$ can bind monkey albumin, and $11 \%\left(8 \mathrm{Nb}_{\mathrm{HSA}}\right)$ can bind mouse albumin (Fig 1c, Methods). Interestingly, $8 \%$ (6 Nb $\mathrm{NSA}_{\mathrm{HA}}$ ) strongly associated with all three albumin orthologs and were confirmed by immunoprecipitations (Fig 1c). For example, $\mathrm{Nb}_{132}$ binds both humans, monkeys, and mouse albumin but not bovine and llama albumin (Fig 19). The high affinity, cross-species $\mathrm{Nb}_{\text {HSA }}$ are particularly useful for $\mathrm{Nb}$-based drug development in the animal models.

We selected $20 \mathrm{Nb}_{\mathrm{HSA}}$ of high yields (from $E$. coli cell lysis) to assess the binding kinetics by surface plasmon resonance (SPR) (Fig 1d, Fig S1). We found a good correlation (Pearson $r=0.78, p<0.001$ ) between the ELISA affinity and SPR $K_{D}$ (Fig 1e). 75\% (15 out of 20) of $\mathrm{Nb}_{\text {HSA }}$ present sub-nM $\mathrm{K}_{\mathrm{D}}$ with different binding kinetics, while the remaining $25 \%$ have single-digit to hundreds of nM affinities (Fig 1f). Next, we evaluated the thermostability of $\mathrm{Nb}_{\mathrm{HSA}}$ by differential scanning fluorimetry. The Nbs are generally thermostable, with melting temperatures between $39 \square \mathrm{C}$ to $70 \square \mathrm{C}$ (Fig 1h, Fig S2, Table S2). The excellent physicochemical properties, including solubility, target specificity, affinity, and stability, are essential for $\mathrm{Nb}$ therapeutic development ${ }^{11,12}$.

\section{Integrative structural proteomics reveals dominant epitopes for $\mathrm{Nb}_{\mathrm{HSA}}$ binding.}

Epitope mapping provides insight into antigen-antibody interactions and is useful for rational drug designs ${ }^{13-15}$. We employed an integrative structure approach by chemical cross-linking/mass spectrometry 

available under aCC-BY-NC-ND 4.0 International license.

(CXMS) and computational modeling to map HSA epitopes for Nb binding. CXMS identifies residue-specific cross-link restraints that are highly informative to interrogate the binding interfaces of protein complexes. Cross-linking information can be readily integrated into other structural biology techniques and computational tools to derive accurate structural models ${ }^{16-21}$.

We purified and reconstituted 38 different HSA-Nb complexes for disuccinimidyl subtracted (DSS) crosslinking, which can reach up to $30 \AA$ between two cross-linked amines (e.g., lysine residues). A total of 125 intersubunit cross-links were confidently identified by high-resolution MS (Table S3, Methods). These cross-links were then used to compute structural models. Integrative modeling analysis revealed that 29 HSA-Nb complexes converged with an average RMSD (root-mean-square-deviation) of $7.4 \AA$ (Fig 2c). Overall, $87.5 \%$ of cross-links were satisfied by the models (i.e., $<30 \AA$ ) (Fig S3b).

Cross-linking based structural modeling identified 6 HSA epitope clusters (from A to F) of $\mathrm{Nb}_{\mathrm{HSA}}$ (Fig 2a, Table S3). Despite the high sequence diversity of CDR3s, $>75 \%$ of the $\mathrm{Nb}_{\mathrm{HSA}}(21 \mathrm{Nbs})$ binds two dominant epitope clusters: clusters A (31.03\%) and E (44.83\%) (Fig 2b), indicating a convergent, CDR3dependent contact between Nbs and HSA. We found excellent shape complementarities between the concave epitopes on HSA and the corresponding convex paratopes of $\mathrm{Nb}_{\mathrm{HSA}}$ for high-affinity interactions (Fig 2d). Interestingly, a sub-nM affinity $\mathrm{Nb}\left(\mathrm{Nb}_{126}\right)$ was identified to localize at the major crevice on $\mathrm{HSA}$ that regulates FcRn binding (Fig S3a), raising a possibility of competitive binding between Nb126 and the FcRn.

\section{Hybrid structural determination of a tetrameric $\mathrm{HSA}-\mathrm{Nb}$ complex}

To further verify our integrative structures, we selected $\mathrm{Nb}_{13}, \mathrm{Nb}_{29}$, and $\mathrm{Nb}_{80}$ that correspond to three epitope clusters A, C, and E, respectively, and employed size-exclusion chromatography (SEC) to confirm that they do not compete for HSA binding. The presence of three separate SEC peaks corresponding to HSA-Nb complexes of different molecular weights indicates that these Nbs bind distinct HSA epitopes (Fig 3a). After SEC, a homogenous fraction of the complex was selected for analysis by negative stain electron microscopy (EM). 22,000 EM particles were selected to reconstruct a 3D density map (Fig 3b, Methods). Consistently, the cross-link models of the tetrameric Nb-HSA complex agreed well with EM density (Fig 3c). Based on our integrative structure, we found that sub-nM Nb $80\left(K_{D}=166 \mathrm{pM}\right)$ and $\mathrm{Nb}_{13}\left(\mathrm{~K}_{\mathrm{D}}=201 \mathrm{pM}\right)$ have better shape complementarity with HSA than $\mathrm{Nb}_{29}\left(\mathrm{~K}_{\mathrm{D}}=1.2 \mathrm{nM}\right)$ (Fig 3d-f). Our models revealed the formation of two crossed, salt bridge pairs between $\mathrm{HSA}_{K 383}$ and $\mathrm{HSA}_{\mathrm{E} 400}$ with the respective CDR residues on $\mathrm{Nb}_{80}$. To validate this, we made two HSA mutants and evaluated their binding to $\mathrm{Nb}_{\mathrm{HSA}}$ (Fig $\mathbf{3 g}$ ). While a single-point mutation $\mathrm{E} 400 \mathrm{R}$ significantly weakened the $\mathrm{HSA}-\mathrm{Nb}_{80}$ association, a double-residue mutation (K383D-E400R) completely abolished the strong interaction (Fig 3h). Collectively, our integrative structure of the tetrameric HSA-Nb complex confirmed the epitope mapping results and provided the structural basis to understand the HSA-Nb interactions.

\section{Development of a proteomic approach that enables specific, accurate and multiplex $\mathrm{Nb}$ pharmacokinetic analysis}

ELISA has been extensively used for the analysis of antibody PK. However, this approach can be significantly limited by the availability of high-quality detection antibodies, rendering specific and accurate PK analysis from the complex serum background challenging. Such a method is particularly challenging for comparative PK analysis of a large set of antibodies as it requires a substantial cohort of animals and slow handling time that may complicate experiments and introduce bias. To alleviate these problems, here we developed a strategy by employing MS2-based quantitative proteomics (parallel reaction monitoring or PRM) to facilitate specific, accurate, and multiplex analysis of $\mathrm{Nb}$ PKs from the serum samples. This approach enables specific detections of at least three femtomoles of an $\mathrm{Nb}\left(10^{-15} \mathrm{~mole}\right)$ per $\mu \mathrm{L}$ of the serum and offers better quantification linearity than the MS-1 based approach $\left(R^{2}=0.999\right)$ (Fig S5, Table S4). The high dynamic range of this approach is essential for accurate PK measurement. 

available under aCC-BY-NC-ND 4.0 International license.

Since most of our $\mathrm{Nb}_{\mathrm{HSA}}$ do not strongly bind mouse albumin, we chose a humanized albumin mouse model to mimic the physiology of endogenous HSA in humans. This mouse model (B6.Cg$\mathrm{Tg}$ (FCGRT)32Dcr Alb ${ }^{\text {em12Mvw }}$ Fcgrt ${ }^{\text {tm1Dcr} / M v w J) ~ r e m o v e d ~ t h e ~ n a t i v e ~ m o u s e ~ a l b u m i n ~ a n d ~ r e p l a c e d ~ t h e ~ m o u s e ~}$ FcRn with a human ortholog. HSA can be later administered to study PK of HSA-based drugs ${ }^{22}$.

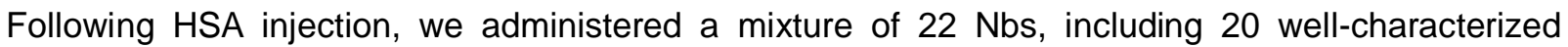
$\mathrm{Nb}_{\text {HSA }}$ (with SPR kinetic and thermostability measurements) and two non-binder control Nbs with equal molarity to this model $(n=3)$ via single bolus intravenous (i.v.) injections (Methods). We used a molar ratio of $1: 5$ between $\mathrm{Nb}_{\mathrm{HSA}}$ and $\mathrm{HSA}$ to ensure an excessive HSA, avoiding potential competitive binding among different $\mathrm{Nb}_{\mathrm{HSA}}$. The blood was sampled at different time points post-injection. Sera fractions containing $\mathrm{Nb}_{\mathrm{HSA}}$ and other serum proteins were efficiently proteolyzed. The resulting signature $\mathrm{Nb}_{\mathrm{HSA}}$ peptides and their fragment ions were accurately quantified by PRM ${ }^{23,24}$ (Fig 4a, Table S4). The median CV (coefficient of variation) of our proteomic quantifications from three animals was 15.3\% (Fig S6).

We observed that the control Nbs were rapidly cleared from the serum with the half-lives $\left(T_{1 / 2} s\right)$ of approximately 26-60 mins, consistent with the previous ELISA measurements ${ }^{25}$. In sharp contrast, our $\mathrm{Nb}_{\text {HSA }}$ showed significantly increased $\mathrm{T}_{1 / 2} \mathrm{~S}$ of up to 771 - fold, from 1.6 days $\left(\mathrm{Nb}_{100}\right)$ to 7.6 days $\left(\mathrm{Nb}_{75}\right)$ (Fig 4b, 4c, Table S2). The $\mathrm{T}_{1 / 2} \mathrm{~S}$ of $\mathrm{Nb}_{\mathrm{HSA}}$ correlated with $\mathrm{T}_{1 / 2}$ of $\mathrm{HSA}$ ( 8 days) that we measured in this model (Fig S7c). To explore the potential mechanism(s) that underlies the relatively fast $T_{1 / 2}$ of $H S A$ in this mouse model (the $T_{1 / 2}$ of HSA in humans is $\sim 21$ days), we employed label-free quantitative proteomics ${ }^{26,27}$ to monitor the longitudinal changes of the blood proteome of a mouse (up to 10 days) post-HSA injection. Four hundred forty-one blood proteins were accurately quantified and clustered based on their relative abundance changes (Fig S8). We found that a group of acute-phase inflammatory proteins, such as Serum Amyloid A and C-reactive protein, increased by hundreds of folds in abundance after 12-24 hours postinjection, before returning to the baseline level after 24-48 hours ${ }^{28,29}$. Interestingly, we observed an increase of serum IgGs after 5-7 days indicating the potential anti-HSA immune response, which may explain the faster-than-expected clearance of the injected HSA in this model ${ }^{30}$.

\section{$\mathrm{Nb}_{\text {HSA }}$ pharmacokinetics are related to their physicochemical and structural properties.}

The findings that $\mathrm{Nb}_{\mathrm{HSA}}$ has diverse $\mathrm{PK}$ prompted us to investigate the potential mechanism(s) contributing to such differences. We analyzed the correlations between the PK and the physicochemical properties of $\mathrm{Nb}_{\mathrm{HSA}}$, including affinity (at both neutral and acidic $\mathrm{pHs}$ ), $\mathrm{T}_{\mathrm{M}}$, pl, and hydrophobicity (Fig $\mathbf{4 d}$ ). We found that $\mathrm{Nb}_{\mathrm{HSA}}$ ELISA affinities at $\mathrm{pH} 5$ (acidic $\mathrm{pH}$ ) and SPR dissociation rates $\mathrm{K}_{\mathrm{d}}$, positively correlated with the elimination rates $(p<0.01)$. In general, the higher the affinities, the slower $\mathrm{Nb}_{\text {HSA }}$ was cleared from the blood. It is conceivable that both the slow dissociation-rates and high-affinity binding at the acidic $\mathrm{pH}$ are important for the extended $\mathrm{T}_{1 / 2}$ of the low abundance $\mathrm{Nb}_{\mathrm{HSA}}-\mathrm{HSA}-\mathrm{FcRn}$ ternary complexes in the endosome. $\mathrm{Nb}_{\mathrm{HSA}}$ with lower affinities at the acidic $\mathrm{pH}$ tend to dissociate faster from the complex and, therefore, have decreased $\mathrm{T}_{1 / 2}$. The only exception was $\mathrm{Nb}_{126}$, which binds strongly with HSA ( $\mathrm{K}_{\mathrm{D}}$ of $251 \mathrm{pM}$ ) and has relatively fast $\mathrm{T}_{1 / 2} \mathrm{~S}(41.4 \mathrm{hrs})$. The interaction with HSA might be interfered with by a structural change of the epitope induced by FcRn binding (Fig S3a) ${ }^{2,30}$.

\section{Development of Duraleukin - a novel application of the $\mathrm{Nb}_{\mathrm{HSA}}$ platform for cancer immunotherapy}

To demonstrate the utility of our Nbs for drug development, we applied them to modify a key cytokine interleukin-2 (IL-2). IL-2 functions primarily to regulate immune cells such as T cells and natural killer cells, thereby regulating immune responses that suppressor cancer ${ }^{31}$. Human IL-2 (hIL-2) was the first FDA-approved cancer immunotherapy drug (in 1992) developed for effective treatment of renal cell carcinoma and metastatic melanoma ${ }^{32}$. $\sim 10 \%$ of these devastating late-stage cancer patients who received high dose hlL-2 treatment had a complete response. However, the clinical efficacy of hIL-2 has been significantly limited by its small size ( 15 kDa) and poor PK (i.e., shorter than 30 minutes in humans) ${ }^{31,32}$. High-dose, repetitive administration of hIL-2 (e.g., i.v. treatment every 8 hours), while critical for its antitumor efficacy, can lead to severe side effects such as liver toxicity and vascular leak syndrome ${ }^{32,33}$. 
We fused our $\mathrm{Nb}_{\mathrm{HSA}}$ with hlL-2 to develop "Duraleukin" for mitigation of the poor PK of hIL-2 (Fig 5a). We chose three high-affinity $\mathrm{Nb}_{\mathrm{HSA}}\left(\mathrm{Nb}_{77}, \mathrm{Nb}_{80}\right.$ and $\left.\mathrm{Nb}_{158}\right)$ that bind both human and mouse albumin to demonstrate the robustness of this approach. Large quantities of Duraleukins $\left(\mathrm{DL}_{77}, \mathrm{DL}_{80}\right.$ and $\left.\mathrm{DL}_{158}\right)$ were rapidly produced from E. coli (Fig $5 \mathbf{b}$, Methods). All three DLs demonstrated excellent thermostability $\left(\mathrm{T}_{\mathrm{m}} \approx\right.$ $60{ }^{\circ} \mathrm{C}$, Fig 5c). They had comparable bioactivities to hlL-2 alone in the in vitro $\mathrm{CD}^{+} \mathrm{T}$ cell proliferation assay (Fig 5d), and were stable for days when incubated with mouse serum at $37^{\circ} \mathrm{C}$ (Fig $\mathbf{5 e}$ ). Moreover, these DLs retained sub-nM affinities for HSA binding (Fig $5 \mathbf{e}$ ). We selected $\mathrm{DL}_{80}$ for further in vivo evaluation because it has a high affinity for both mouse and human albumin binding, and remained associated with $\mathrm{HSA}$ at acidic $\mathrm{pH}$ (Fig $\mathbf{5 g}$ ).

\section{Duraleukin demonstrates superior therapeutic efficacy for melanoma treatment in a mouse model.}

We confirmed that $\mathrm{DL}_{80}$ had a 46-fold improvement of PK compared with hIL-2 in C57BL/6J mouse (Fig S9). This relatively moderate improvement corresponds to the half-life of endogenous mouse albumin $\left(<1\right.$ day) ${ }^{25}$. We then assessed its therapeutic efficacy in the B16F10 melanoma model ${ }^{34}$. Tumor-bearing C57BL/6J mice were intraperitoneally administered with equimolar of either $\mathrm{DL}_{80}$ or hIL-2 at each injection. The animals were treated with different frequencies (every six days for $\mathrm{DL}_{80}$ and hIL-2 daily) for a 24-day treatment. TA99 monoclonal antibody that recognizes melanoma marker TRP1 and functions synergistically with hIL-2, was co-treated for both groups ${ }^{35-38}$ (Methods). We continuously monitored tumor sizes and survival for 62 days starting from the first treatment (Fig 6a, 6b). We observed that both DL $_{80}$ and hIL-2 treated groups exhibited significant reductions in tumor loads and better overall survival than the PBS controls. As little as $1 / 6$ total therapeutic dose was applied to the $\mathrm{DL}_{80}$-treated animals, and due to the relatively short T1/2 of mouse albumin, only a moderate PK improvement was observed in the C57BL/6J mice. Despite this, we observed near-complete tumor recessions for the $\mathrm{DL}_{80}$ responsive animals. In contrast, clear rebounds of tumorigenesis in the hIL-2 treated mice were evident (Fig 6a), indicating the potential benefits of the sustainable antitumor activity of $\mathrm{DL}_{80}$ for improving melanoma treatment.

To explore the mechanisms that contribute to Duraleukin's superior antitumor activity, we isolated tumors at different stages and analyzed their immune cells by flow cytometry (Fig 6c, Fig S10). We observed significant and persistent increases of tumor-infiltrating immune cells, including $\mathrm{CD}^{+} \mathrm{T}$ cells and natural killer (NK) cells in the $\mathrm{DL}_{80}$-treated tumor tissues at day three post-treatment. At the same time, hIL2 appeared to lose its activity for promoting $T$ cell expansion. Our results indicate that Duraleukin exerts its long-lasting antitumor activity by promoting tumor-infiltrating immune cells.

\section{Discussion}

The short serum half-lives limit the therapeutic and diagnostic efficacy of many small biotherapeutics, including cytokines, hormones, and Nbs. Here we develop a robust platform based on a large, diverse set of high-quality $\mathrm{Nb}_{\mathrm{HSA}}$ to improve PK. We have employed and developed multidisciplinary approaches that span biochemistry, biophysics, structural proteomics, and integrative structural biology, longitudinal blood proteomics, and a quantitative proteomics-based PK assay that collectively enabled systematic characterizations of Nbs for advanced biomedical applications. We have positively evaluated the outstanding $\mathrm{PK}$ of $\mathrm{Nb}_{\mathrm{HSA}}$ in a humanized HSA mouse model. To demonstrate the utility of this Nb platform, we applied several cross-species $\mathrm{Nb}_{\mathrm{HSA}}$ to a key cancer-fighting cytokine (IL-2) and developed a specific $\mathrm{Nb}$-based treatment (Duraleukin) for cancer. We demonstrated Duraleukin's increased antitumor activity compared to IL-2 therapy alone in a melanoma mouse model.

The $\mathrm{Nb}$ platform that we have developed here likely represents a significant step towards tailored, optimal drug delivery. First, it permits minimal interference with the bioactivity of the small target drug compared with other approaches such as chemical modifications and direct fusion to HSA ${ }^{1,5}$. The robustness of $\mathrm{Nb}_{\mathrm{HSA}}$ is desirable for bioengineering. Second, it comprises a set of well-characterized $\mathrm{Nb}_{\mathrm{HSA}}$ of excellent solubility, stability, and affinity. Their favorable physicochemical and structural properties are critical for drug development, administration, manufacturing, and storage ${ }^{12}$. Rapid bioengineering and cost- 

available under aCC-BY-NC-ND 4.0 International license.

effective production of Duraleukins, as demonstrated here, would be important for the future development of duraleukin technology towards clinical applications ${ }^{32}$. Third, it offers a wide range of PK, biophysical and structural properties towards possible tailored drug development. Fourth, it does not elicit Fc-associated antibody-dependent cellular cytotoxicity (ADCC) that is likely toxic to the functional cells by which the $\mathrm{Nb}$ fusion constructs target (such as IL-2R $\mathrm{R}^{+} \mathrm{T}$ cells). Combined with the high sequence similarity of Nbs to human $\lg G$ s, our approach may restrain the toxicity for clinical applications ${ }^{9,39}$.

Our investigation leveraged a powerful combination of proteomic technologies for drug development. The integrative structural analysis revealed major HSA epitopes and provided a structural basis to understand $\mathrm{Nb}_{\mathrm{HSA}}$ interactions with $\mathrm{HSA}$ and their PKs. Our analysis underlies the importance of highaffinity, acidic $\mathrm{pH}$-dependent binding of $\mathrm{Nb}_{\mathrm{HSA}}$ for half-life extensions. Our results indicate the presence of low intracellular concentration(s) of HSA-FcRn complex in vivo and the acidic microenvironment(s) of the FcRn receptor-mediated transcytosis ${ }^{3,4,40}$. Moreover, we found that the PK of our most stable $\mathrm{Nb}_{\mathrm{HSA}}$ is consistent with the half-life of HSA in the humanized mouse model. It is anticipated that $\mathrm{Nb}_{\mathrm{HSA}}$ will have significantly improved PK in the non-human primate models and humans.

We developed Duraleukins by taking advantage of the cross-species $\mathrm{Nb}_{\mathrm{HSA}}$ that help translate the preclinical data of animal models into clinical studies. Despite using a much smaller administration dose than hIL-2, Duraleukin 80 outperformed it for melanoma treatment. The improved drug efficacy of Duraleukin is likely due to the robust cytokine activity and improved half-life. The retention of albumin in the tumor interstitium has been reported ${ }^{3,41,42}$, raising a possibility that the superior efficacy of Duraleukin is related to its potentially favorable tumor localization as a cargo of albumin.

This proof-of-concept might be broadly applicable to other small antitumor cytokines such as hIL-15 43, ultimately leading to enhanced antitumor activity, optimal dosing regimen, better drug safety, and improved patient compliance. It is conceivable that a combination of Duraleukin and an immune checkpoint blockade therapy like PD-1/L1 or CTLA-4 may further improve cancer treatment in a synergistic manner 44,45 . It is also feasible to produce a trifunctional construct by adding another $\mathrm{Nb}$ that binds a prominent tumor surface marker (e.g., EGFR and HER2) for a more target-specific, and potentially more efficient, and safer therapy ${ }^{46}$. Future studies will be needed to investigate the $\mathrm{Nb}_{\text {HSA }}$ and Duraleukin for preclinical and clinical applications.

\section{Figure legends}




\section{Figure 1}

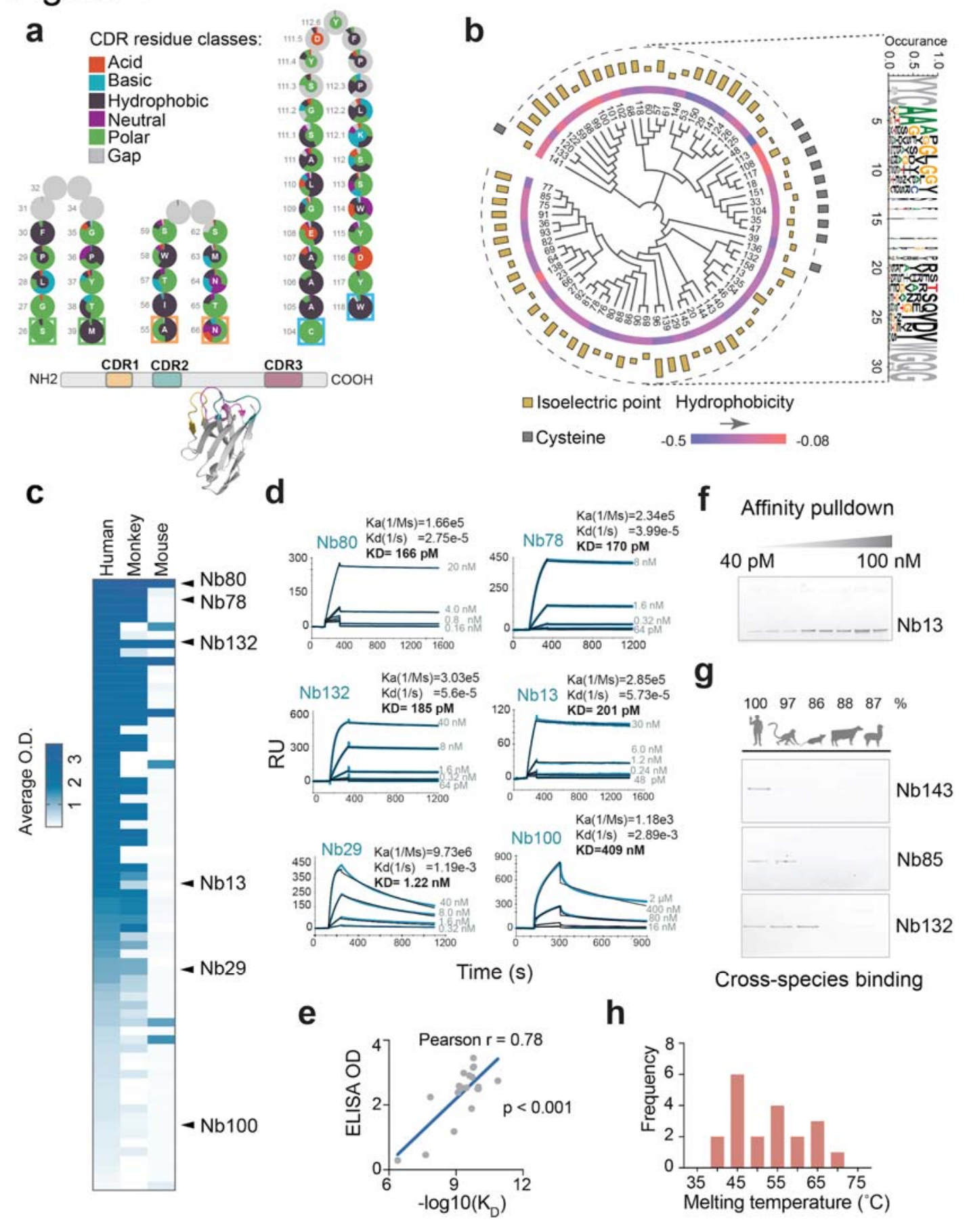

Figure 1. Identification and characterization of $\mathrm{Nb}_{\mathrm{HSA}}$.

a) Schematic structure and amino acid composition of $\mathrm{Nb}_{\text {HSA. }} 71$ different Nbs were analyzed by Yvis. The amino acid frequency at each CDR position was calculated. Amino acids were color-coded and classified based on the physicochemical properties.

b) Circos and sequence logo plots showing the diversity of CDR3.

c) ELISA heat map of albumin cross-species binding of 71 different Nbs.

d) Binding kinetics of 6 representative Nbs by SPR (surface plasmon resonance).

e) Correlation between ELISA O.D. (optical density) and SPR $K_{D}$ affinity. 
bioRxiv preprint doi: https://doi.org/10.1101/2020.08.19.257725; this version posted August 20,2020. The copyright holder for this preprint (which was not certified by peer review) is the author/funder, who has granted bioRxiv a license to display the preprint in perpetuity. It is made available under aCC-BY-NC-ND 4.0 International license.

f) Immunoprecipitation of the $\mathrm{HSA}-\mathrm{Nb}_{13}$ complex at different concentrations of $\mathrm{Nb}_{13}$.

g) Validation of $\mathrm{Nb}$ cross-species reactivity by immunoprecipitation. Three $\mathrm{Nbs}\left(\mathrm{Nb}_{143}, \mathrm{Nb}_{85}\right.$, and $\left.\mathrm{Nb}_{132}\right)$ were immunoprecipitated by affinity resins coupled with albumin of different species, including human, monkey, mouse, bovine, and llama.

h) The plot of the thermostability of $20 \mathrm{Nb}_{\mathrm{HSA}}$ selected for measurement by differential scanning fluorimetry. 


\section{Figure 2}

a

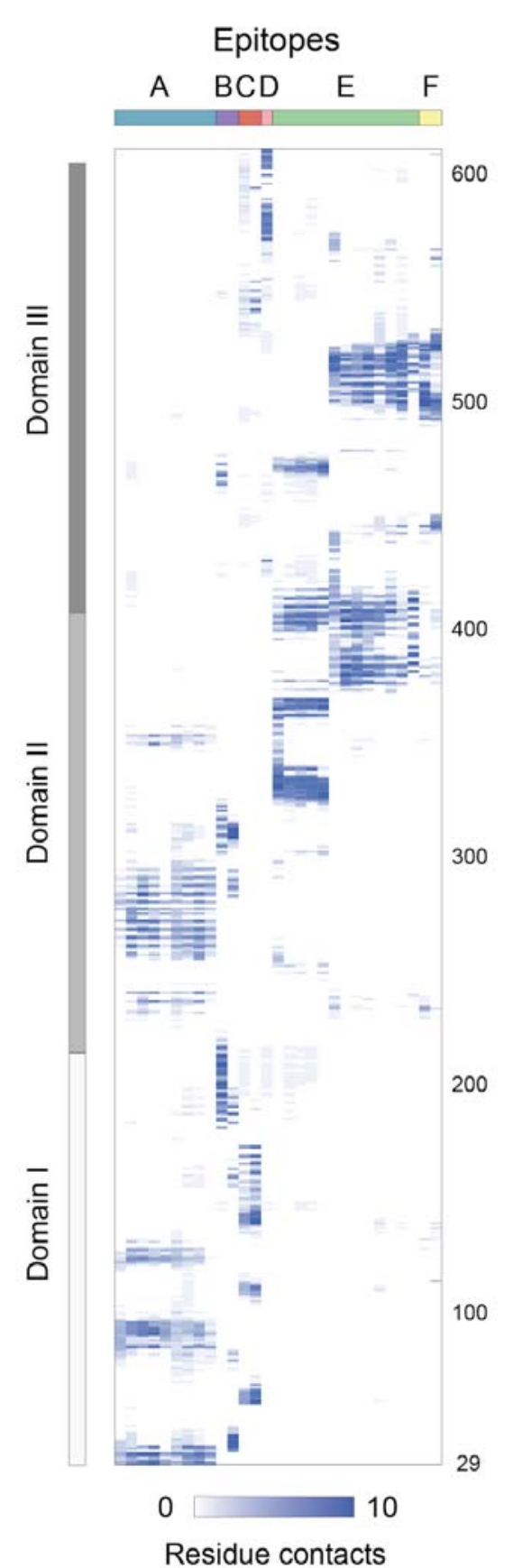

b
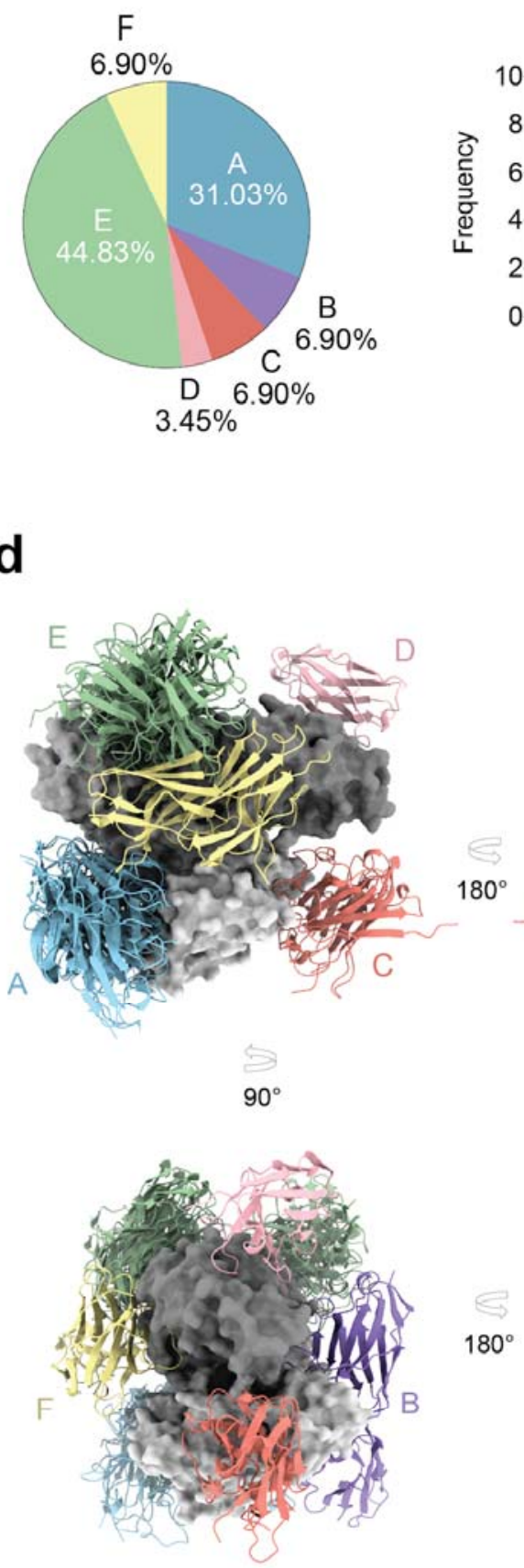

C

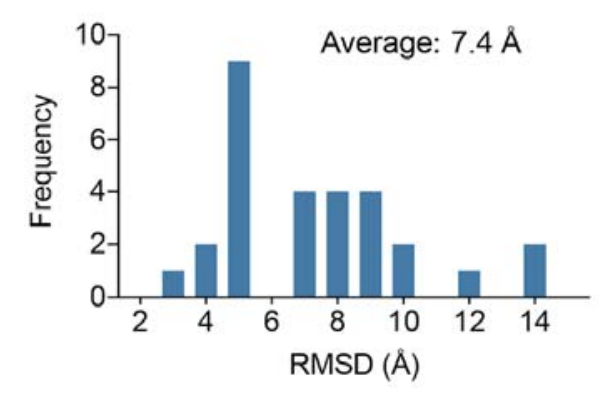


bioRxiv preprint doi: https://doi.org/10.1101/2020.08.19.257725; this version posted August 20, 2020. The copyright holder for this preprint (which was not certified by peer review) is the author/funder, who has granted bioRxiv a license to display the preprint in perpetuity. It is made available under aCC-BY-NC-ND 4.0 International license.

vary on other binding residues. $\mathrm{E}_{\mathrm{type} 1}$ : residues 321-331, 334-335, 358, 360-365, 395-413, 465-470; $\mathrm{E}_{\mathrm{type2}}$ : residues 371-387, 396-410, 494-519.

b) Percentage of epitope-specific $\mathrm{Nb}_{\mathrm{HSA}}$ based on converged cross-link models.

c) The RMSD (root-mean-square deviation, $\AA$ ) distribution of the cross-link models.

d) Integrative structural models of $\mathrm{HSA}-\mathrm{Nb}_{\mathrm{HSA}}$ complexes. Only the top-scored $\mathrm{Nb}_{\mathrm{HSA}}$ models were shown. Different molecules were presented in different colors. Grey (surface presentation): HSA (with three domains DI, DII, and DIII). $\mathrm{Nb}_{\mathrm{HSA}}$ corresponding to different epitopes were presented as cartoons. Epitope Cluster A: blue; B: purple; C: salmon; D: light pink; E: green; F: yellow. 


\section{Figure 3}

a

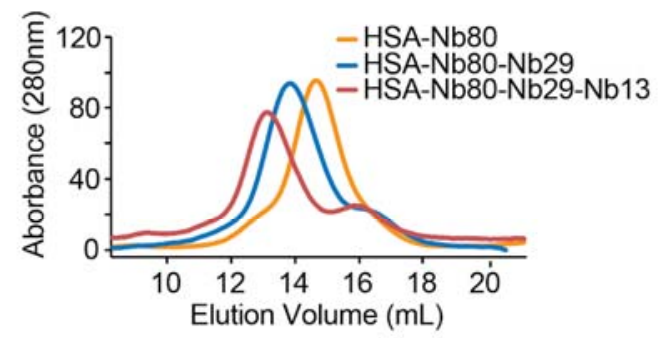

b

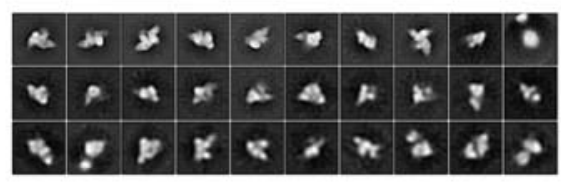

C

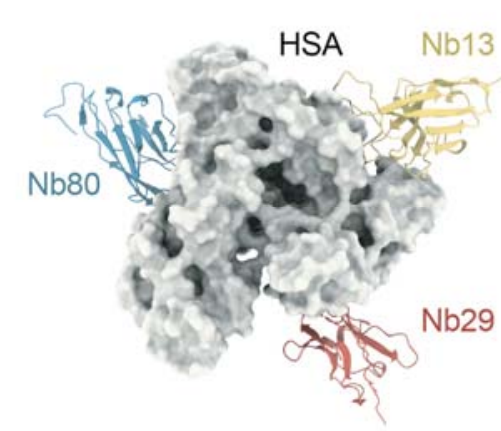

d

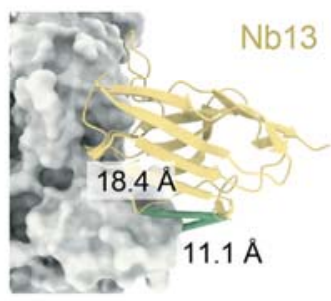

g

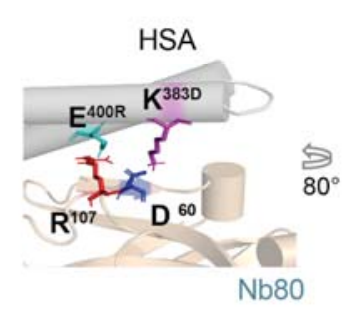

e

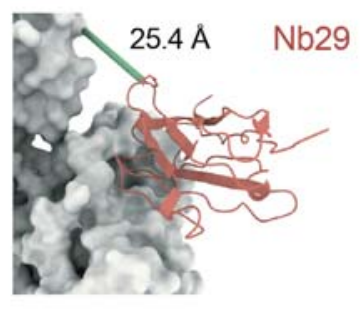

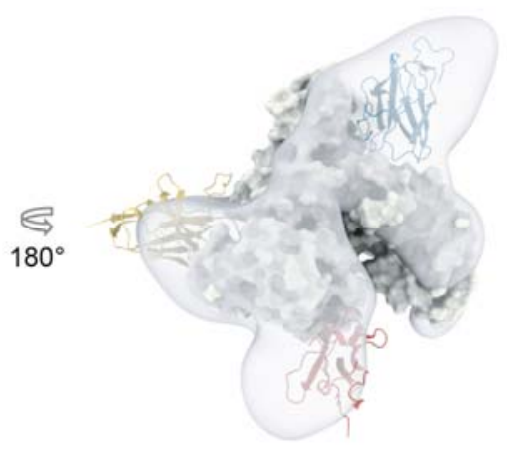

f

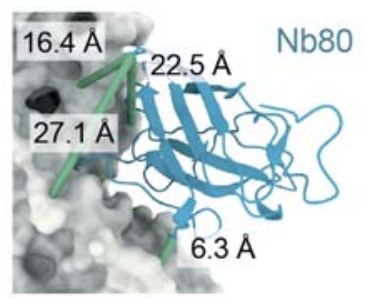

h
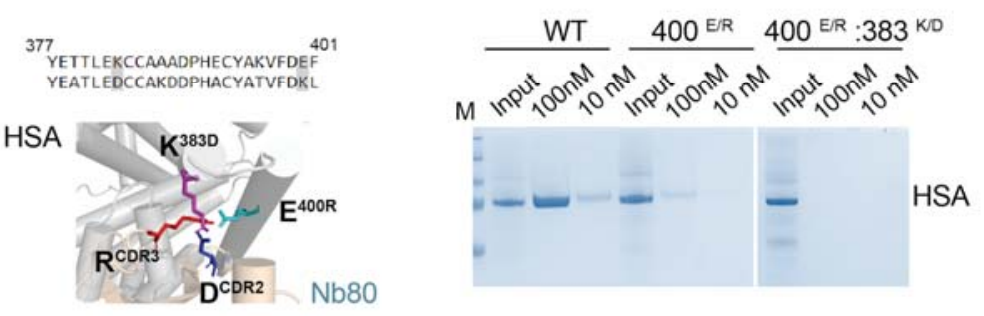

Figure 3. Integrative structural characterization of a tetrameric HSA-Nb complex.

a) Size-exclusion chromatography (SEC) analysis of the reconstituted tetrameric complex, including $\mathrm{Nb}_{13}$, $\mathrm{Nb}_{29}, \mathrm{Nb}_{80}$, and $\mathrm{HSA}$.

b) Representative negative stain EM images of the tetrameric complex.

c) Overlapping of the cross-link structure model of the tetrameric complex with the negative stain EM structure. $\mathrm{Nb}_{\mathrm{HSA}}$ were presented in different colors. Yellow: $\mathrm{Nb} 13$; salmon: $\mathrm{Nb29}$; blue: $\mathrm{Nb80}$.

d)-f) Close-up views of the interfaces of the tetrameric HSA-Nb complex and the cross-link restraints. 
bioRxiv preprint doi: https://doi.org/10.1101/2020.08.19.257725; this version posted August 20, 2020. The copyright holder for this preprint (which was not certified by peer review) is the author/funder, who has granted bioRxiv a license to display the preprint in perpetuity. It is made available under aCC-BY-NC-ND 4.0 International license.

g) A cross-link model of HSA and Nb80 interaction showing the putative salt bridges. Sidechains of two charged residues on HSA (K383 and E400) and the corresponding residues on Nb80 were shown. The HSA sequence (from residue 377 to residue 401) was aligned with camelid albumin.

h) HSA site-directed mutagenesis and immunoprecipitation of the mutant $\mathrm{HSA}$. $\mathrm{Nb}_{80}$-conjugated resins were used to pull down different HSA mutants, including E400R and E400R-K383D.

\section{Figure 4}

a

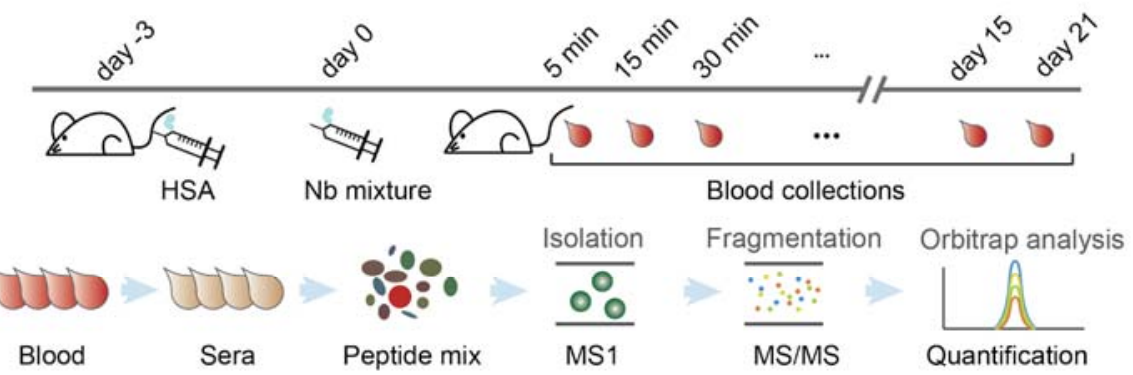

b

C
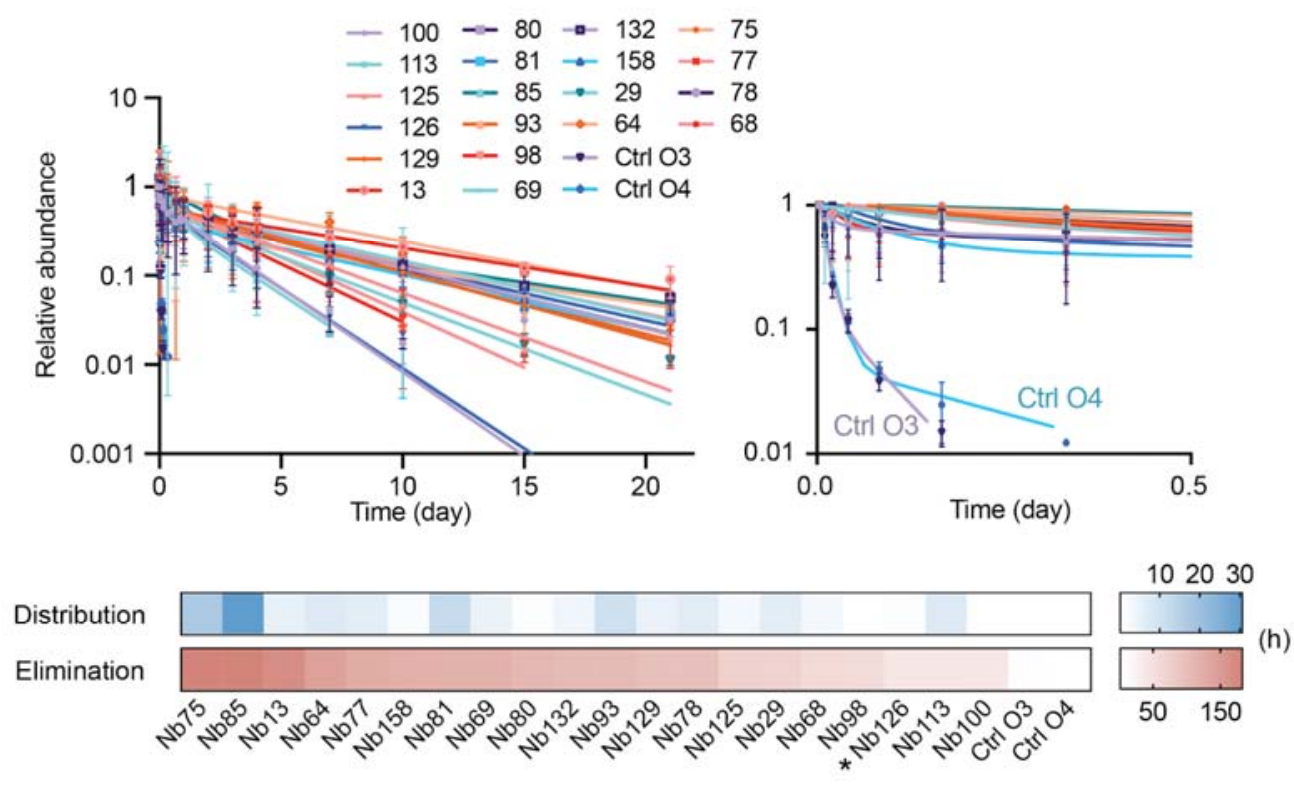

d

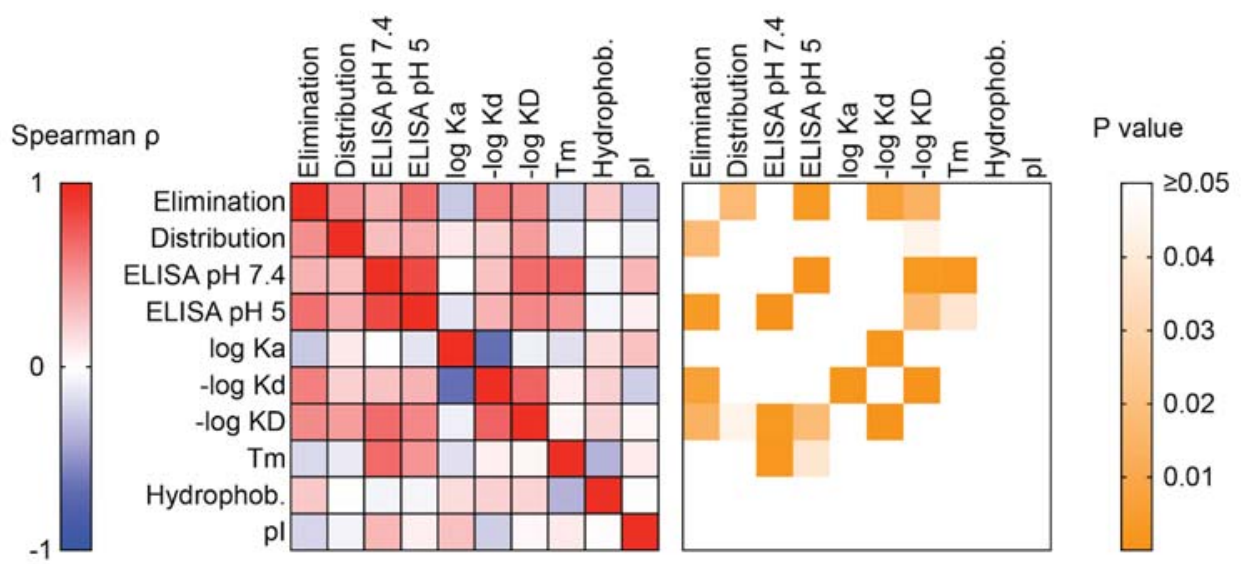

Figure 4. High-throughput $\mathrm{Nb}$ pharmacokinetics in a humanized albumin mouse model. 

available under aCC-BY-NC-ND 4.0 International license.

a) Schematics of the MS-based assay for multiplexed pharmacokinetic (PK) measurement. Briefly, after consecutive injections of HSA and the $\mathrm{Nb}$ mixtures into the mouse model, blood was collected at 21 different time points and processed for proteomics-based pharmacokinetic analysis.

b) PK analysis of $22 \mathrm{Nbs}$ in a humanized albumin mouse model. Single bolus administration of an equimolar mixture of $22 \mathrm{Nbs}$, including $20 \mathrm{Nb}_{\mathrm{HSA}}$ and two non-binder controls were administered to three animals via i.v.injection. Serum samples were collected at different time points and proteolyzed. The resulting peptides were analyzed by LC coupled to MS (PRM). Each data point indicates the median $\mathrm{Nb}$ abundance from three different animals. The analysis was repeated three times. The data was then fitted into a two-phase decay model to calculate the Nb half-lives.

c) Heatmap analysis of the distribution and elimination of Nb PK. *, See Fig S3A.

d) Correlative analysis between PK and the properties of Nbs. For each correlation analysis, the correlation coefficient Spearman $\rho$, and the corresponding $p$-value were calculated using Prism GraphPad. 


\section{Figure 5}

a

b

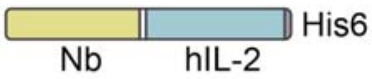

E. coli Culture Duraleukin

Harvest

Cell Pellet

Detergent
Wash

Water

Wash

Inclusion Body Denatured Protein
C

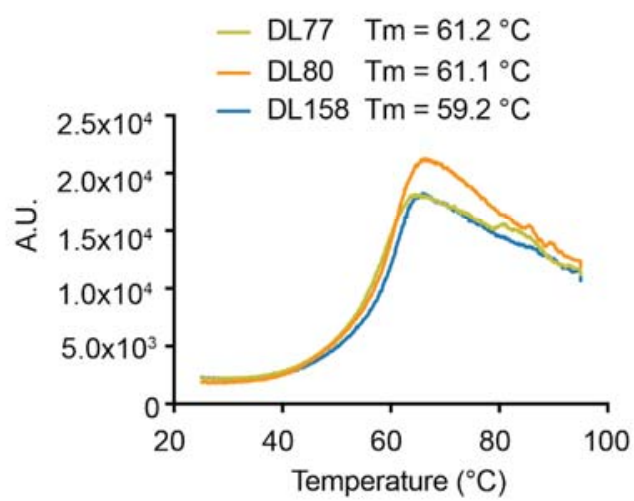

d

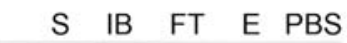

Duraleukin

e

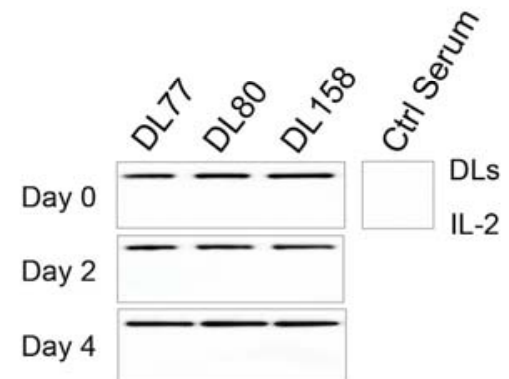

f

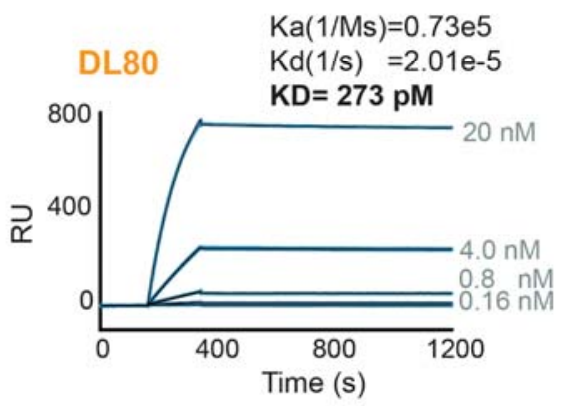

g
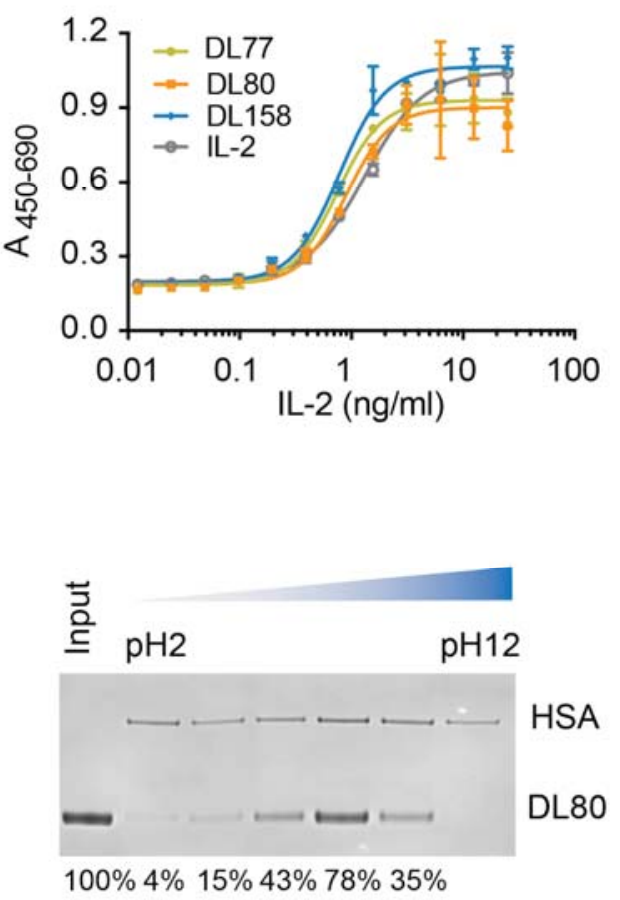

Figure 5. Development of Duraleukin- a novel class of $\mathrm{Nb}_{\mathrm{HSA}}$-fusion cytokine.

a) Schematic design of Duraleukin, including an $\mathrm{N}$-terminal $\mathrm{Nb}_{\mathrm{HSA}}$, a short flexible linker sequence ((GGGGS $\left.)_{2}\right)$, and hIL-2 followed by a C-terminal His6 tag.

b) Schematics of large-scale Duraleukin production from E. coli. A representative SDS-PAGE analysis of purified Duraleukin. S: soluble fraction. IB: inclusion body; FT: flow-through; E: elution; PBS: after endotoxin removal and dialysis in PBS.

c) Thermostability of Duraleukins by differential scanning fluorimetry. 
bioRxiv preprint doi: https://doi.org/10.1101/2020.08.19.257725; this version posted August 20,2020. The copyright holder for this preprint (which was not certified by peer review) is the author/funder, who has granted bioRxiv a license to display the preprint in perpetuity. It is made available under aCC-BY-NC-ND 4.0 International license.

d) In vitro CTLL-2 cell proliferation assay of Duraleukin and hIL-2. The X-axis is the concentration of hIL-2 ( $\mathrm{ng} / \mathrm{ml}$ ). The $\mathrm{Y}$-axis is the absorbance at $450 \mathrm{nM}$ subtracted by absorbance at $690 \mathrm{~nm}$ (background signal) for the measurement of $T$ cell proliferation.

e) The resistance of three DLs to serum proteases. Purified DLs were incubated with the mouse serum for the indicated periods. After incubation, DLs were detected by western blot using an anti-IL-2 monoclonal antibody (BG5).

f) The SPR kinetic measurement of DL80 for HSA binding.

g) Immunoprecipitation assay (pH-dependent) of DL80 for HSA binding. HSA-conjugated agarose resin was used to pull down DL80 at various concentrations. Immunoprecipitated DL80 at different pH was normalized and quantified by ImageJ. 


\section{Figure 6}

a

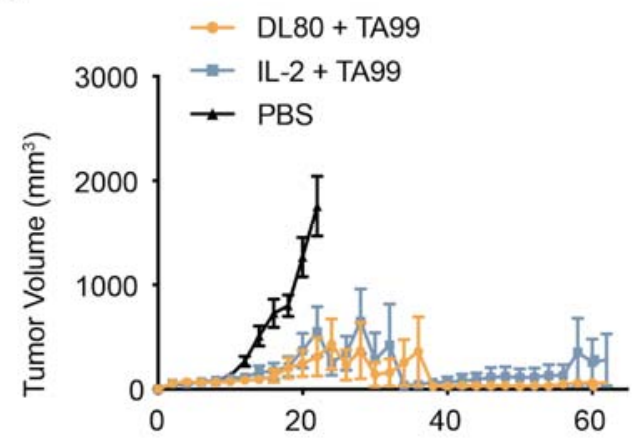

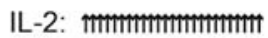

Duraleukin: $\uparrow \uparrow \uparrow$

TA99: $\uparrow \uparrow \uparrow$

PBS: $\uparrow \quad \uparrow \quad \uparrow \quad \uparrow \quad \uparrow$

Time after tumor inoculation (days)

C

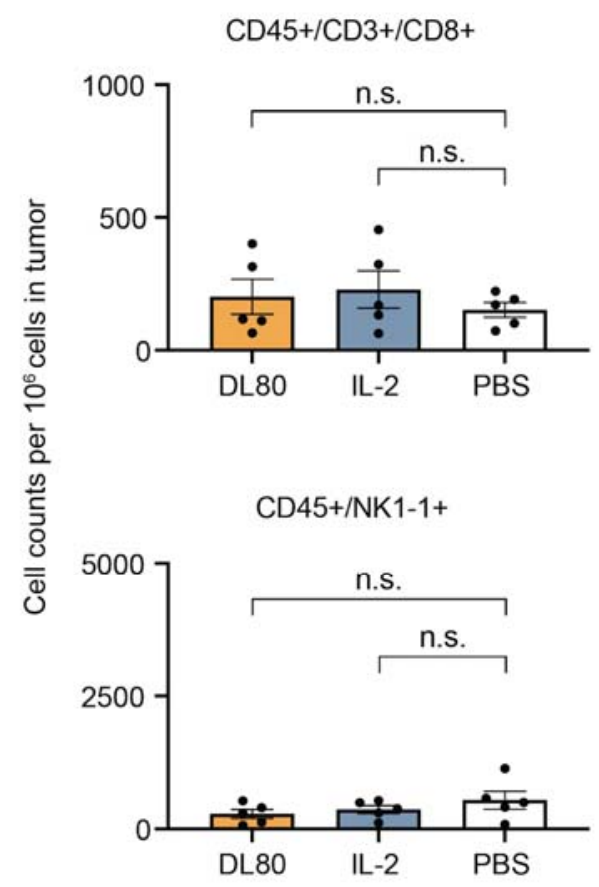

b

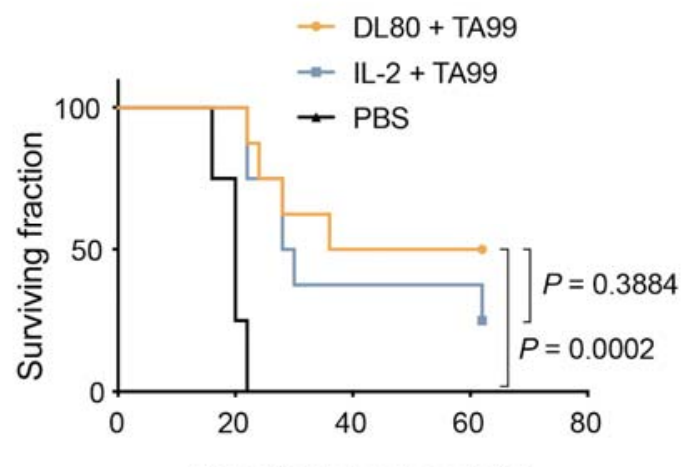

Time after tumor inoculation (days)

Day 3

CD45+/CD3+/CD8+
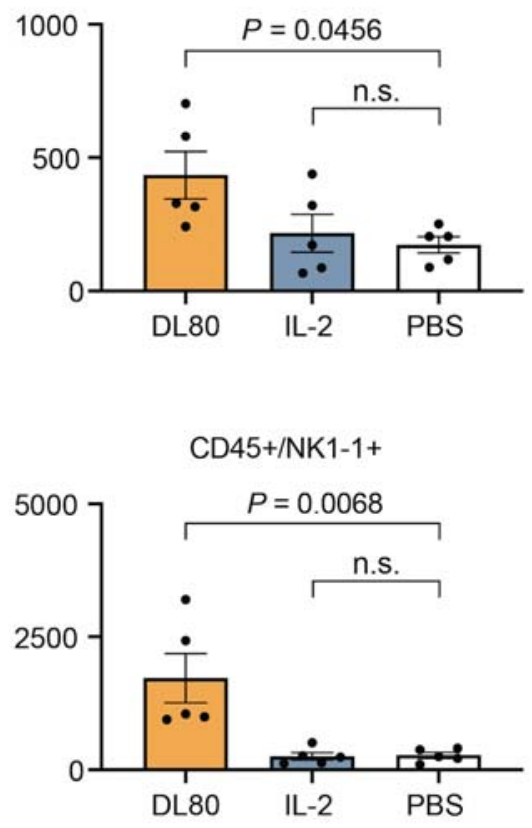

Figure 6. Evaluation of the in vivo efficacy of Duraleukin in a melanoma mouse model.

a) The tumor growth curve. C57BL/6J mice bearing subcutaneous B16F10 tumors were treated with a combination of TA99 and Duraleukin or hIL-2 ( $n=8$ /group) with different dosage intervals. PBS treatment was used for control.

b) Animal survival curve after treatment.

c) Flow cytometry analysis of tumor-infiltrating immune cells ( $n=5 /$ group). The $y$-axis is the respective immune cell count based on a million total cells from the isolated tumor. 
bioRxiv preprint doi: https://doi.org/10.1101/2020.08.19.257725; this version posted August 20,2020. The copyright holder for this preprint

(which was not certified by peer review) is the author/funder, who has granted bioRxiv a license to display the preprint in perpetuity. It is made available under aCC-BY-NC-ND 4.0 International license.

\section{Supplemental Tables}

Table S1: $71 \mathrm{Nb}_{\mathrm{HSA}}$ sequences, the pl, hydrophobicity, and the number of cysteine residues of $\mathrm{Nb}_{\mathrm{HSA}}$ CDR3s, and the ELISA affinities of $\mathrm{Nb}_{\mathrm{HSA}}$ towards different albumin species.

Table S2: SPR kinetic analysis, thermostability, and pharmacokinetic analysis of 20 different $\mathrm{Nb}_{\mathrm{HSA}}$.

Table S3: Cross-link information and the cross-link models of the HSA-Nb ${ }_{H S A}$ complexes.

Table S4: Ion information of MS1-based and PRM quantification of $\mathrm{Nb}_{\mathrm{HSA}}$. 
bioRxiv preprint doi: https://doi.org/10.1101/2020.08.19.257725; this version posted August 20,2020. The copyright holder for this preprint (which was not certified by peer review) is the author/funder, who has granted bioRxiv a license to display the preprint in perpetuity. It is made available under aCC-BY-NC-ND 4.0 International license.

\section{Supplemental Figure 1}
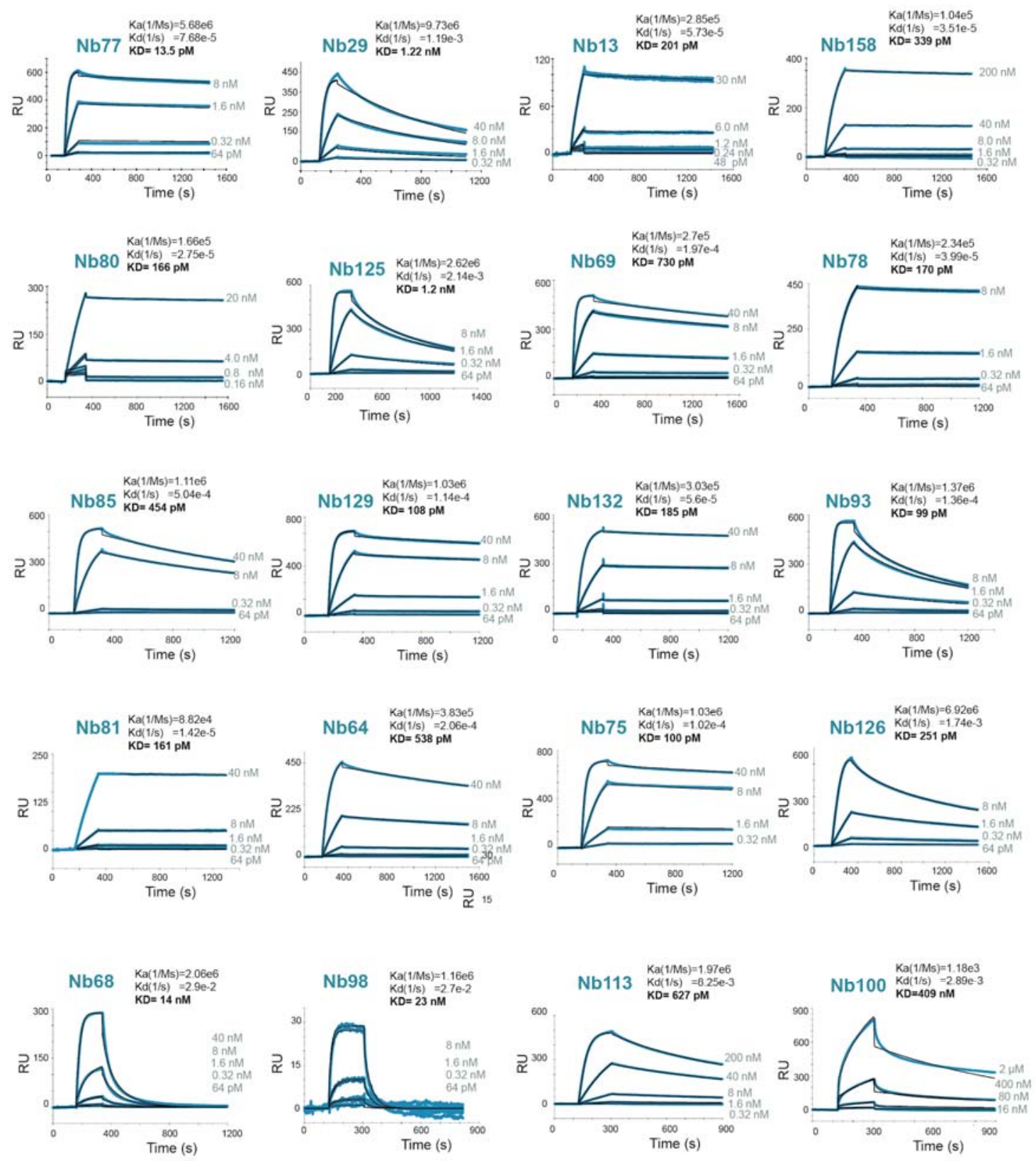

Figure S1. SPR affinity measurement of $20 \mathrm{Nb}_{\mathrm{HSA}}$.

HSA binding kinetics of $20 \mathrm{Nb}_{\mathrm{HSA}}$ was measured by SPR (Biacore 3000). $\mathrm{K}_{\mathrm{d}}$, dissociation rate constant; $\mathrm{K}_{\mathrm{a}}$, association rate constant; $\mathrm{K}_{\mathrm{D}}$, equilibrium dissociation constant. 


\section{Supplemental Figure 2}

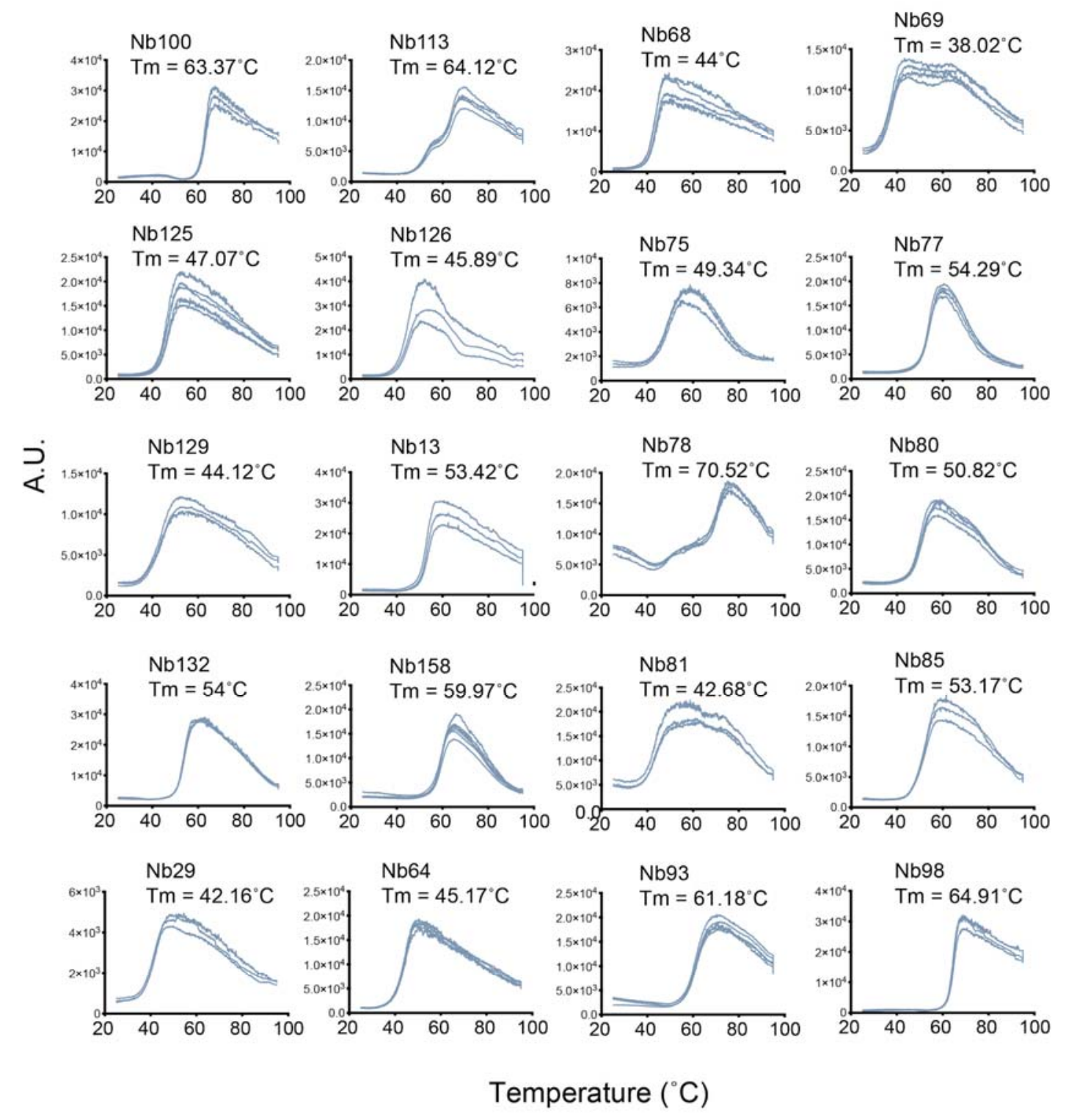

Figure S2. Thermostability measurements of 20 HSA-Nbs. The thermostability of $20 \mathrm{Nb}_{\mathrm{HSA}}$ was measured by differential scanning fluorimetry. Each measurement was repeated 3-6 times. $\mathrm{T}_{\mathrm{M}}$ : melting temperature. A.U.: arbitrary unit. 


\section{Supplemental Figure 3}

a

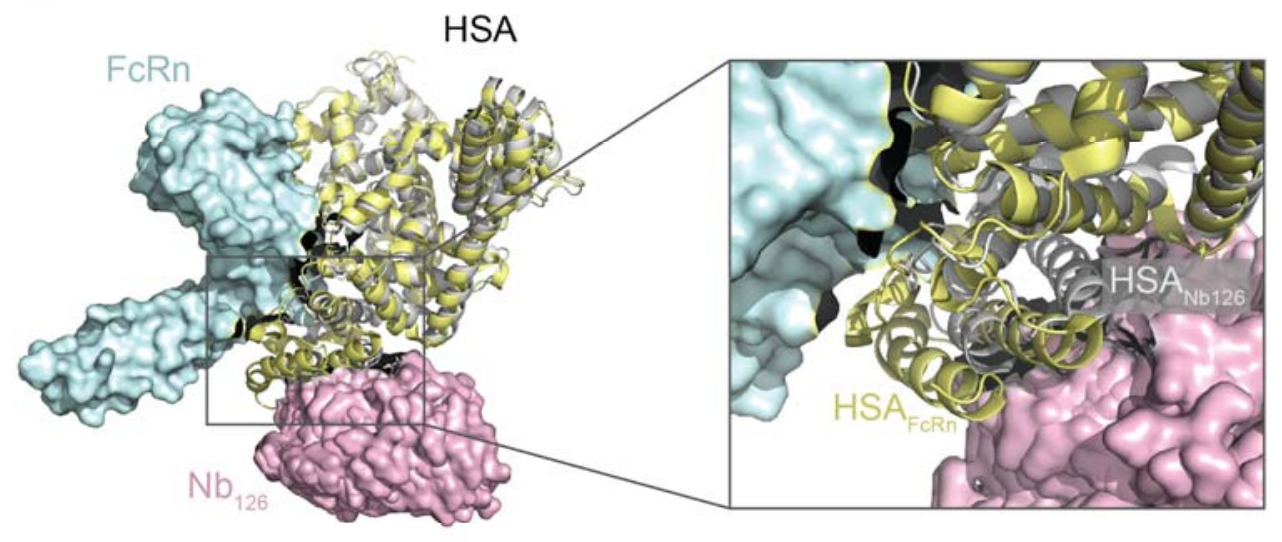

b

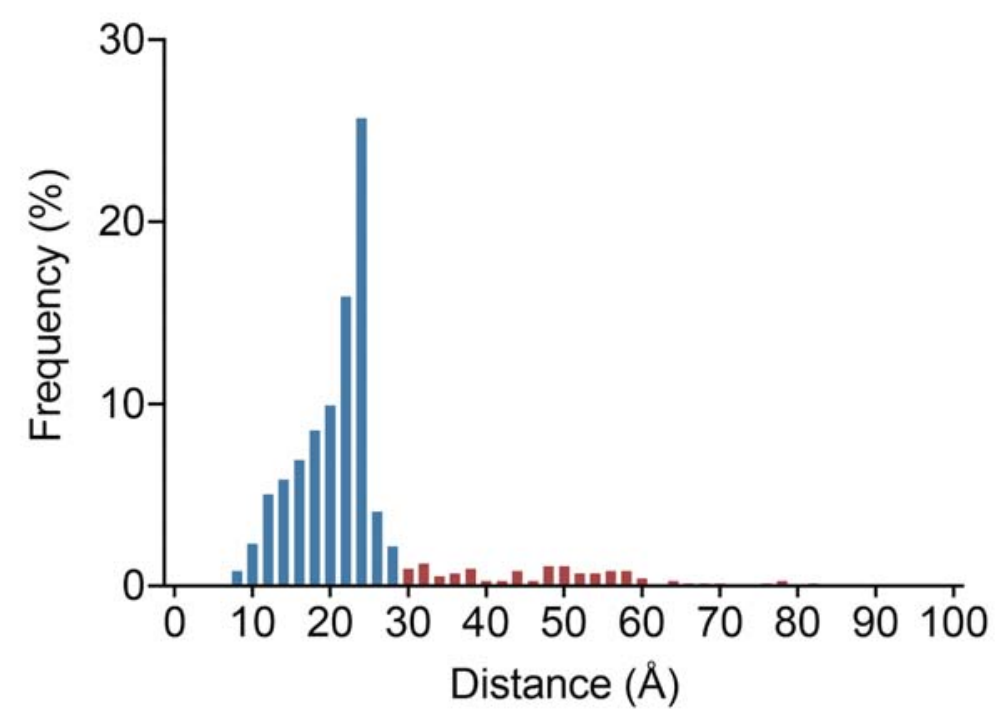

Figure S3. Overlay of FcRn binding HSA and $\mathrm{Nb}$ binding HSA structural models.

a) Overlay of a crystallographic model of FcRn-HSA complex (PDB 4NOF) and the top 4 converged crosslink models of the $\mathrm{Nb}_{126}$ - $\mathrm{HSA}$ complex. HSA is presented in cartoon style. $\mathrm{Nbs}$ and $\mathrm{FcRn}$ are presented as surfaces. Yellow: HSA bound with FcRn; blue: FcRn; grey: HSA bound with Nbs.

b) The plot of the distances of the HSA-Nb intersubunit cross-links that are measured on the converged cross-link models. 


\section{Supplementary Figure 4}

a

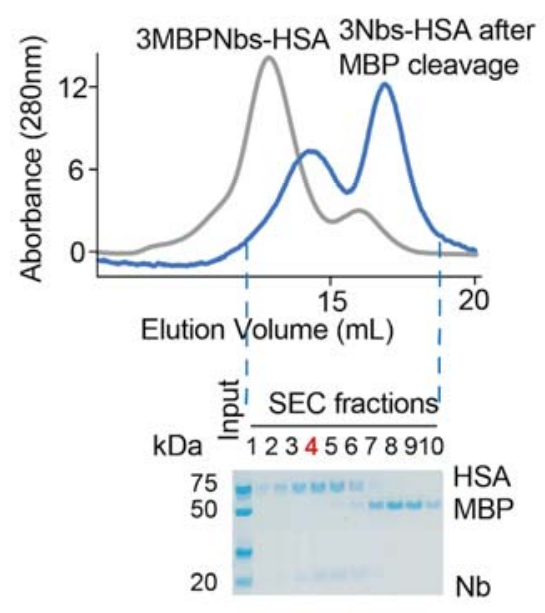

C

MBP-Nb80-Nb13-Nb29-MBP-HSA complex
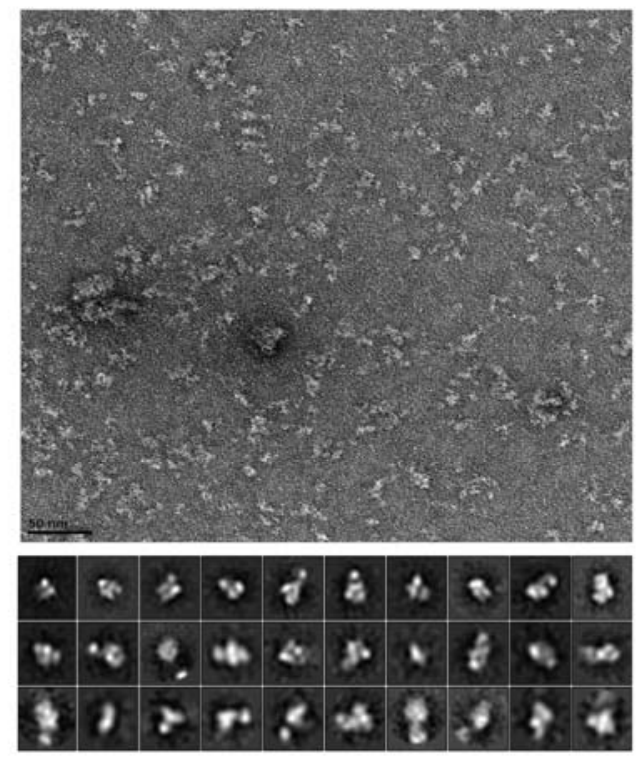

b Nb80-Nb13-Nb29-HSA complex
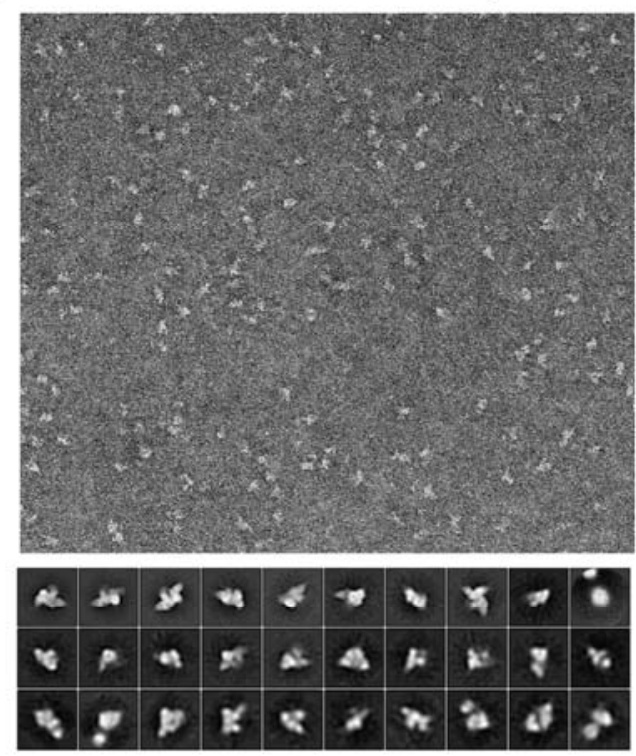

d
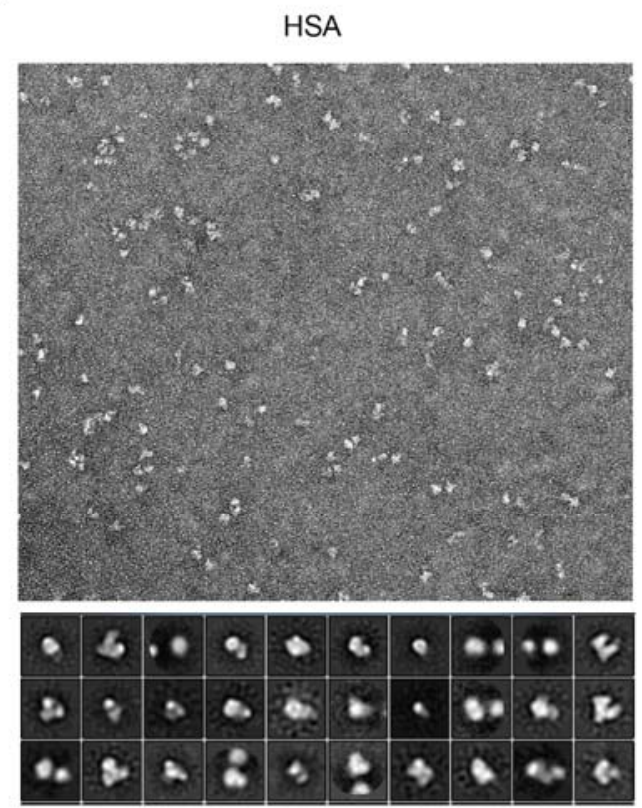

\section{Figure S4. Purification and particle selection of tetrameric Nb-HSA complex.}

a) Purification of a homogenous HSA-Nb ${ }_{80}-\mathrm{Nb}_{13}-\mathrm{Nb}_{29}$ complex after removal of MBP tag by TEV protease cleavage. Size-exclusion chromatography and SDS-PAGE analysis confirmed the successful separation of the cleaved and uncleaved complexes. The homogenous SEC fraction four was used for negative stain EM analysis.

b) Representative negative stain EM images of the purified tetrameric complex without the MBP tag.

c) Representative negative stain EM images of the tetrameric complex in which each Nbs was fused with an MBP tag.

d) Representative negative stain EM particles of HSA. 


\section{Supplemental Figure 5}

a

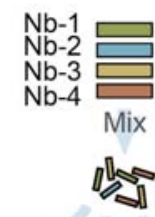

$6,60, \ldots, 60,000 \mathrm{fmol}$

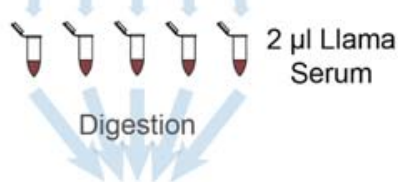

LC/MS analysis b
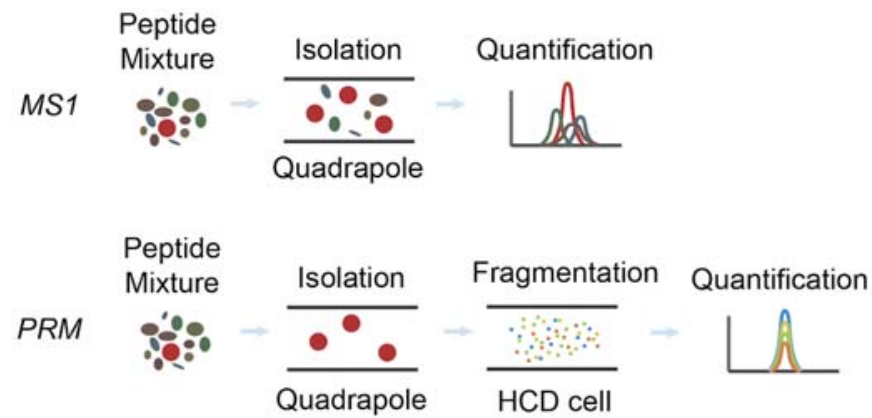

C

\begin{tabular}{|c|c|c|c|c|}
\hline Num. & Peptide & $\mathrm{m} / \mathrm{z}$ & Charge state & Retention time (min) \\
\hline 1 & SGGSTYYADSVK & 617.7829 & $2+$ & $5-8$ \\
\hline 2 & SSWYDYWGQGTQVTVSEPK & 1109.5080 & $2+$ & $13.5-16.5$ \\
\hline 3 & EFVAAISR & 446.7480 & $2+$ & $6.9-9.9$ \\
\hline 4 & NTVYLEMNSLKPEDTAVYSCGAGVSDYGCYR & 1173.8549 & $3+$ & $12.6-15.6$ \\
\hline 5 & LSCAASGGTFSNECMGWFR & 1069.4480 & $2+$ & $13.1-16.1$ \\
\hline 6 & STGHISYADSVQGR & 493.2392 & $3+$ & $4.6-7.6$ \\
\hline 7 & TASGGYHLDTDRPQYWGQGTQVTVSEPK & 770.3692 & $4+$ & $9-12$ \\
\hline 8 & EFVAAISSTFGTPYYTDSMK & 1108.0168 & $2+$ & $14.5-17.5$ \\
\hline 9 & IVSNSNYAR & 512.2645 & $2+$ & $3.7-6.7$ \\
\hline 10 & LSCAASDR & 440.2031 & $2+$ & $2.6-5.6$ \\
\hline 11 & NTVYIEMNSLKPEDTAVYSCAAGASDYGCYHTSGIK & 993.9486 & $4+$ & $11.8-14.8$ \\
\hline 12 & LSCAASGGTFSNSCMGWFR & 1048.4427 & $2+$ & $12.9-15.9$ \\
\hline 13 & STGHTTYADSVEGR & 740.8367 & $2+$ & 4-7 \\
\hline
\end{tabular}

d

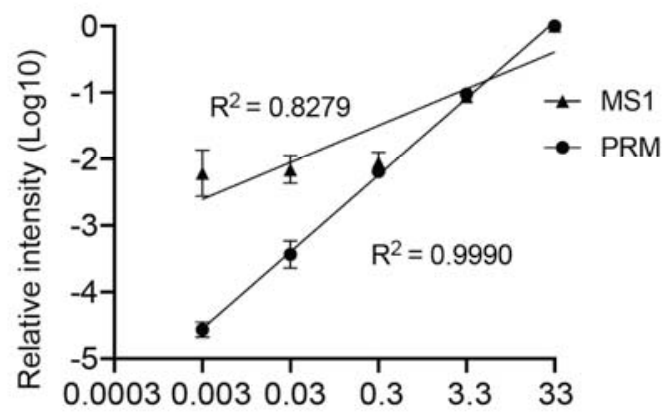

Conc. of "spike-in" Nbs in serum (pmol/ $\mu \mathrm{L})$

Figure S5. Development of an MS-based assay for multiplex Nb PK analysis.

a) Schematic design of the method development. 4 different Nbs were first mixed in equal molarity. A tenfold serial dilution of the Nbs from 60 pmole to 6 fmole was added to $2 \mu$ llama serum. Sera proteins including the spike-in Nbs were proteolyzed. 1/1000 of the proteolyzed peptides of each sample was loaded onto the column and analyzed by LC/MS.

b) Schematic comparison of MS1-based and MS2-based label-free quantification.

c) Selected peptide information for MS1 quantification. 
d) Comparisons of the quantification linearity and sensitivity between MS1- and MS2-based label-free quantification approaches. Five orders of magnitude of quantification linearity $\left(R^{2}=0.999\right)$ was detected by PRM.

\section{Supplementary Figure 6}

a

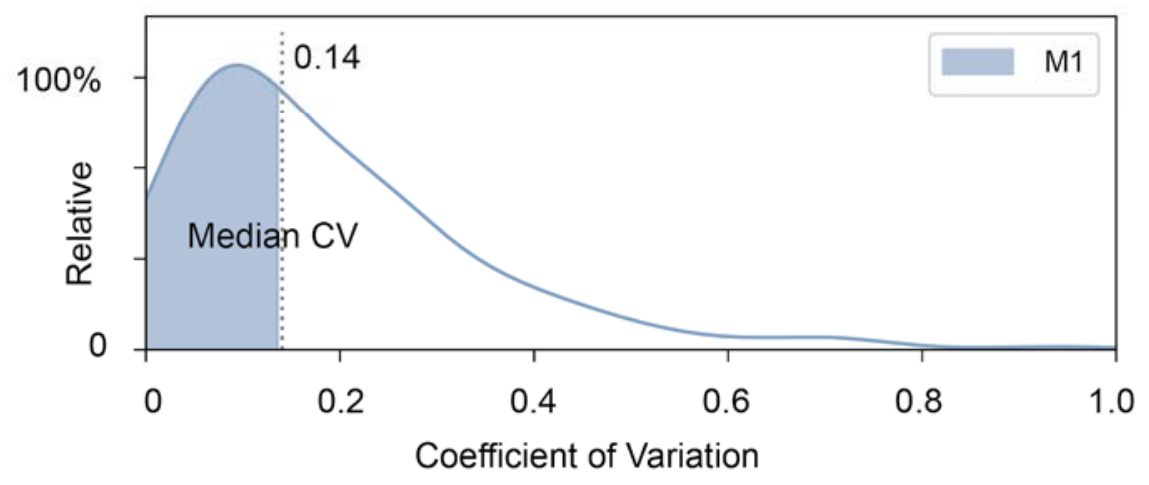

b

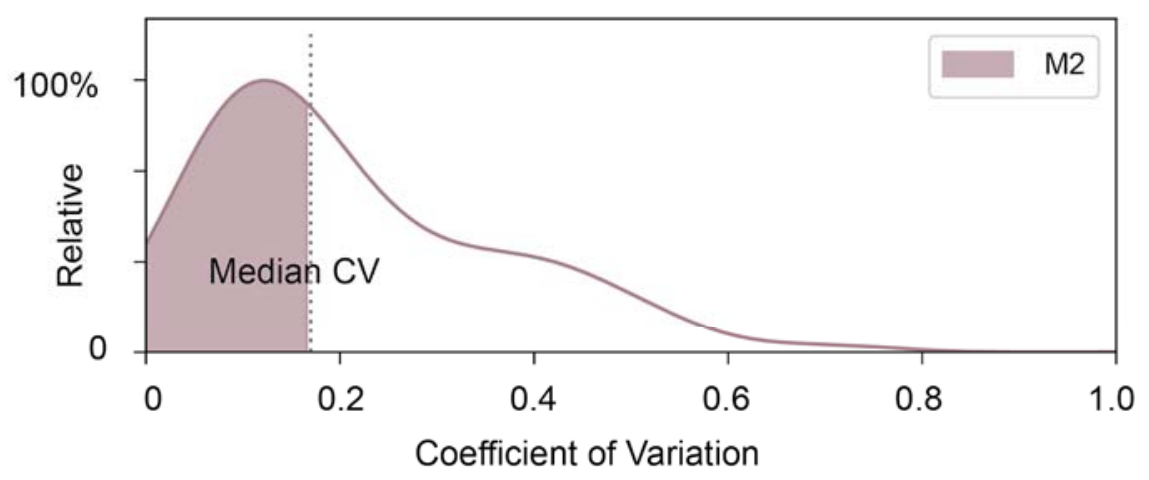

C

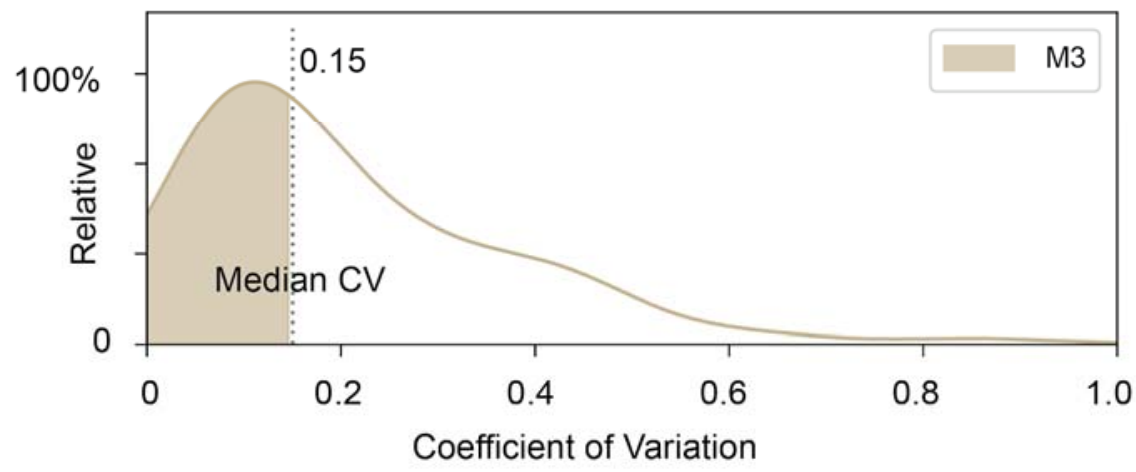

Figure S6. Coefficient of variation of in vivo $\mathrm{Nb}$ quantification.

The coefficient of variations (CV) of $\mathrm{Nb}$ proteomic quantifications was plotted based on three technical replicates. M1- M3 indicates the measurements from three different animals. 


\section{Supplementary Fig 7}

a

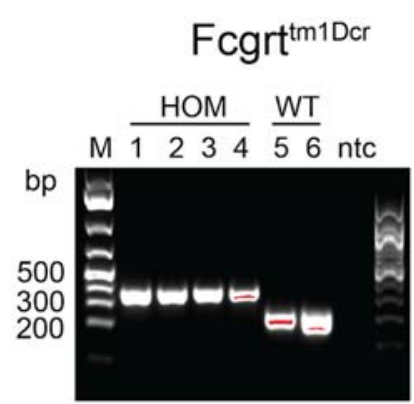

C

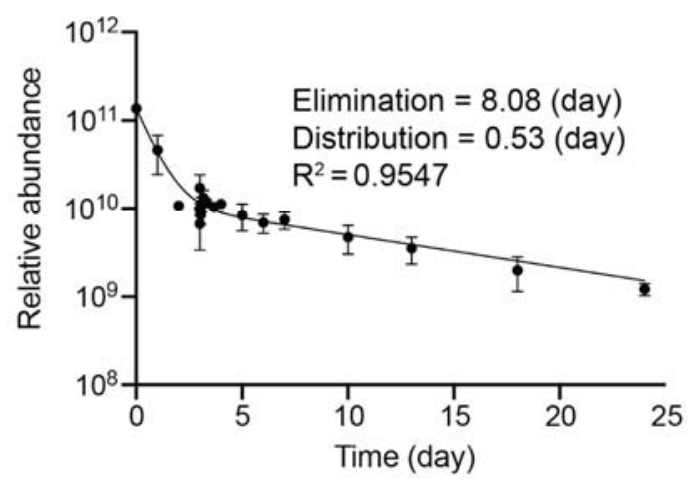

b $\quad$ Alb $b^{\mathrm{em} 12 \mathrm{Mvw}}$

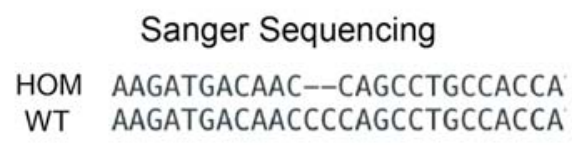

WT Albem12Mvw

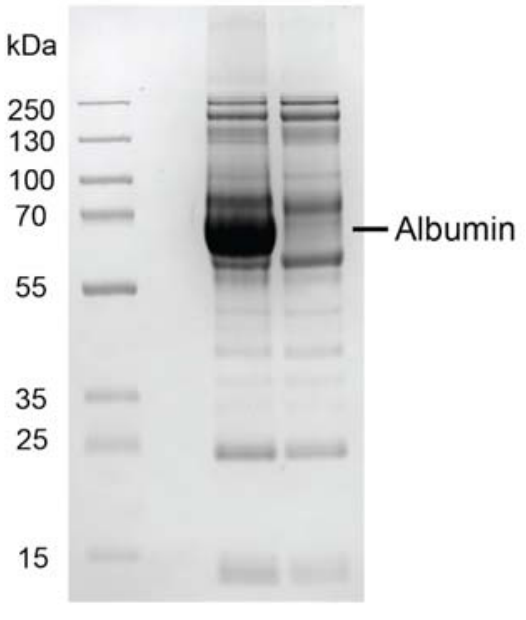

Figure S7. Verification of B6.Cg-Tg(FCGRT)32Dcr Alb ${ }^{e m 12 M v w}$ Fcgrt ${ }^{t m 1 D c r} / \mathrm{MvwJ}$ mouse model.

a) Verification of the Fcgrt ${ }^{\text {tm1Dcr }}$ homozygous strain (human FcRn knock-in) by DNA electrophoresis. HOM: homozygous mouse.

b) Verification of the $A / b^{\text {em12Mvw }}$ strain by Sanger sequencing (upper panel) and SDS-PAGE (phenotypic)

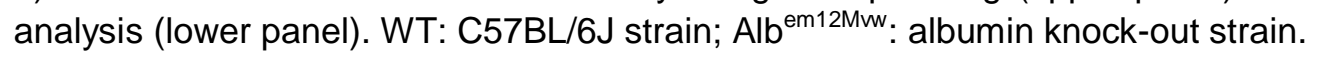

c) Pharmacokinetics of HSA in the mouse model measured by label-free LC/MS. 
bioRxiv preprint doi: https://doi.org/10.1101/2020.08.19.257725; this version posted August 20,2020. The copyright holder for this preprint (which was not certified by peer review) is the author/funder, who has granted bioRxiv a license to display the preprint in perpetuity. It is made available under aCC-BY-NC-ND 4.0 International license.

\section{Supplementary Figure 8}

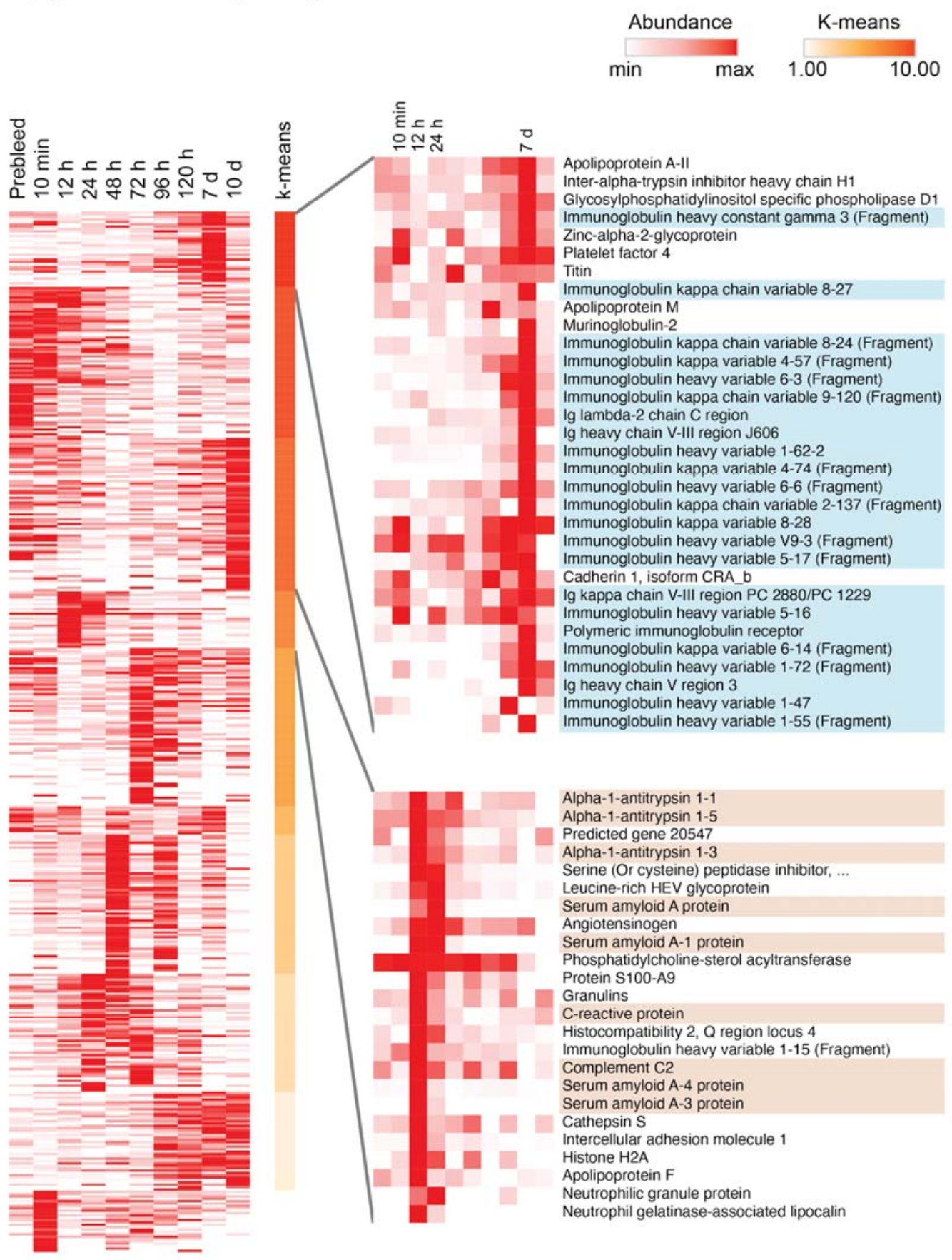

Figure S8. Serum protein quantification upon HSA administration in the humanized mouse model. Mouse blood was collected at different time points. The resulting serum proteomes were quantified by label-free LC/MS. The relative abundances of individual proteins among ten different time points were quantified and clustered based on the K-means method. Serum protein groups peaked at 12-24 hours (e.g., acute-phase inflammatory proteins) or at day 7 (immunoglobulins) were zoomed in. 


\section{Supplementary Fig 9}

\begin{tabular}{|c|c|c|}
\hline & IL-2 & Duraleukin 80 \\
Elimination & 0.0086 & 0.40 \\
\hline Distribution & $\sim 2.7 \mathrm{e}-006$ & 0.039 \\
\hline
\end{tabular}

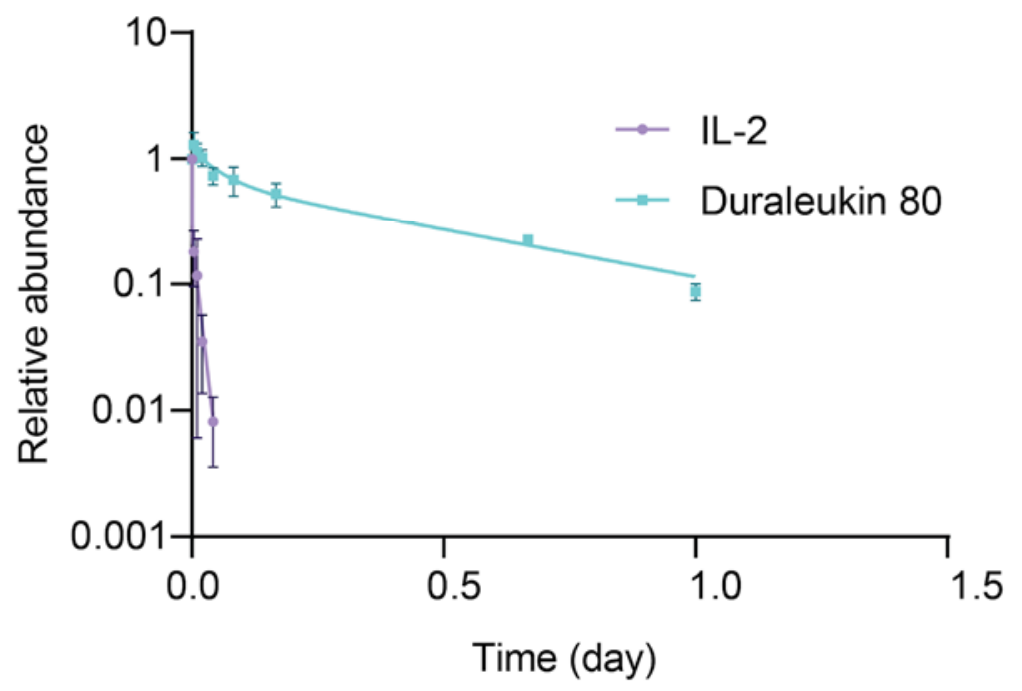

Figure S9. Pharmacokinetics (day) of $\mathrm{DL}_{80}$ in $\mathrm{C57BL} / 6 \mathrm{~J}$ mouse. C57BL/6J mice were treated with $\mathrm{DL}_{80}$ or hIL-2 (equimolar). Blood was sampled at different times (up to 1 day) and was collected for ELISA measurements using an anti-hIL-2 monoclonal antibody (BG5). The distribution and elimination rates (day) were calculated based on the ELISA PK curves by fitting into a two-phase decay model (Methods). 


\section{Supplementary Figure 10}

\section{Day 1}
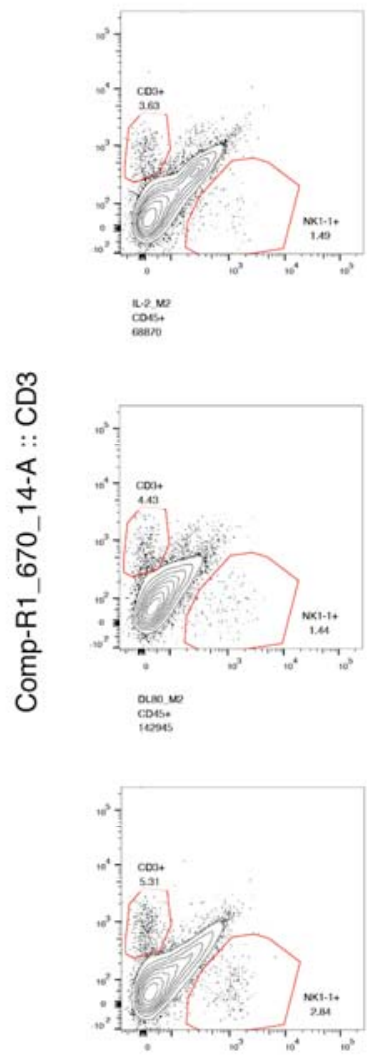

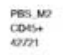

Comp-G1_585_15-A $\because$ NK1-1
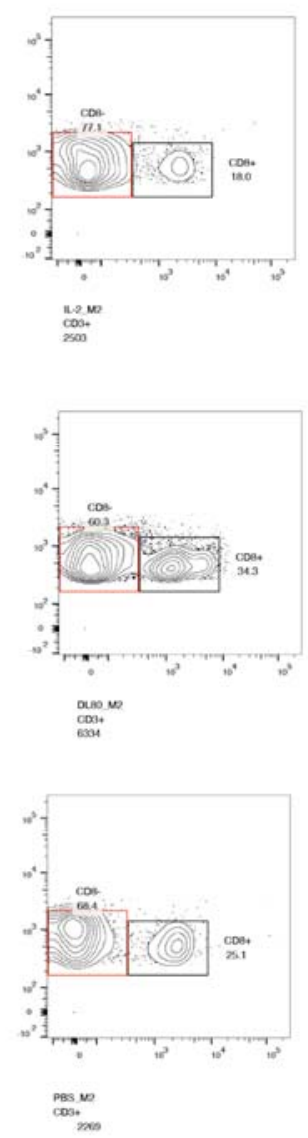

Comp-V5_712_21-A $::$ CD8
Day 3
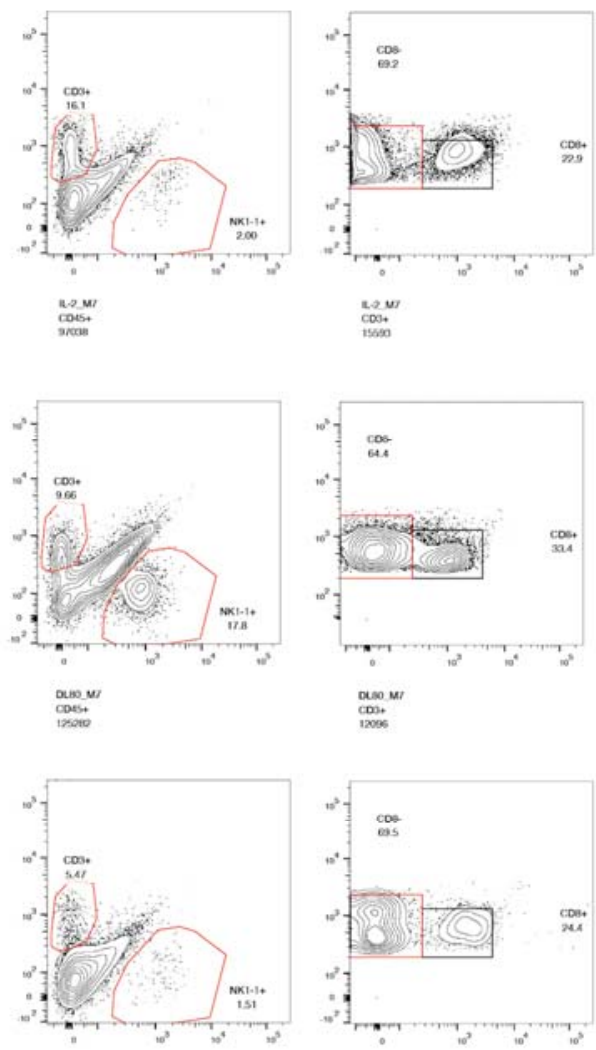

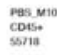

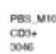

Comp-G1_585_15-A $\because$ NK1-1
Comp-V5_712_21-A $\because \mathrm{CD} 8$

Figure S10. Representative flow cytometry analyses of the $\mathrm{CD8}^{+} \mathrm{T}$ cells and NK cells isolated from the mouse melanoma post-treatment by either Duraleukin, IL-2, or PBS.

Melanoma tumor tissues were isolated from the animals at day one and day three post-treatment by either Duraleukin (DL), IL-2, or PBS control. A mixture of tumor cells and immune cells were isolated, and the samples were stained by antibodies that recognize specific immune cell markers before analysis by flow cytometry. IL-2 treated samples: upper panel; DL-treated samples: middle panel; PBS-treated samples: lower panel. Left: day 1 post-treatment; Right: day 3 post-treatment. $n=5 / g r o u p$.

\section{Methods}

Nb DNA synthesis and cloning 
bioRxiv preprint doi: https://doi.org/10.1101/2020.08.19.257725; this version posted August 20, 2020 . The copyright holder for this preprint (which was not certified by peer review) is the author/funder, who has granted bioRxiv a license to display the preprint in perpetuity. It is made available under aCC-BY-NC-ND 4.0 International license.

$\mathrm{Nb}$ genes were codon-optimized for expression in Escherichia coli and the nucleotides were in vitro synthesized (Synbio). The $\mathrm{Nb}$ genes were cloned into a pET-21b (+) vector at BamHI and Xhol restriction sites, or a pMAL-c5X vector at BamHI and EcoRI restriction sites.

\section{Nb Purification}

$\mathrm{Nb}$ DNA constructs were transformed into BL21(DE3) cells and plated on Agar with $50 \mu \mathrm{g} / \mathrm{ml}$ ampicillin at $37{ }^{\circ} \mathrm{C}$ overnight. A single bacterial colony was picked and cultured in LB broth to reach O.D. at $\sim 450 \mathrm{~nm}$. 0.1 or $0.5 \mathrm{mM}$ IPTG was added to the $E$. coli cell culture for MBP fusion Nbs or his-tagged Nbs induction at $16^{\circ} \mathrm{C}$ overnight. Cells were then harvested, briefly sonicated, and lysed on ice with a lysis buffer (1xPBS, $150 \mathrm{mM} \mathrm{NaCl}, 0.2 \% \mathrm{TX}-100$ with protease inhibitor). After lysis, soluble protein extract was collected at 15,000xg for 10 mins, and recombinant his-tagged Nbs were purified by His6-Cobalt resin (Thermo) and eluted by imidazole; while MBP-fusion Nbs were purified by amylose resin (NEB) and eluted by maltose. The eluted Nbs were subsequently dialyzed in the dialysis buffer (e.g., 1x DPBS, pH 7.4). A HiLoad 16/600 Superdex 200 pg column (GE Healthcare) on an ÄKTA FPLC protein purification system (GE Healthcare) was used to further purify the Nbs and ensure their monomeric states. The purified Nbs were analyzed by SDS-PAGE. For the animal experiments, excessive endotoxin in the Nbs was removed (below $0.1 \mathrm{EU} /$ dose) by the oxinEraser Endotoxin Removal column (Genscript) and measured by ToxinSensor Chromogenic LAL Endotoxin Assay Kit (Genscript). The purified Nbs were further sterilized by passing a $0.2 \mu \mathrm{m}$ filter (Millex) and were stored at $-80^{\circ} \mathrm{C}$ before use.

\section{ELISA (Enzyme-linked immunosorbent assay)}

Indirect ELISA was carried out to measure the relative affinities of Nbs. Albumin was coated onto a 96-well ELISA plate (R\&D system) at 1-10 ng/well in coating buffer (15 mM sodium carbonate, $35 \mathrm{mM}$ sodium bicarbonate, $\mathrm{pH} 9.6$ ) overnight at $4^{\circ} \mathrm{C}$ and was blocked with a blocking buffer (DPBS, $0.05 \%$ Tween $20,5 \%$ milk) at room temperature for $2 \mathrm{hrs}$. $\mathrm{Nb}_{\mathrm{HSA}}$ were diluted in the blocking buffer and incubated with albumin for 2 hrs. HRP-conjugated secondary antibodies against His-tag (Genscript) were diluted 1:5,000-10,000 and incubated with the well for $1 \mathrm{hr}$ at room temperature. After PBST (DPBS, 0.05\% Tween 20) washes, the samples were further incubated under dark with freshly prepared w3,3',5,5'-Tetramethylbenzidine (TMB) substrate for 10 mins to develop the signals. After the STOP solution (R\&D system), the plates were read at multiple wavelengths (the optical density at $550 \mathrm{~nm}$ wavelength subtracted from the density at $450 \mathrm{~nm}$ ) on a plate reader (Multiskan GO,Thermo Fisher). The relative affinity of each $\mathrm{Nb}$ was determined by the average of O.D. readouts. For human and monkey albumin, relative affinity of each $\mathrm{Nb}$ was tested at $\mathrm{Nb}$ concentration of $1 \mu \mathrm{M}, 100 \mathrm{nM}, 10 \mathrm{nM}, 1 \mathrm{nM}$, and $100 \mathrm{pM}$. An average ELISA O.D. of $>0.1$ was used as the cutoff value to assign albumin binding Nbs. For mouse albumin, relative affinity was tested at one $\mu \mathrm{M}$ and $\mathrm{a}$ cutoff O.D. of $>1$ was used.

In vitro pull-down assay (Immunoprecipitation)

$\mathrm{Nb}$ or serum albumin was coupled to $\mathrm{CNBr}$-activated sepharose resin (GE Healthcare). For the in vitro pulldown assay, different concentrations of Nbs were incubated with the human serum albumin coupled resin. Samples were incubated for $15-30 \mathrm{~min}$ at $4^{\circ} \mathrm{C}$ with gentle agitation. The resin was collected and washed three times with a washing buffer and was boiled in the LDS sample loading buffer (Thermo) before SDS PAGE analysis.

\section{$\mathrm{Nb}$ Affinity measurement by surface plasmon resonance (SPR)}

Surface plasmon resonance (SPR, Biacore 3000 system, GE Healthcare) was used to measure $\mathrm{Nb}$ affinities. Briefly, human serum albumin was immobilized to the flow channels of an activated CM5 sensorchip. Protein analytes were diluted to $10 \mu \mathrm{g} / \mathrm{ml}$ in $10 \mathrm{mM}$ sodium acetate, $\mathrm{pH} 4.5$, and injected into the SPR system at $5 \mu \mathrm{l} / \mathrm{min}$ for $420 \mathrm{~s}$. The surface was then blocked by $1 \mathrm{M}$ ethanolamine- $\mathrm{HCl}(\mathrm{pH} 8.5)$. For each $\mathrm{Nb}$ analyte, a series of dilution (spanning 1,000-fold concentration range) was injected in duplicate, with HBS-EP+ running buffer (GE-Healthcare) at a flow rate of $20-30 \mu \mathrm{l} / \mathrm{min}$ for $120-180 \mathrm{~s}$, followed by a dissociation time of $10-20$ mins based on dissociation rate. Between each injection, the sensor chip surface was regenerated twice with a low $\mathrm{pH}$ buffer containing ten $\mathrm{mM}$ glycine- $\mathrm{HCl}(\mathrm{pH} 1.5-2.5)$ at a flow 

available under aCC-BY-NC-ND 4.0 International license.

rate of $40-50 \mu \mathrm{l} / \mathrm{min}$ for $30 \mathrm{~s}-1 \mathrm{~min}$. Binding sensorgrams for each $\mathrm{Nb}$ were processed and analyzed using BIAevaluation by fitting with the 1:1 Langmuir model.

Clustering and phylogenetic tree analysis of $\mathrm{Nb}_{\mathrm{HSA}}$

A phylogenetic tree was generated by Clustal Omega ${ }^{47}$ with the input of unique $\mathrm{Nb}_{\mathrm{HSA}}$ CDR3 sequences and the adjacent framework sequences (i.e., YYCAA to the N-terminus and WGQG to the C-terminus of CDR3s) to help alignments. The data was plotted by ITol (Interactive Tree of Life) ${ }^{48}$. Isoelectric points and hydrophobicities of the CDR3s were calculated using the BioPython library. The sequence logo was plotted using WebLogo ${ }^{49}$.

\section{Thermostability analysis of $\mathrm{Nb}_{\mathrm{HSA}}$}

The thermal stability of $\mathrm{Nb}_{\text {HSA }}$ was measured by differential scanning fluorimetry (DSF). To prepare DSF samples, $\mathrm{Nb}_{\mathrm{HSA}}$ were mixed with SYPRO orange dye (Invitrogen) in PBS to reach a final concentration of 2.5-15 $\mu \mathrm{M}$. The samples were analyzed by a 7900HT Fast Real-Time PCR System (Applied Biosystems) in triplicate. The temperature was programmed to increase from $25^{\circ} \mathrm{C}$ to $95^{\circ} \mathrm{C}$ with a ramp rate of $1^{\circ} \mathrm{C} / \mathrm{min}$ to generate the melting curves. The melting point was calculated by first derivatives method ${ }^{50}$

\section{Chemical cross-linking and mass spectrometry (CXMS)}

$\mathrm{Nb}$ was incubated with albumin in PBS and $1 \mathrm{mM}$ dithiothreitol (DTT) to allow the formation of the complex. $\mathrm{HSA}-\mathrm{Nb}_{\mathrm{HSA}}$ complexes were crosslinked with $1 \mathrm{mM}$ disuccinimidyl suberate (DSS, ThermoFisher Scientific) for $23 \mathrm{~min}$ at $25^{\circ} \mathrm{C}$ with gentle agitation. The crosslinking reaction was then quenched with $50 \mathrm{mM}$ ammonium bicarbonate $(A B C)$ for $10 \mathrm{~min}$ at room temperature. After protein reduction and alkylation, the cross-linked samples were separated by a 4-12\% SDS-PAGE gel (NuPAGE, Thermo Fisher). The regions corresponding to the cross-linked species $(\sim 130 \mathrm{kDa})$ were cut and in-gel digested with trypsin and Lys-C as previously described ${ }^{16,19,51}$. After proteolysis, the peptide mixtures were desalted and analyzed with a nano-LC 1200 (Thermo Fisher) coupled to a Q Exactive ${ }^{\mathrm{TM}}$ HF-X Hybrid Quadrupole-Orbitrap ${ }^{\mathrm{TM}}$ mass

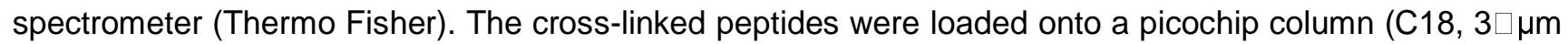
particle size, $300 \square \AA$ pore size, $50 \square \mu \mathrm{m} \square \times \square \square 10.5 \square \mathrm{cm}$; New Objective) and eluted using a $60 \square \mathrm{min}$ LC gradient : 5\% B-8\% B, $0-5 \mathrm{~min} ; 8 \%$ B - 32\% B, $5-45 \mathrm{~min} ; 32 \% \mathrm{~B}-100 \% \mathrm{~B}, 45-49 \mathrm{~min} ; 100 \%$ B, 49 $54 \mathrm{~min} ; 100 \%$ B - $5 \%$ B, $54 \mathrm{~min}-54 \mathrm{~min} 10 \mathrm{sec} ; 5 \% \mathrm{~B}, 54 \mathrm{~min} 10 \mathrm{sec}-60 \mathrm{~min} 10 \mathrm{sec}$; mobile phase $A$ consisted of $0.1 \%$ formic acid (FA), and mobile phase B consisted of $0.1 \%$ FA in $80 \%$ acetonitrile. The QE HF-X instrument was operated in the data-dependent mode, where the top 8 most abundant ions (mass range 380-2,000, charge state $\square 3-7$ ) were fragmented by high-energy collisional dissociation (normalized collision energy 27). The target resolution was 120,000 for MS and 15,000 for MS/MS analyses. The quadrupole isolation window was $1.8 \square \mathrm{Th}$, and the maximum injection time for MS/MS was set at $120 \square \mathrm{ms}$. After the MS analysis, the data was searched by pLink for the identification of cross-linked peptides. The mass accuracy was specified as 10 and 20 $\square$ p.p.m. for MS and MS/MS, respectively. Other search parameters included cysteine carbamidomethylation as a fixed modification and methionine oxidation as a variable modification. A maximum of three trypsin missed-cleavage sites was allowed. The initial search results were obtained using the default $5 \%$ false discovery rate, estimated using a target-decoy search strategy. The crosslink spectra were then manually checked to remove potential false-positive identifications essentially as previously described ${ }^{16,19,51,52}$.

\section{Integrative structural modeling of HSA-Nb complexes}

Structural models for Nbs were obtained using a multi-template comparative modeling protocol of MODELLER $^{53}$. Next, we refined the CDR3 loop and selected the top 5 scoring loop conformations for the downstream docking. Each $\mathrm{Nb}$ model was then docked to the HSA structure (PDB 4g03) by an antibodyantigen docking protocol of PatchDock software that focuses the search to the CDRs ${ }^{54}$ and optimizes CXMS-based distance restraints satisfaction ${ }^{55}$. A restraint was considered satisfied if the Ca-Ca distance between the cross-linked residues was within $30 \AA$ for DSS cross-linkers ${ }^{16,56}$. The models were then rescored by a statistical potential SOAP ${ }^{57}$. The antigen interface residues (distance $<6 \AA$ from $\mathrm{Nb}$ atoms) among the 10 best scoring models according to the SOAP score, were used to determine the epitopes. Convergence was measured as the average RMSD among the 10 top-scoring models. Once the epitopes 

available under aCC-BY-NC-ND 4.0 International license.

were defined, we clustered the Nbs based on the epitope similarity using hierarchical clustering. The clusters reveal the most immunogenic surface patches on the antigens.

\section{Size exclusion chromatography (SEC) and negative stain electron microscopy}

HSA and MBP-Nbs were mixed in a HSA:Nb ratio of 1:1.2 and incubated at room temperature for 2 hours in PBS and 2 mM DTT. The complexes were analyzed by SEC (Superdex200, GE LifeSciences). HSA and the tetrameric $\mathrm{HSA}-\mathrm{Nb}_{\mathrm{HSA}}$ complex were visualized by transmission electron microscopy (TEM) under negative staining. For TEM analysis, the complexes were digested overnight at $4{ }^{\circ} \mathrm{C}$ with TEV protease to remove MBP tag. Protein was diluted to a final concentration of $30 \mu \mathrm{g} / \mathrm{ml}$ (HSA in PBS; HSA-Nb complexes in Tris $20 \mathrm{mM}, 200 \mathrm{mM} \mathrm{NaCl}, 3 \%$ Glycerol) and deposited on carbon-coated CF400-CU grids (EMS) which were freshly glow discharged. After 30 seconds of incubation, the excessive protein was removed, and the grid was stained with two drops of uranyl acetate $2 \% \mathrm{w} / \mathrm{v}$. Electron micrographs were recorded in an $\mathrm{FEI}$ TECNAI T12 operating at $120 \mathrm{kV}$ with a $2 \mathrm{k} \times 2 \mathrm{k}$ Gatan UltraScan 1000. Raw images were converted by IMOD $4.8{ }^{58}$ and particles were selected using EMAN2 ${ }^{59}$. Particle processing and 3D reconstruction were done by Relion $3.0^{60}$ with several rounds of auto-refine iterations. The final 3D structures were obtained with 4,000 particles for HSA and 21,400 particles for the tetrameric complex. Crystallographic structural models (PDB: 1 AO6 and 5VNW) were used for the initial fitting by Chimera ${ }^{61}$.

\section{Site-directed mutagenesis}

An HSA expression plasmid was obtained from Addgene (ALB-bio-His, Plasmid \#52176). E400R and K383D point mutations were introduced to the HSA sequence by the Q5 site-directed mutagenesis kit. After sequence verification by Sanger Sequencing, plasmids bearing wild type HSA and the mutants were transfected to HeLa cells using Lipofectamine 3000 transfection kit (Invitrogen) and Opti-MEM (Gibco) according to the manufacturer's protocol. The cells were cultured overnight before a change of medium to DMEM without FBS supplements to remove BSA. After a $48 \mathrm{~h}$ culture at $37^{\circ} \mathrm{C}, 5 \% \mathrm{CO}_{2}$, the media expressing HSA were collected and stored at $-20^{\circ} \mathrm{C}$. The media were analyzed by SDS-PAGE and Western Blotting to confirm protein expression.

\section{MS quantification of $\mathrm{Nb}$ pharmacokinetics}

$600 \mu \mathrm{g} / \mathrm{g}$ of HSA (w:w) was administered in B6.Cg-Tg(FCGRT)32Dcr Alb ${ }^{\text {em12Mvw }}$ Fcgrt ${ }^{\text {tm1Dcr}} /$ MvwJ mice (JAX, $\mathrm{n}=3$ ) by intravenous (i.v.) injection three days before the injection of Nbs. A mixture of Nbs including 20 $\mathrm{Nb}_{\mathrm{HSA}}$ and 2 control Nbs in equal molarity were then injected at $30 \mu \mathrm{g} / \mathrm{g}$ (w:w, day 0 ). After injections, the whole blood samples were collected from the tail veins of the mice. The blood sampling time for HSA was pre-dose (0 min), $10 \mathrm{~min}, 24 \mathrm{~h}, 48 \mathrm{~h}$. The sampling time for $\mathrm{Nb}$ mixture was pre-dose $(0 \mathrm{~min}), 5,15,30 \mathrm{~min}$, $1,2,4,8,16,24 \mathrm{hrs}, 2,3,4,7,10,15,21$ days post-dose. Whole blood samples were allowed to clot at room temperature for $30 \mathrm{~min}$ and were centrifuged at $4^{\circ} \mathrm{C}, 20,000 \times \mathrm{g}$ for $3 \mathrm{~min}$. Serum proteins from the supernatants were collected for the downstream proteomic analysis.

Serum samples were reduced in $8 \mathrm{M}$ urea digestion buffer (with $50 \mathrm{mM}$ Ammonium bicarbonate, $5 \mathrm{mM}$ TCEP, and DTT) at $57^{\circ} \mathrm{C}$ for $1 \mathrm{hr}$, and alkylated in the dark with $30 \mathrm{mM}$ lodoacetamide for 30 mins at room temperature. The samples were in-solution digested with 1:100 (w/w) trypsin and Lys-C at $37^{\circ} \mathrm{C}$ overnight, with incubation with another bolus of trypsin 4 hours. After proteolysis, the peptide mixtures were desalted and analyzed with a nano easyLC 1200 device coupled with a Q Exactive ${ }^{\mathrm{TM}}$ HF-X Hybrid Quadrupole Orbitrap $^{\text {TM }}$ mass spectrometer (Thermo Fisher). Briefly, Nb peptides were loaded onto a Picochip column (C18, $1.9 \mu \mathrm{m}$ particle size, $120 \square \AA ̊$ pore size, $75 \square \mu \mathrm{m} \square \mathrm{x} \square 25 \square \mathrm{cm}$; New Objective) and eluted using a 45-min liquid chromatography gradient (5\% B-8\% B, 0-3 min; 8\% B-42\% B, 3-35 min; 42\% B-100\% B, $35-40$ min; $100 \%$ B, 40 - $45 \mathrm{~min}$; mobile phase $A$ consisted of $0.1 \%$ formic acid (FA), and mobile phase $B$ consisted of $0.1 \% \mathrm{FA}$ in $80 \%$ acetonitrile $(\mathrm{ACN})$ ). The flow rate was $\sim 300 \mathrm{nl} / \mathrm{min}$. The QE HF-X instrument was operated in the data-dependent mode, where the top 6 most abundant ions (mass range $300-2,000$, charge state $\square 2$ - 8) were fragmented by high-energy collisional dissociation (HCD). The target resolution was 120,000 for MS and 60,000 for MS2 analyses. The quadrupole isolation window was $1.8 \square T h$, and the maximum injection time for MS/MS was $120 \square \mathrm{ms}$. 
bioRxiv preprint doi: https://doi.org/10.1101/2020.08.19.257725; this version posted August 20, 2020 . The copyright holder for this preprint (which was not certified by peer review) is the author/funder, who has granted bioRxiv a license to display the preprint in perpetuity. It is made available under aCC-BY-NC-ND 4.0 International license.

Serum proteins including Nbs were first identified by MaxQuant version 1.6.1.0 ${ }^{62}$. Up to 4 unique and specific tryptic peptides with the preference of CDR3-containing peptides with high intensities were selected from each $\mathrm{Nb}$.

For the MS1-based quantification, the area under the curve (AUC) of the selected peptides were calculated from the raw data by using Xcalibur Qual Browser. For each Nb, AUCs of the selected peptides were averaged to represent the abundance of the Nbs. Selected peptides were validated by MS/MS.

For the MS2-based quantification, an inclusion list of the Nb peptides to be monitored was generated. An LC RT window of $-2 \sim+3$ min (for a 90-min LC gradient) was used to ensure that all the targeted peptides were included. The instrument was operated in a data-independent model where the targeted peptides were specifically selected for fragmentation (HCD normalized energy 27). Up to 5 abundant fragment ions from each peptide were chosen to increase the specificity of our quantification. AUCs of the fragment ions were calculated using Xcalibur Qual Browser. The relative abundance of Nbs was presented as the median AUC intensities of their respective MS2 fragment ions. It was further normalized based on the total MS1 ion current (TIC) of each LC run. An in-house script was developed to enable automatic quantification described above. The samples were analyzed in triplicates. The abundance of serum $\mathrm{Nbs}$ in pharmacokinetics analysis was determined by averaging technical and biological replicates; the resulting data was used to fit into a two-phase decay model by Prism GraphPad.

\section{Serum proteomic quantification}

$1 \mathrm{mg} \mathrm{HSA}$ was administered to a B6.Cg-Tg(FCGRT)32Dcr Alb em12Mvw Fcgrt ${ }^{\text {m1Dcr}} / \mathrm{MvwJ}$ mouse. Blood samples were collected from the tail vein at the following time: pre-dose, $10 \mathrm{~min}, 24,48,72,96 \mathrm{~h}, 7,10$ days. Serum sample preparation and in-solution digestion of serum proteins were processed, as previously mentioned. Peptide samples were analyzed with a nano easyLC 1000 device coupled with a $Q$ Exactive ${ }^{\mathrm{TM}}$ HF-X Hybrid Quadrupole Orbitrap ${ }^{T M}$ mass spectrometer (Thermo Fisher). Briefly, Nb peptides were loaded onto an analytic column (1.6 $\mu \mathrm{m}$ particle size, $100 \square \AA$ pore size, $75 \square \mu \mathrm{m} \square \mathrm{x} \square 25 \square \mathrm{cm}$; lonOpticks) and eluted using a 90-min liquid chromatography gradient. A QE HF-X instrument was used for analysis. The quadrupole isolation window was $1.6 \square \mathrm{Th}$, and the maximum injection time for MS/MS was set at $100 \square \mathrm{ms}$. Serum protein levels were quantified using MaxQuant version 1.6.1.0. The resulting raw data were searched against a mouse Uniprot FASTA protein database (December 2018) with fixed modification of carbamidomethylation and variable modifications of methionine oxidation and N-terminal acetylation. Trypsin was set as a digestion enzyme, and a maximal missed cleavage of 2 was allowed. Protein's false discovery rate was set to be 0.01 . Minimal peptide length was 7 , and maximal peptide mass was $4600 \mathrm{Da}$. Minimal ratio count of label-free quantification was set to be 2 . Serum protein abundance at each time point is derived by averaging ion intensities of 3 technical replicates and normalized based on baseline abundance. Serum proteins were then clustered using the $\mathrm{K}$-means clustering algorithm $(\mathrm{K}=10)$, and heatmap was generated by software Morpheus (https://software.broadinstitute.org/morpheus).

\section{Purification of Duraleukins}

hIL-2 (C125A) sequence was fused to C-termini of Nb sequences at the DNA level with a flexible linker $(\text { GGGGS })_{2}$ (Gly-Gly-Gly-Gly-Ser-Gly-Gly-Gly-Gly-Ser). The resulting DNA sequences were synthesized and cloned into pET-21b(+) (Synbio). Plasmids were transformed into BL21(DE3) E. coli cells to produce Duraleukins. After IPTG induction, Duraleukins were purified from the cell pallets. Cell pellets containing the inclusion bodies of Duraleukins were washed with a solubilization buffer $A(0.1 \mathrm{M}$ Tris, $2 \%$ sodium deoxycholate (SDC), $5 \mathrm{mM}$ EDTA, pH 8) and sonicated on ice. Cell lysates were spun down at 12,000 $\times \mathrm{g}$ for $20 \mathrm{~min} 4^{\circ} \mathrm{C}$. Supernatants were discarded, and the pellets were saved for analysis. Cell pellets were washed with Milli-Q water and spun down at $12,000 \times \mathrm{g}$ for $20 \mathrm{~min}$ at $4^{\circ} \mathrm{C}$. Solubilization buffer $\mathrm{B}(0.1 \mathrm{M}$ Tris, $6 \mathrm{M}$ guanidine hydrochloride $(\mathrm{GuHCl}), \mathrm{pH} 8)$ was added to the pallets and incubated for $1 \mathrm{~h}$ incubation at room temperature with gentle agitation. After centrifugation $12,000 \times \mathrm{g}$ for $20 \mathrm{~min}$ at $4^{\circ} \mathrm{C}$, the supernatants that contain soluble forms of Duraleukins were collected, and subsequently diluted with a Duraleukin refolding buffer $(0.1 \mathrm{M}$ Tris, $\mathrm{pH}$, the final concentration of $10 \mathrm{mM}$ reduced and $1 \mathrm{mM}$ oxidized glutathione) to a $\mathrm{GuHCl}$ concentration of $2 \mathrm{M}$ and a protein concentration of $\sim 0.3 \mathrm{mg} / \mathrm{mL}$. The solutions 

available under aCC-BY-NC-ND 4.0 International license.

were then incubated at room temperature for $16 \mathrm{~h}$ with gently rotating to allow protein refolding. The insoluble fraction was removed by centrifugation at $16,000 \times \mathrm{g}$ for $20 \mathrm{~min}$ at $4^{\circ} \mathrm{C}$, and refolded Duraleukins were obtained in the supernatants. IMAC and FPLC purification, detoxification, and sterilization were performed as previously described.

In vitro T cell proliferation assay

CTLL-2 cells (ATCC) were cultured, according to ATCC's protocol. The complete culture medium was formulated as $10 \% \mathrm{FBS}$, an additional $2 \mathrm{mM} \mathrm{L}$-glutamine, and $1 \mathrm{mM}$ sodium pyruvate in ATCC-formulated RPMI-1640 containing 10\% T-STIM with Con A (Corning). For CTLL-2 proliferation assay, cells were grown to a density of $1 \times 10^{5} \mathrm{cells} / \mathrm{mL}$. Duraleukins or hIL-2 (PeproTech) were added into the wells of a flat-bottom 96-well tissue culture microplate. The final concentration of hIL-2 and Duraleukins was adjusted to 0.01 25 $\mathrm{ng} / \mathrm{mL}$ and $0.025 \sim 50 \mathrm{ng} / \mathrm{mL}$ by 2 -fold serial dilution. Every concentration group was tested in duplicate. $10^{4}$ cells were seeded to each well of the plate, and the total volume in each well was $100 \mu \mathrm{L}$. The cells were then incubated at $37^{\circ} \mathrm{C}, 5 \% \mathrm{CO}_{2}$ for $56 \mathrm{~h} .10 \mu \mathrm{L}$ of WST-1 reagent (Roche) was added to each well and the cells were incubated for another four $h$. The plate was shaken at 1,000 rpm for $1 \mathrm{~min}$ before analysis. $A$ spectrometer read absorbance at $450 \mathrm{~nm}$. $690 \mathrm{~nm}$ was used as a reference wavelength. A dose-response curve was fit via nonlinear regression using GraphPad Prism 7.

\section{Generation and treatment of melanoma mouse model}

B16F10 (ATCC) was cultured, according to ATCC's protocol. The complete medium is formulated as $10 \%$ FBS in ATCC-formulated DMEM. C57BL/6J mice were purchased from The Jackson Laboratory. All mice were aged eight weeks before tumor inoculation. B16F10 melanoma cells were grown into the logarithmic growth phase ( $\leq 50 \%$ confluent), harvested, and adjusted to a concentration of $1 \times 107 \mathrm{cells} / \mathrm{ml}$ in ice-cold HBSS. Mice were anesthetized with isoflurane and shaved in the middle of the back with a razor. $100 \mu \mathrm{l}$ $\left(10^{6}\right)$ of cells is subcutaneously (s.c.) injected to the middle of the shaved area with a 291/2-G insulin syringe (EXEL). For tumor growth experiments, intravenous (i.v.) injection of DL80 (17 $\mu \mathrm{g})$, hIL-2 $(7.5 \mu \mathrm{g}$, PeproTech), TA99 (125 $\mu \mathrm{g}$, BioXCell) and PBS were done on indicated days. For flow cytometry analysis, a single i.v. administration of DL80 $(17 \mu \mathrm{g})$ or hIL-2 $(7.5 \mu \mathrm{g})$ was done on day 12.

\section{Flow cytometry}

The tumor was isolated from the mice $(n=5) 1$ or 3 days after a single dose treatment. Cell suspensions were harvested by mechanical dissection and Collagenase IV Cocktail digestion (formulated as $7.4 \mathrm{kU}$ Collagenase Type 4, $53 \mathrm{kU}$ Deoxyribonuclease I, $20 \mathrm{mg}$ Soybean Trypsin Inhibitor in $10 \mathrm{~mL}$ cocktail; Worthington Biochemical). The suspensions were passed through $40 \mu \mathrm{m}$ cell strainers to ensure singularity. Cells were first treated with BioWhittaker ACK lysing buffer (Lonza), followed by TruStain FcX (BioLegend) and stained with antibodies against CD45 (clone 30-F11), CD3 (clone 17A2), CD8a (clone 53-6.7), NK1.1 (clone PK136). All antibodies are purchased from Biolegend. All samples were analyzed on a BD LSRFortessa cell analyzer. Data analysis was performed by Flowjo and Prism GraphPad.

\section{Acknowledgment}

This work was supported by the Pitt SOM start-up funds (Y.S.), a UPMC Aging Institute pilot fund (Y.S.), and a grant from the Alzheimer's Association and Michael J. Fox Foundation (Y.S.).

\section{Contributions}

Y.S and Z.S conceived the research. Y.S. supervised the studies. Y.X and Y.S identified the Nbs. Z.S and Y.X performed major experiments and data analysis with help from Y.S, S.V, Z.X, A.V, C.J, G.C, B.H, G.C, Z. Sang, J.L and K.C. D.S and C.C performed structural modeling. Thank P. Duprex (Vaccine center, Pitt) for his assistance in the SPR experiments, D.Goebe, for critical reading of the manuscript. Y.S and Z.S drafted the manuscript with input from all the authors. 
bioRxiv preprint doi: https://doi.org/10.1101/2020.08.19.257725; this version posted August 20, 2020 . The copyright holder for this preprint (which was not certified by peer review) is the author/funder, who has granted bioRxiv a license to display the preprint in perpetuity. It is made available under aCC-BY-NC-ND 4.0 International license.

\section{Completing Interests}

The University of Pittsburgh has filed a provisional patent encompassing the technologies described in this manuscript.

\section{References}

1 Larsen, M. T., Kuhlmann, M., Hvam, M. L. \& Howard, K. A. Albumin-based drug delivery: harnessing nature to cure disease. Mol Cell Ther 4, 3, doi:10.1186/s40591-016-0048-8 (2016).

2 Sand, K. M. K. et al. Unraveling the interaction between FcRn and albumin: opportunities for design of albumin-based therapeutics. Frontiers in Immunology 5, 1-21, doi:10.3389/fimmu.2014.00682 (2015).

3 Merlot, A. M., Kalinowski, D. S. \& Richardson, D. R. Unraveling the mysteries of serum albuminmore than just a serum protein. Frontiers in Physiology 5, doi:ARTN 299

10.3389/fphys.2014.00299 (2014).

4 Peters, T. All about albumin : biochemistry, genetics, and medical applications. (Academic Press, 1996).

5 Sleep, D., Cameron, J. \& Evans, L. R. Albumin as a versatile platform for drug half-life extension. Biochimica Et Biophysica Acta-General Subjects 1830, 5526-5534, doi:10.1016/j.bbagen.2013.04.023 (2013).

6 Kontermann, R. E. Half-life extended biotherapeutics. Expert Opin Biol Ther 16, 903-915, doi:10.1517/14712598.2016.1165661 (2016).

7 Hamers-Casterman, C. et al. Naturally occurring antibodies devoid of light chains. Nature 363, 446448, doi:10.1038/363446a0 (1993).

8 Jovcevska, I. \& Muyldermans, S. The Therapeutic Potential of Nanobodies. BioDrugs 34, 11-26, doi:10.1007/s40259-019-00392-z (2020).

9 Steeland, S., Vandenbroucke, R. E. \& Libert, C. Nanobodies as therapeutics: big opportunities for small antibodies. Drug Discovery Today 21, 1076-1113, doi:10.1016/j.drudis.2016.04.003 (2016).

10 Fridy, P. C. et al. A robust pipeline for rapid production of versatile nanobody repertoires. Nat Methods 11, 1253-1260, doi:10.1038/nmeth.3170 (2014).

11 Carter, P. J. Potent antibody therapeutics by design. Nat Rev Immunol 6, 343-357, doi:10.1038/nri1837 (2006).

12 Holliger, P. \& Hudson, P. J. Engineered antibody fragments and the rise of single domains. Nat Biotechnol 23, 1126-1136, doi:10.1038/nbt1142 (2005).

13 D Brooks, B. The importance of epitope binning for biological drug discovery. Current drug discovery technologies 11, 109-112 (2014).

14 Nivarthi, U. K. et al. Mapping the human memory B cell and serum neutralizing antibody responses to dengue virus serotype 4 infection and vaccination. Journal of virology 91, e02041-02016 (2017).

15 Flyak, A. I. et al. Broadly neutralizing antibodies from human survivors target a conserved site in the Ebola virus glycoprotein HR2-MPER region. Nature microbiology 3, 670-677 (2018).

16 Shi, Y. et al. Structural characterization by cross-linking reveals the detailed architecture of a coatomer-related heptameric module from the nuclear pore complex. Mol Cell Proteomics 13, 29272943, doi:10.1074/mcp.M114.041673 (2014).

17 Rout, M. P. \& Sali, A. Principles for Integrative Structural Biology Studies. Cell 177, 1384-1403, doi:10.1016/j.cell.2019.05.016 (2019).

18 Chait, B. T., Cadene, M., Olinares, P. D., Rout, M. P. \& Shi, Y. Revealing Higher Order Protein Structure Using Mass Spectrometry. J Am Soc Mass Spectrom 27, 952-965, doi:10.1007/s13361016-1385-1 (2016).

19 Shi, Y. et al. A strategy for dissecting the architectures of native macromolecular assemblies. Nat Methods 12, 1135-1138, doi:10.1038/nmeth.3617 (2015).

20 Russel, D. et al. Putting the pieces together: integrative modeling platform software for structure determination of macromolecular assemblies. PLoS Biol 10, e1001244, doi:10.1371/journal.pbio.1001244 (2012). 
bioRxiv preprint doi: https://doi.org/10.1101/2020.08.19.257725; this version posted August 20, 2020 . The copyright holder for this preprint

(which was not certified by peer review) is the author/funder, who has granted bioRxiv a license to display the preprint in perpetuity. It is made available under aCC-BY-NC-ND 4.0 International license.

21 Yu, C. \& Huang, L. Cross-Linking Mass Spectrometry: An Emerging Technology for Interactomics and Structural Biology. Analytical Chemistry 90, 144-165, doi:10.1021/acs.analchem.7b04431 (2018).

22 Low, B. E. \& Wiles, M. V. A Humanized Mouse Model to Study Human Albumin and Albumin Conjugates Pharmacokinetics. Methods Mol Biol 1438, 115-122, doi:10.1007/978-1-4939-3661-8_7 (2016).

23 Peterson, A. C., Russell, J. D., Bailey, D. J., Westphall, M. S. \& Coon, J. J. Parallel reaction monitoring for high resolution and high mass accuracy quantitative, targeted proteomics. Mol Cell Proteomics 11, 1475-1488, doi:10.1074/mcp.0112.020131 (2012).

24 Gallien, S. et al. Targeted Proteomic Quantification on Quadrupole-Orbitrap Mass Spectrometer. Molecular \& Cellular Proteomics 11, 1709-1723, doi:10.1074/mcp.0112.019802 (2012).

25 Hoefman, S., Ottevaere, I., Baumeister, J. \& Sargentini-Maier, M. L. Pre-clinical intravenous serum

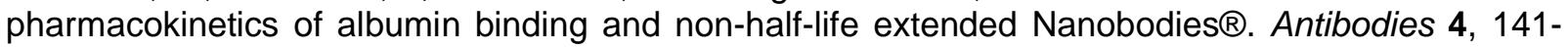
156 (2015).

26 Anderson, N. L. The clinical plasma proteome: a survey of clinical assays for proteins in plasma and serum. Clin Chem 56, 177-185, doi:10.1373/clinchem.2009.126706 (2010).

27 Geyer, P. E., Holdt, L. M., Teupser, D. \& Mann, M. Revisiting biomarker discovery by plasma proteomics. Molecular Systems Biology 13, doi:ARTN 942

10.15252/msb.20156297 (2017).

28 Uhlar, C. M. \& Whitehead, A. S. Serum amyloid A, the major vertebrate acute-phase reactant. European Journal of Biochemistry 265, 501-523, doi:DOI 10.1046/j.1432-1327.1999.00657.x (1999).

29 Sproston, N. R. \& Ashworth, J. J. Role of C-Reactive Protein at Sites of Inflammation and Infection. Frontiers in Immunology 9, doi:ARTN 754

10.3389/fimmu.2018.00754 (2018).

30 Schmidt, M. M. et al. Crystal Structure of an HSA/FcRn Complex Reveals Recycling by Competitive Mimicry of HSA Ligands at a pH-Dependent Hydrophobic Interface. Structure 21, 1966-1978, doi:10.1016/j.str.2013.08.022 (2013).

31 Boyman, O. \& Sprent, J. The role of interleukin-2 during homeostasis and activation of the immune system. Nat Rev Immunol 12, 180-190, doi:10.1038/nri3156 (2012).

32 Rosenberg, S. A. IL-2: the first effective immunotherapy for human cancer. J Immunol 192, 54515458, doi:10.4049/jimmunol.1490019 (2014).

33 Schwartz, R. N., Stover, L. \& Dutcher, J. P. Managing toxicities of high-dose interleukin-2. Oncology (Williston Park) 16, 11-20 (2002).

34 Overwijk, W. W. \& Restifo, N. P. B16 as a mouse model for human melanoma. Curr Protoc Immunol Chapter 20, Unit 20 21, doi:10.1002/0471142735.im2001s39 (2001).

35 Zhu, E. F. et al. Synergistic innate and adaptive immune response to combination immunotherapy with anti-tumor antigen antibodies and extended serum half-life IL-2. Cancer Cell 27, 489-501, doi:10.1016/j.ccell.2015.03.004 (2015).

36 Moynihan, K. D. et al. Eradication of large established tumors in mice by combination immunotherapy that engages innate and adaptive immune responses. Nat Med 22, 1402-1410, doi:10.1038/nm.4200 (2016).

37 Silva, D. A. et al. De novo design of potent and selective mimics of IL-2 and IL-15. Nature 565, 186191, doi:10.1038/s41586-018-0830-7 (2019).

38 Sun, Z. et al. A next-generation tumor-targeting IL-2 preferentially promotes tumor-infiltrating CD8(+) T-cell response and effective tumor control. Nat Commun 10, 3874, doi:10.1038/s41467-019-11782w (2019).

39 Hassanzadeh-Ghassabeh, G., Devoogdt, N., De Pauw, P., Vincke, C. \& Muyldermans, S. Nanobodies and their potential applications. Nanomedicine 8, 1013-1026, doi:10.2217/Nnm.13.86 (2013).

40 Pyzik, M., Rath, T., Lencer, W. I., Baker, K. \& Blumberg, R. S. FcRn: The Architect Behind the Immune and Nonimmune Functions of IgG and Albumin. Journal of Immunology 194, 4595-4603, doi:10.4049/jimmunol.1403014 (2015).

41 Greish, K. Enhanced permeability and retention of macromolecular drugs in solid tumors: a royal gate for targeted anticancer nanomedicines. $J$ Drug Target 15, 457-464, doi:10.1080/10611860701539584 (2007).

42 Finicle, B. T., Jayashankar, V. \& Edinger, A. L. Nutrient scavenging in cancer. Nat Rev Cancer 18, 619-633, doi:10.1038/s41568-018-0048-x (2018).

43 Steel, J. C., Waldmann, T. A. \& Morris, J. C. Interleukin-15 biology and its therapeutic implications in cancer. Trends in pharmacological sciences 33, 35-41 (2012). 

available under aCC-BY-NC-ND 4.0 International license.

44 Ring, A. M. et al. Adrenaline-activated structure of beta2-adrenoceptor stabilized by an engineered nanobody. Nature 502, 575-579, doi:10.1038/nature12572 (2013).

45 Khair, D. O. et al. Combining Immune Checkpoint Inhibitors: Established and Emerging Targets and Strategies to Improve Outcomes in Melanoma. Frontiers in Immunology 10, doi:10.3389/fimmu.2019.00453 (2019).

46 Hirsch, F. R., Varella-Garcia, M. \& Cappuzzo, F. Predictive value of EGFR and HER2 overexpression in advanced non-small-cell lung cancer. Oncogene 28 Suppl 1, S32-37, doi:10.1038/onc.2009.199 (2009).

47 Sievers, F. \& Higgins, D. G. Clustal Omega, accurate alignment of very large numbers of sequences. Methods Mol Biol 1079, 105-116, doi:10.1007/978-1-62703-646-7_6 (2014).

48 Letunic, I. \& Bork, P. Interactive Tree Of Life (iTOL): an online tool for phylogenetic tree display and annotation. Bioinformatics 23, 127-128, doi:10.1093/bioinformatics/btl529 (2007).

49 Crooks, G. E., Hon, G., Chandonia, J. M. \& Brenner, S. E. WebLogo: a sequence logo generator. Genome Res 14, 1188-1190, doi:10.1101/gr.849004 (2004).

50 Niesen, F. H., Berglund, H. \& Vedadi, M. The use of differential scanning fluorimetry to detect ligand interactions that promote protein stability. Nat Protoc 2, 2212-2221, doi:10.1038/nprot.2007.321 (2007).

51 Xiang, Y., Shen, Z. \& Shi, Y. Chemical Cross-Linking and Mass Spectrometric Analysis of the Endogenous Yeast Exosome Complexes. Methods Mol Biol 2062, 383-400, doi:10.1007/978-14939-9822-7_18 (2020).

$52 \mathrm{Kim}, \mathrm{S}$. J. et al. Integrative structure and functional anatomy of a nuclear pore complex. Nature 555, 475-482, doi:10.1038/nature26003 (2018).

53 Webb, B. \& Sali, A. Comparative Protein Structure Modeling Using MODELLER. Curr Protoc Bioinformatics 47, 56 1-32, doi:10.1002/0471250953.bi0506s47 (2014).

54 Schneidman-Duhovny, D., Inbar, Y., Nussinov, R. \& Wolfson, H. J. PatchDock and SymmDock: servers for rigid and symmetric docking. Nucleic Acids Research 33, W363-W367, doi:10.1093/nar/gki481 (2005).

55 Schneidman-Duhovny, D. \& Wolfson, H. J. Modeling of Multimolecular Complexes. Methods Mol Biol 2112, 163-174, doi:10.1007/978-1-0716-0270-6_12 (2020).

56 Fernandez-Martinez, J. et al. Structure and Function of the Nuclear Pore Complex Cytoplasmic mRNA Export Platform. Cell 167, 1215-1228 e1225, doi:10.1016/j.cell.2016.10.028 (2016).

57 Dong, G. Q., Fan, H., Schneidman-Duhovny, D., Webb, B. \& Sali, A. Optimized atomic statistical potentials: assessment of protein interfaces and loops. Bioinformatics 29, 3158-3166, doi:10.1093/bioinformatics/btt560 (2013).

58 Mastronarde, D. N. \& Held, S. R. Automated tilt series alignment and tomographic reconstruction in IMOD. J Struct Biol 197, 102-113, doi:10.1016/j.jsb.2016.07.011 (2017).

59 Tang, G. et al. EMAN2: an extensible image processing suite for electron microscopy. J Struct Biol 157, 38-46, doi:10.1016/j.jsb.2006.05.009 (2007).

60 Scheres, S. H. RELION: implementation of a Bayesian approach to cryo-EM structure determination. J Struct Biol 180, 519-530, doi:10.1016/j.jsb.2012.09.006 (2012).

61 Pettersen, E. F. et al. UCSF Chimera--a visualization system for exploratory research and analysis. J Comput Chem 25, 1605-1612, doi:10.1002/jcc.20084 (2004).

62 Cox, J. \& Mann, M. MaxQuant enables high peptide identification rates, individualized p.p.b.-range mass accuracies and proteome-wide protein quantification. Nat Biotechnol 26, 1367-1372, doi:10.1038/nbt.1511 (2008). 


\section{Figure 1}

a CDR residue classes: ${ }_{111.5}^{1126}$ है 8 b

Acid

Basic

Hydrophobic

Neutral

Polar

Gap

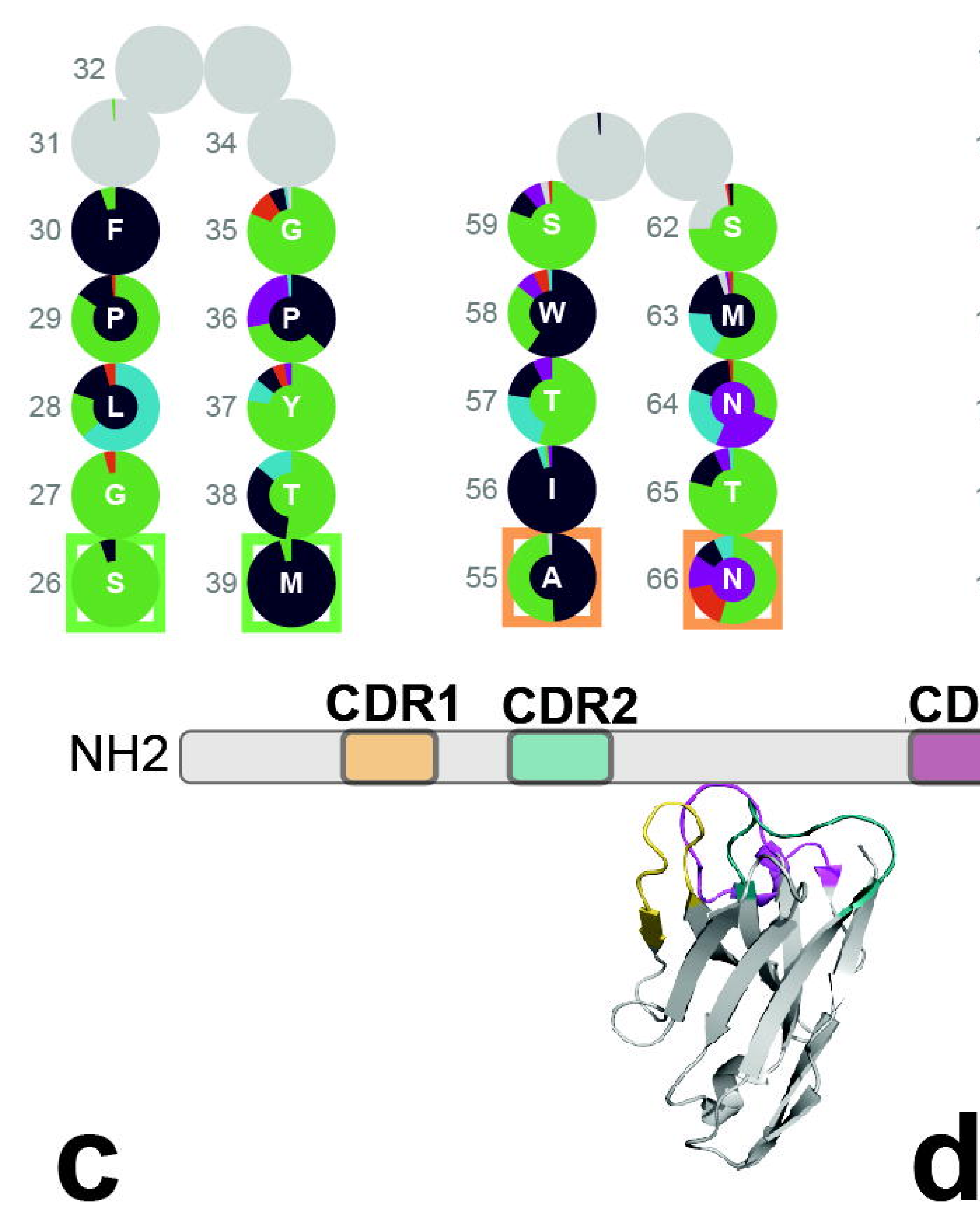

CDR3 $\mathrm{COOH}$


$\square$ Isoelectric point Hydrophobicity
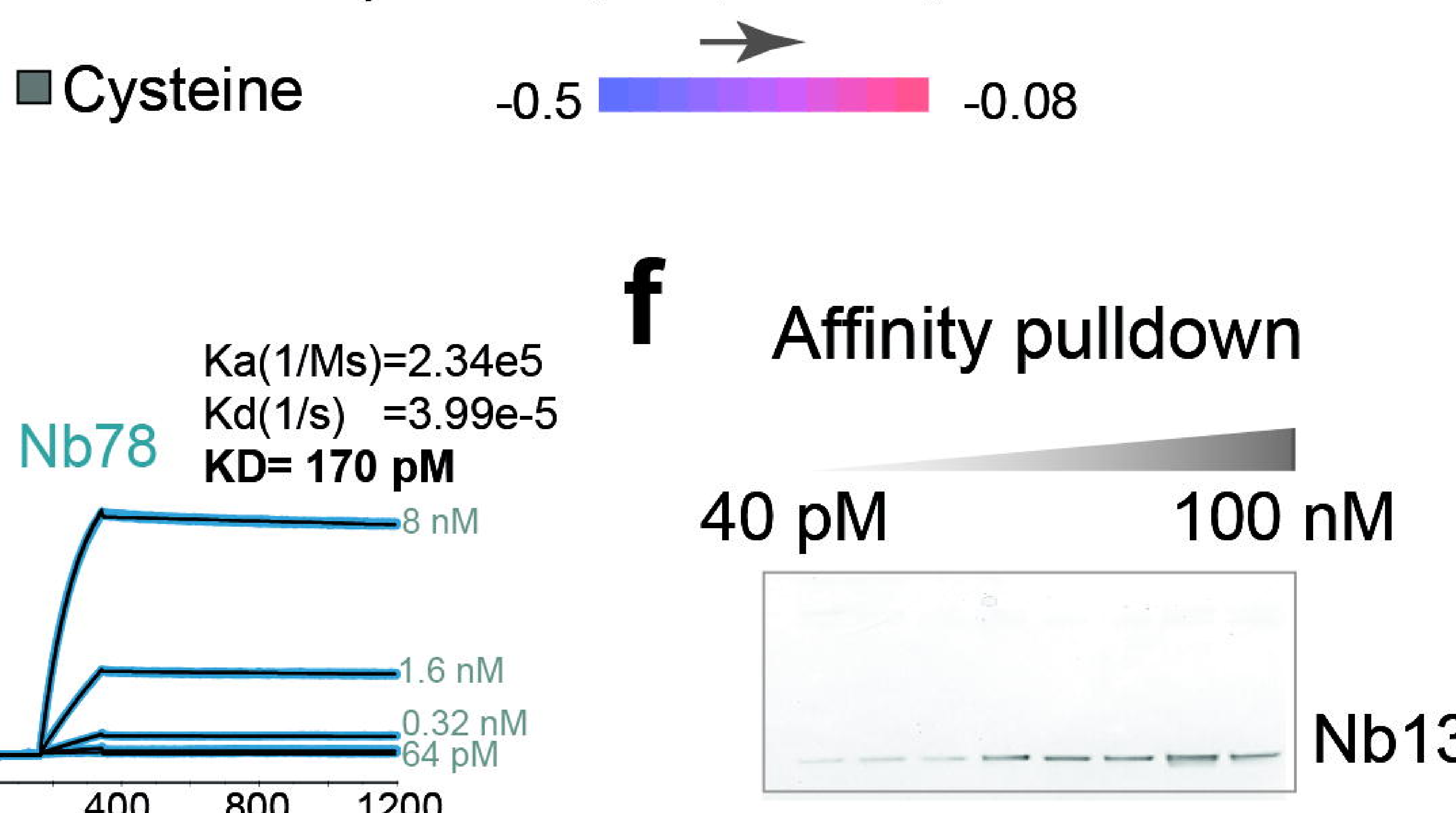

$\mathrm{Nb} 13$

g
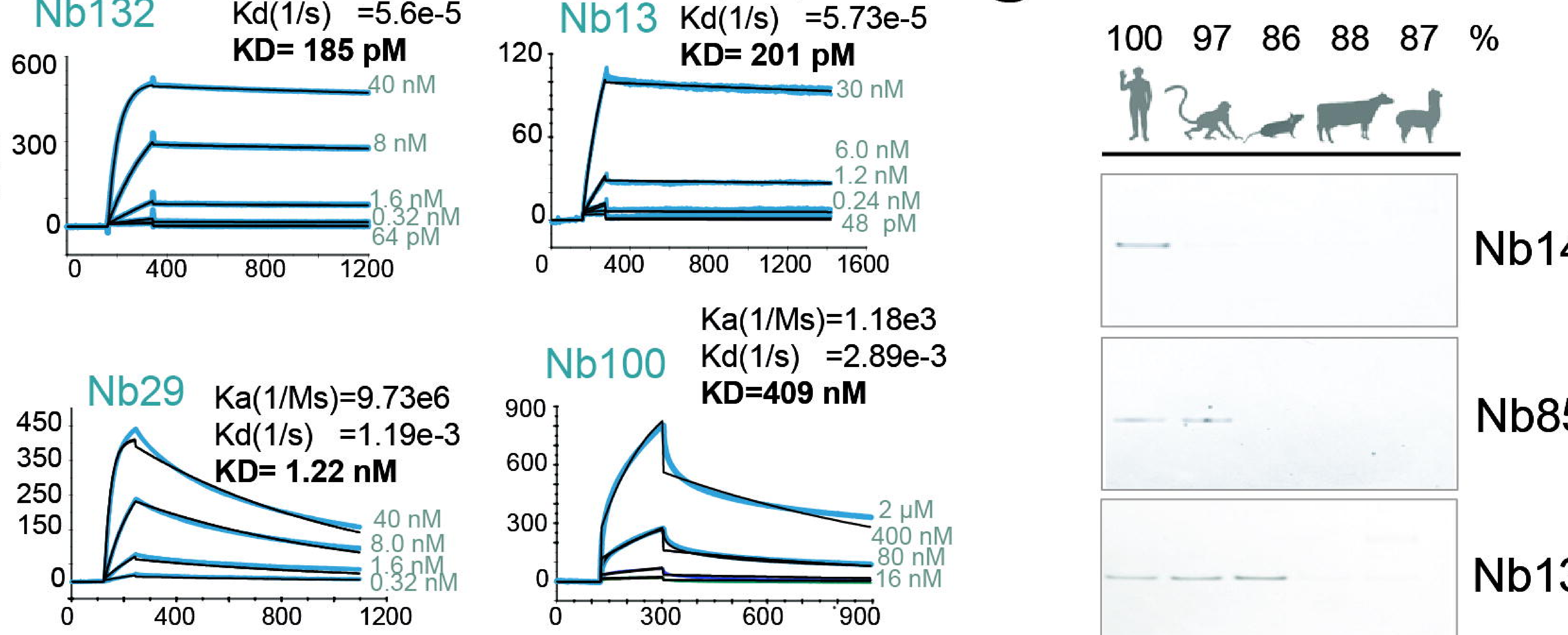

Time (s)
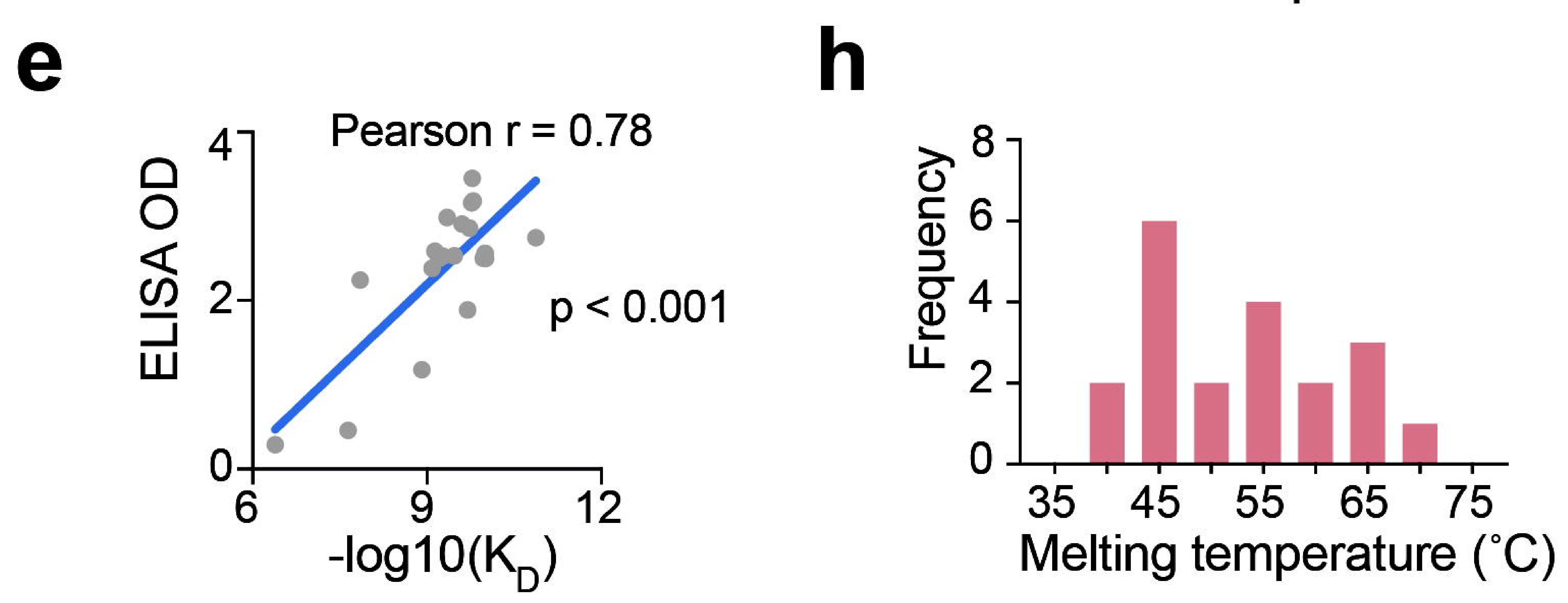

$\mathrm{Nb} 143$

$\mathrm{Nb85}$

$\mathrm{Nb} 132$

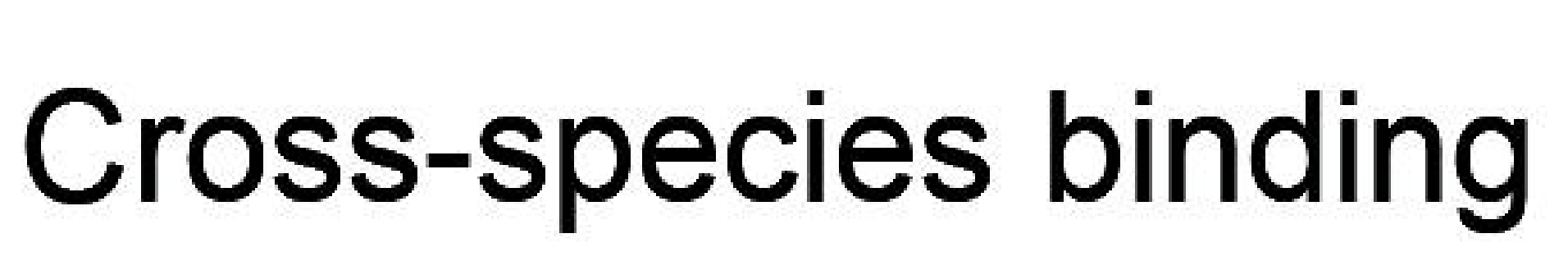




\section{Figure 2}

a

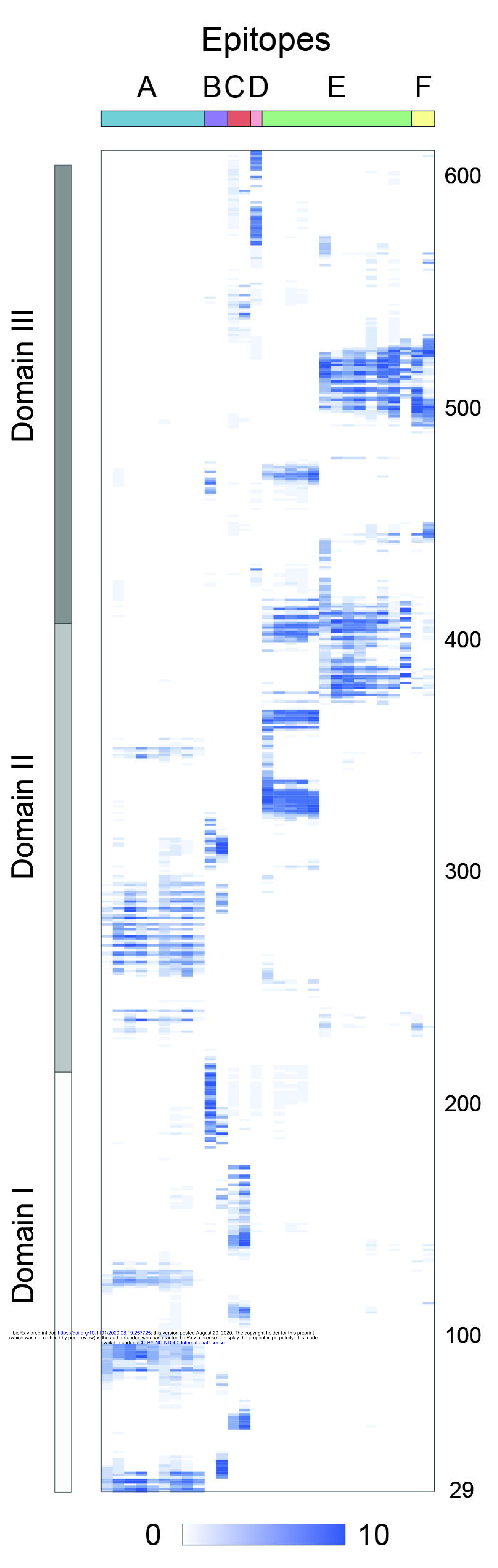

b

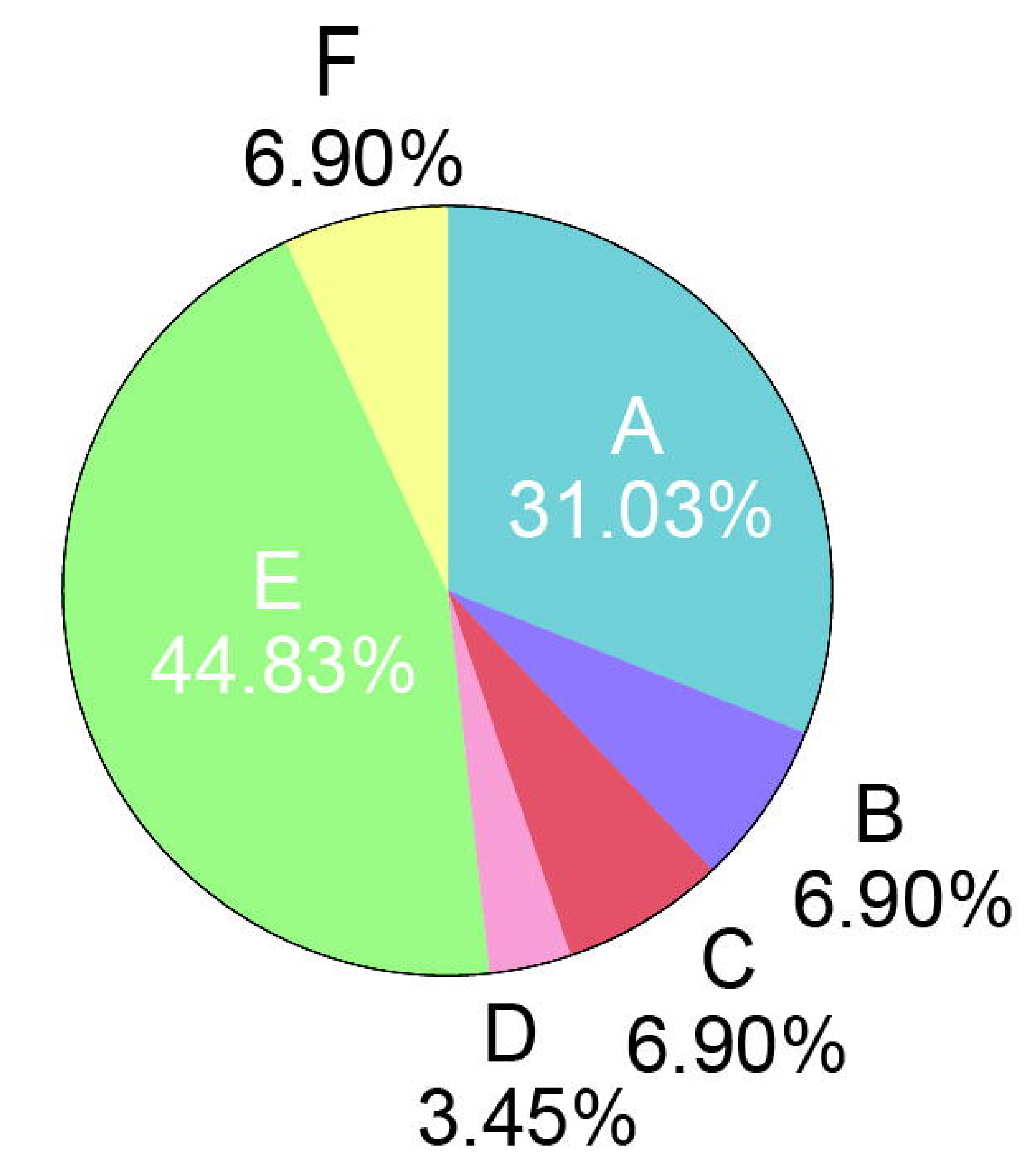

d

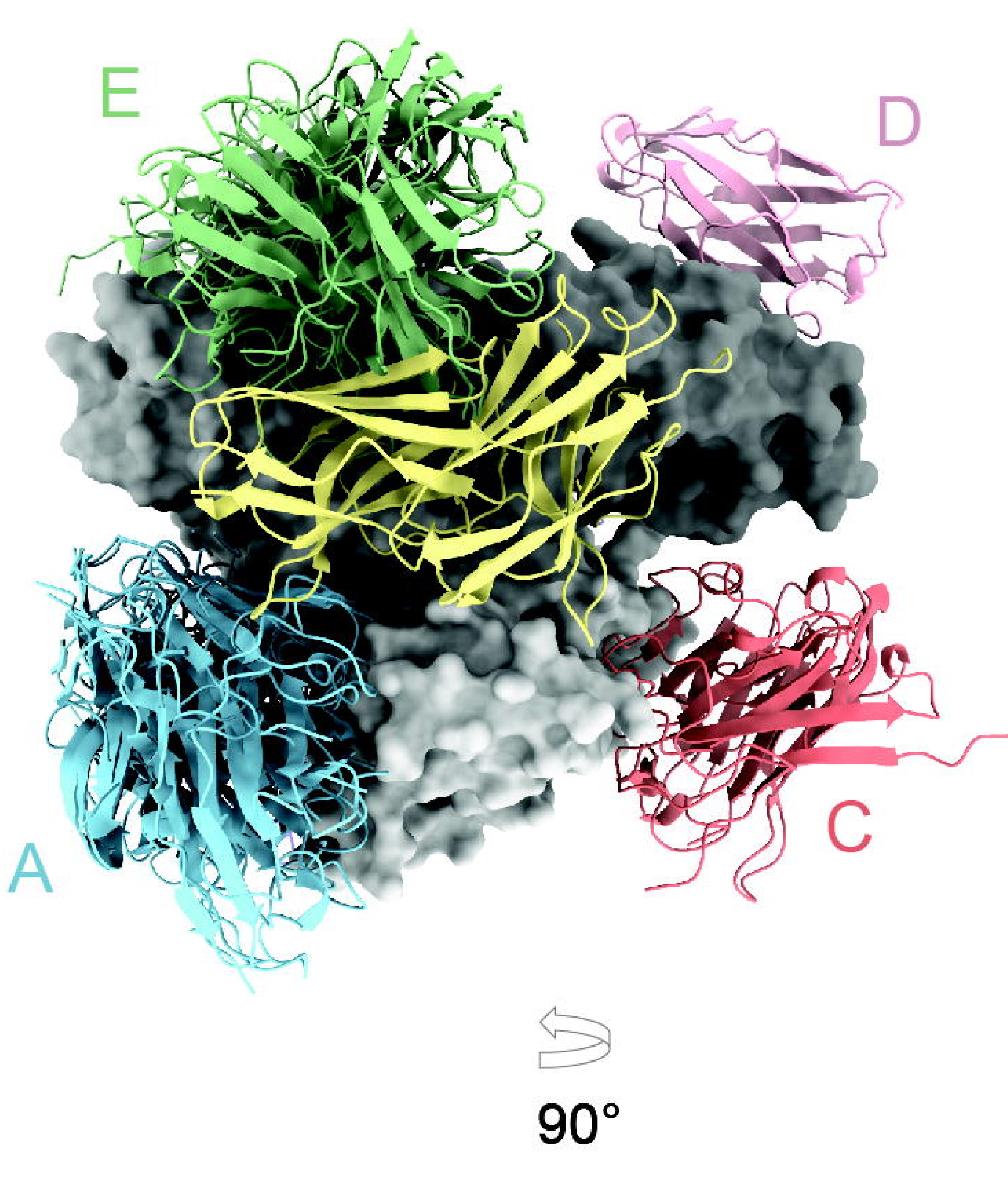

180

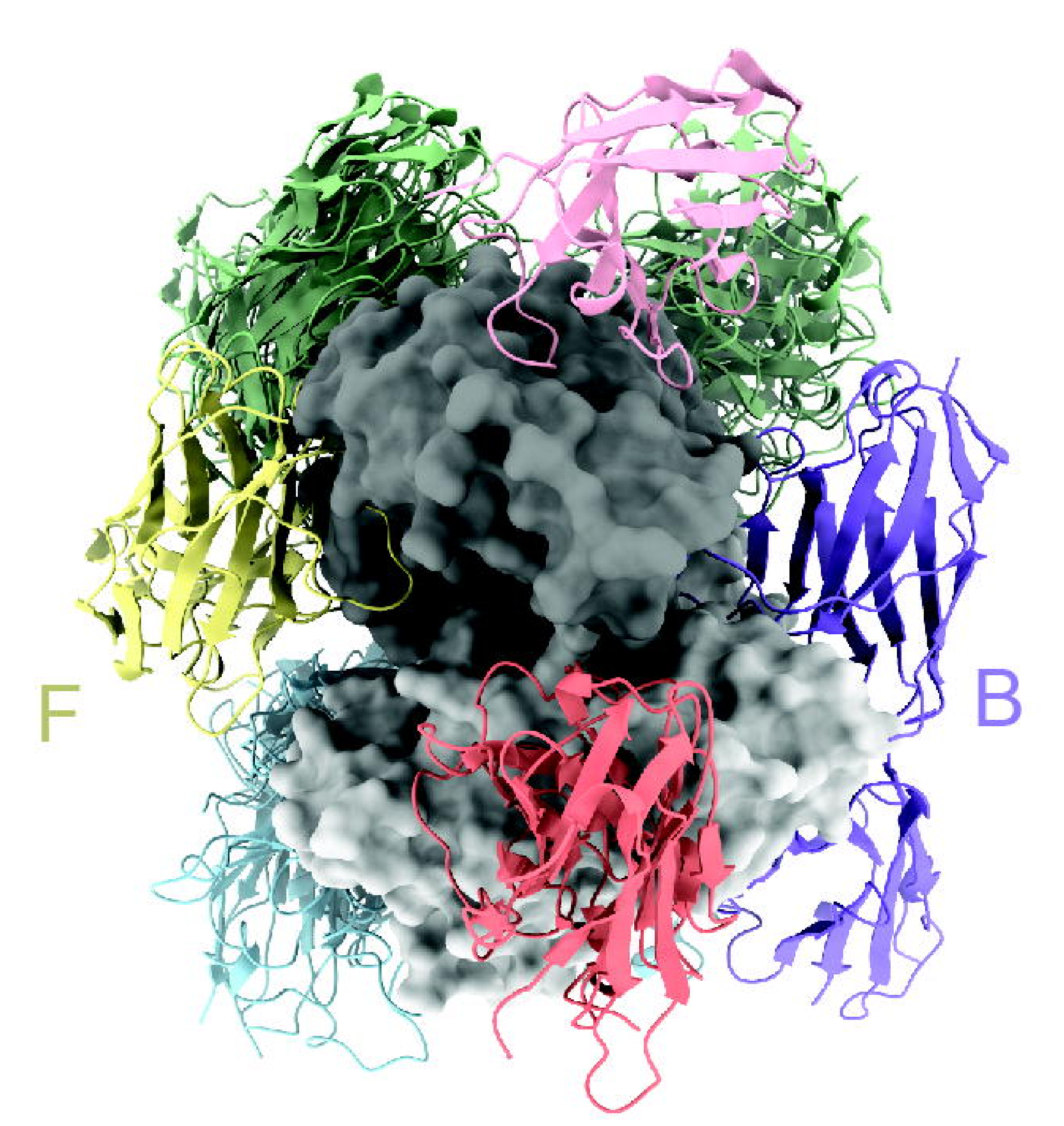

C

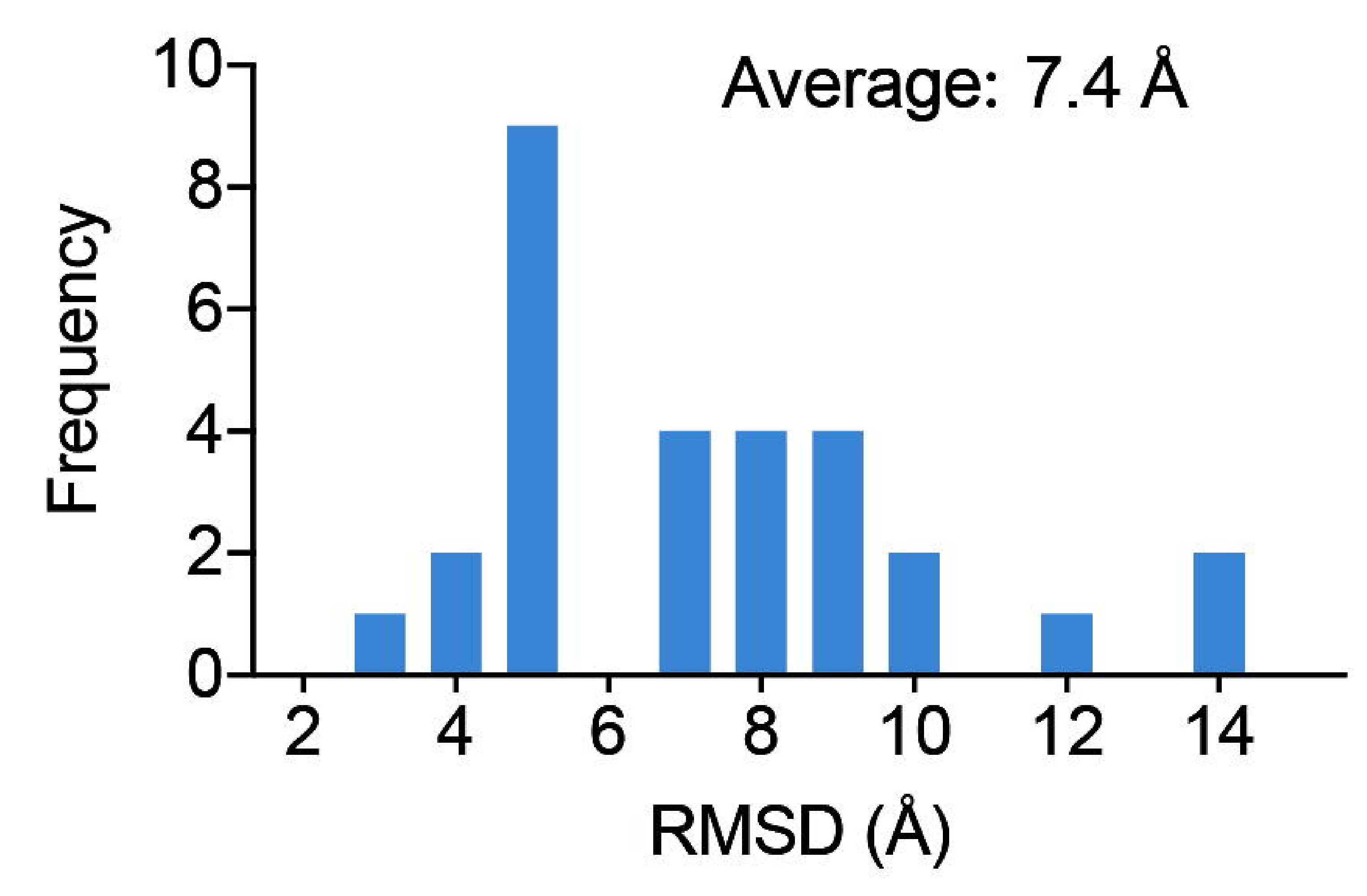

Residue contacts 
Figure 3

a

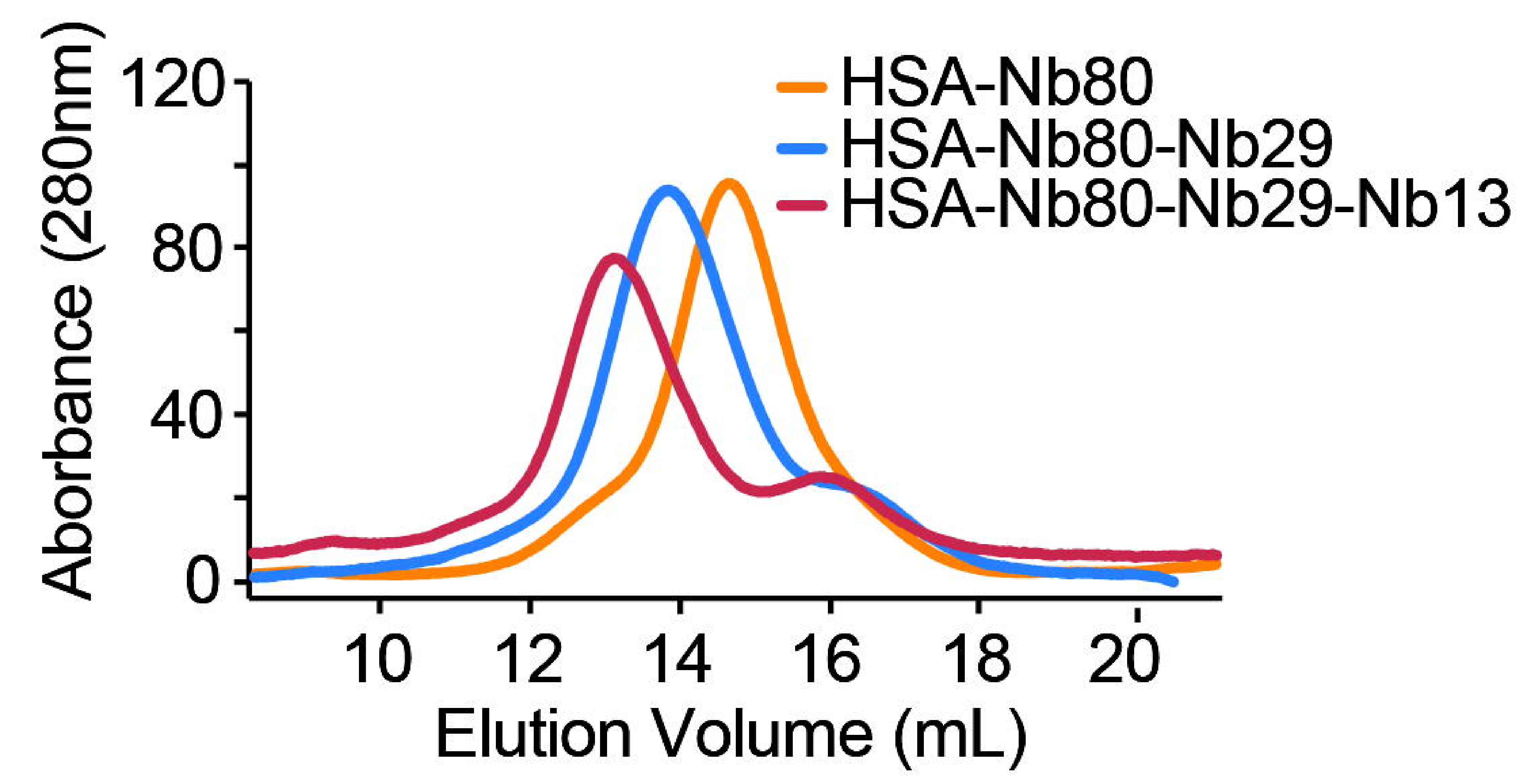

b

\begin{tabular}{|c|c|c|c|c|c|c|c|c|c|}
\hline 2 & 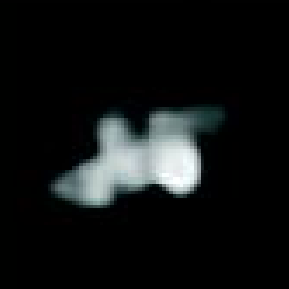 & $y$ & 4 & 6 & 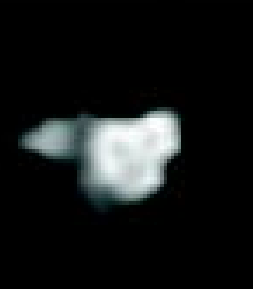 & $\Delta$ & $y$ & $\Rightarrow$ & \\
\hline & $P$ & $\mu$ & $x$ & $\Delta$ & 4 & $B$ & $x$ & 8 & \\
\hline & $=$ & 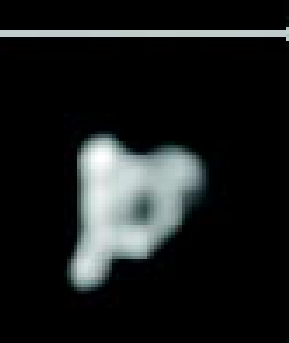 & $\mathbf{K}$ & 8 & $z$ & $n$ & a & of & \\
\hline
\end{tabular}

C
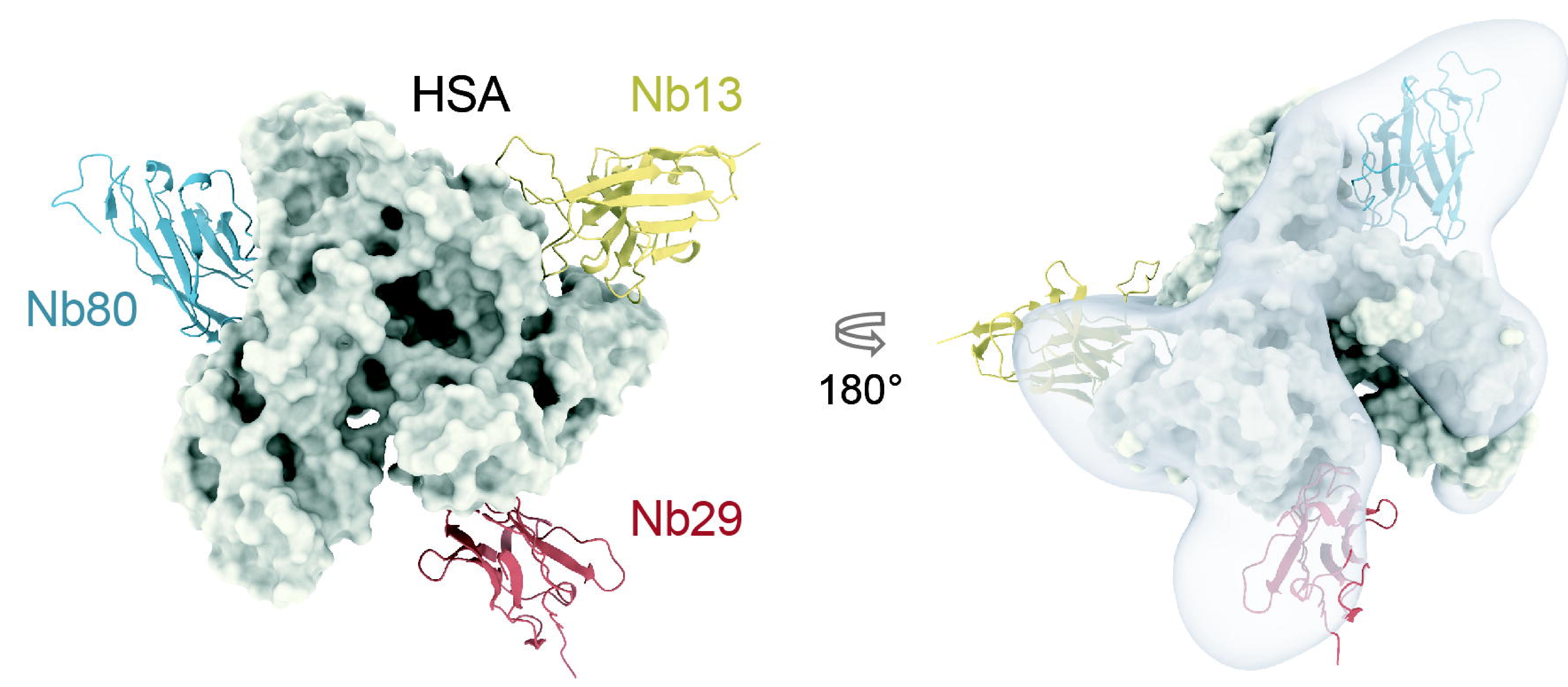

d

e
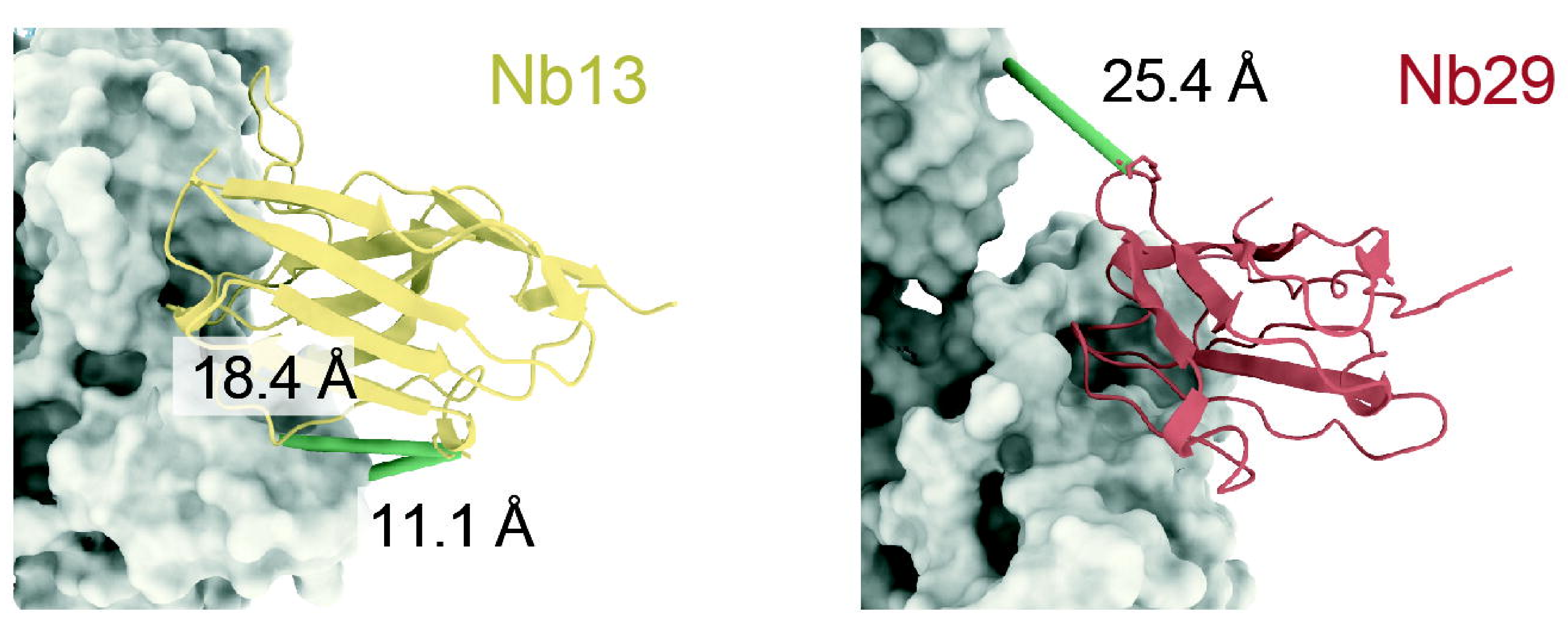

f

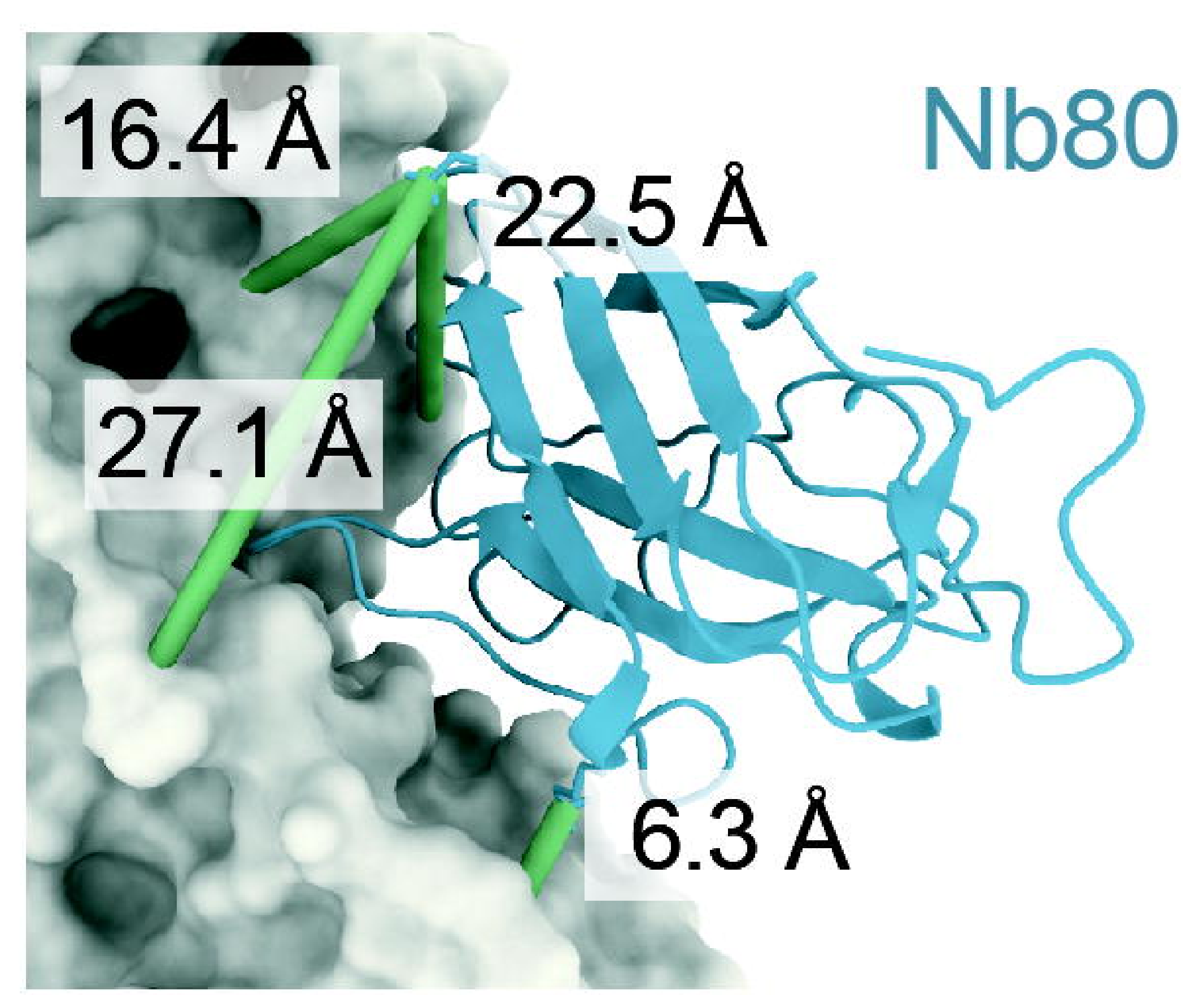

g

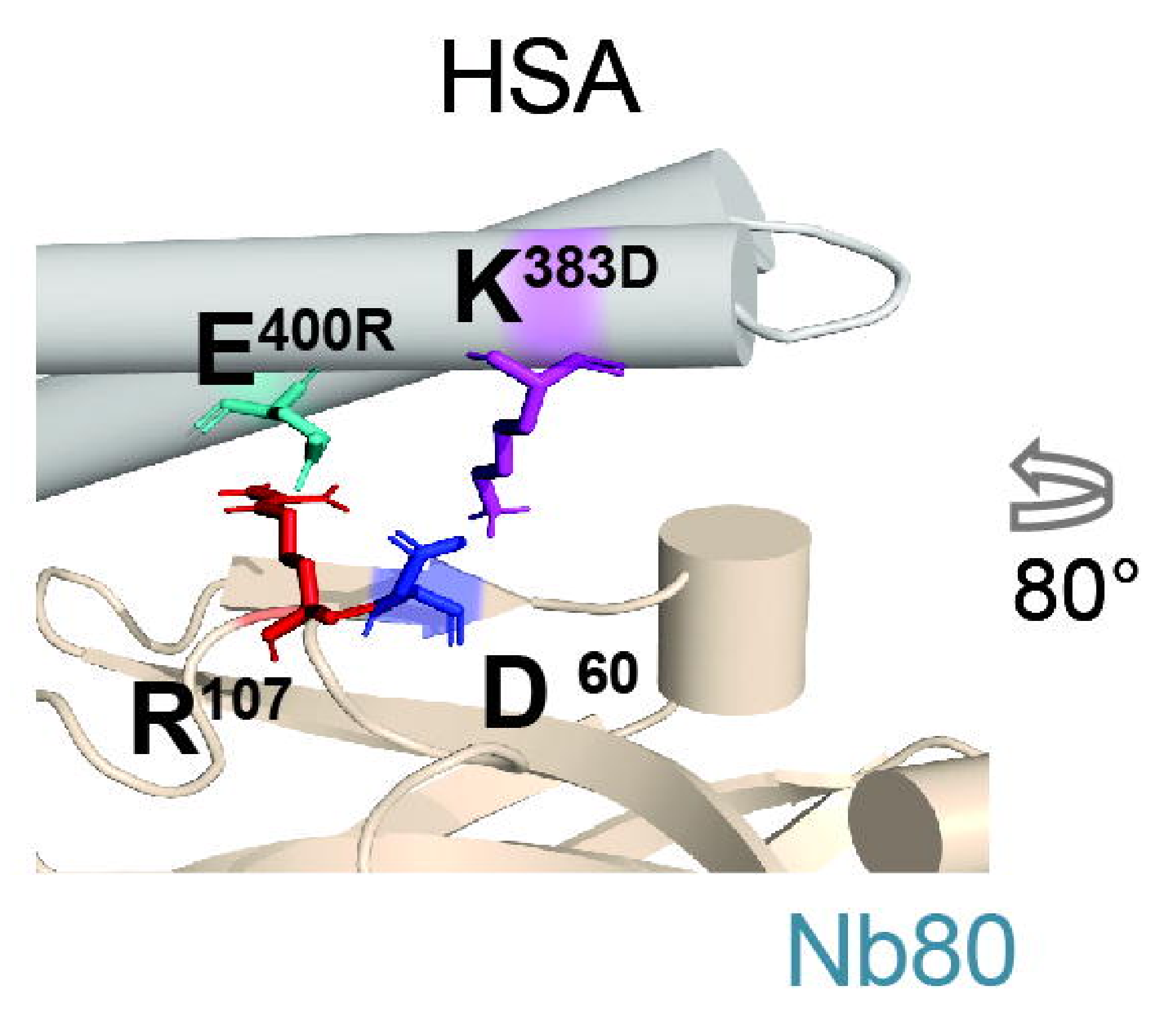

377 YETTLEKCCAAADPHECYAKVFDEF
401 YEATLEDCCAKDDPHACYATVFDKL

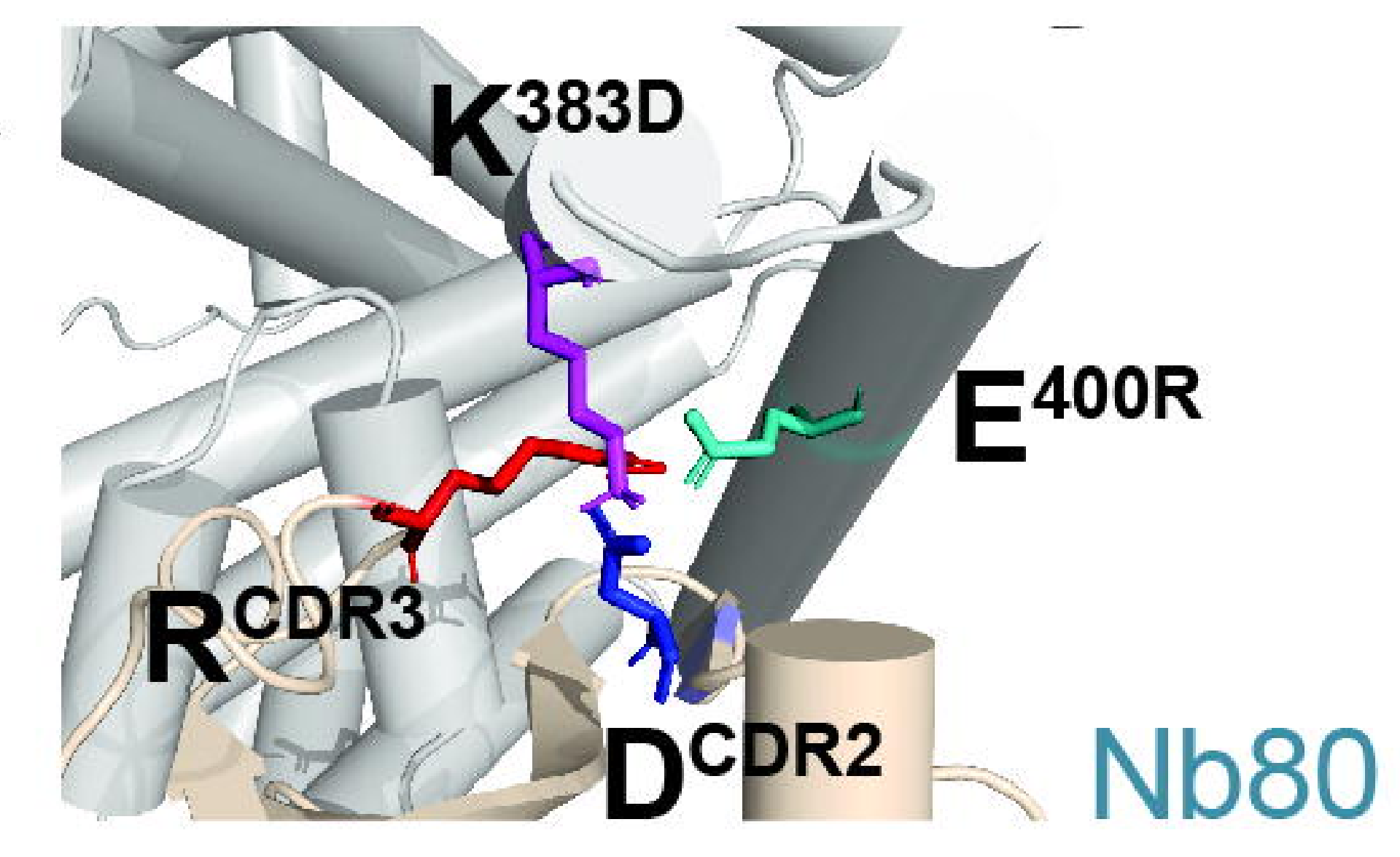

h

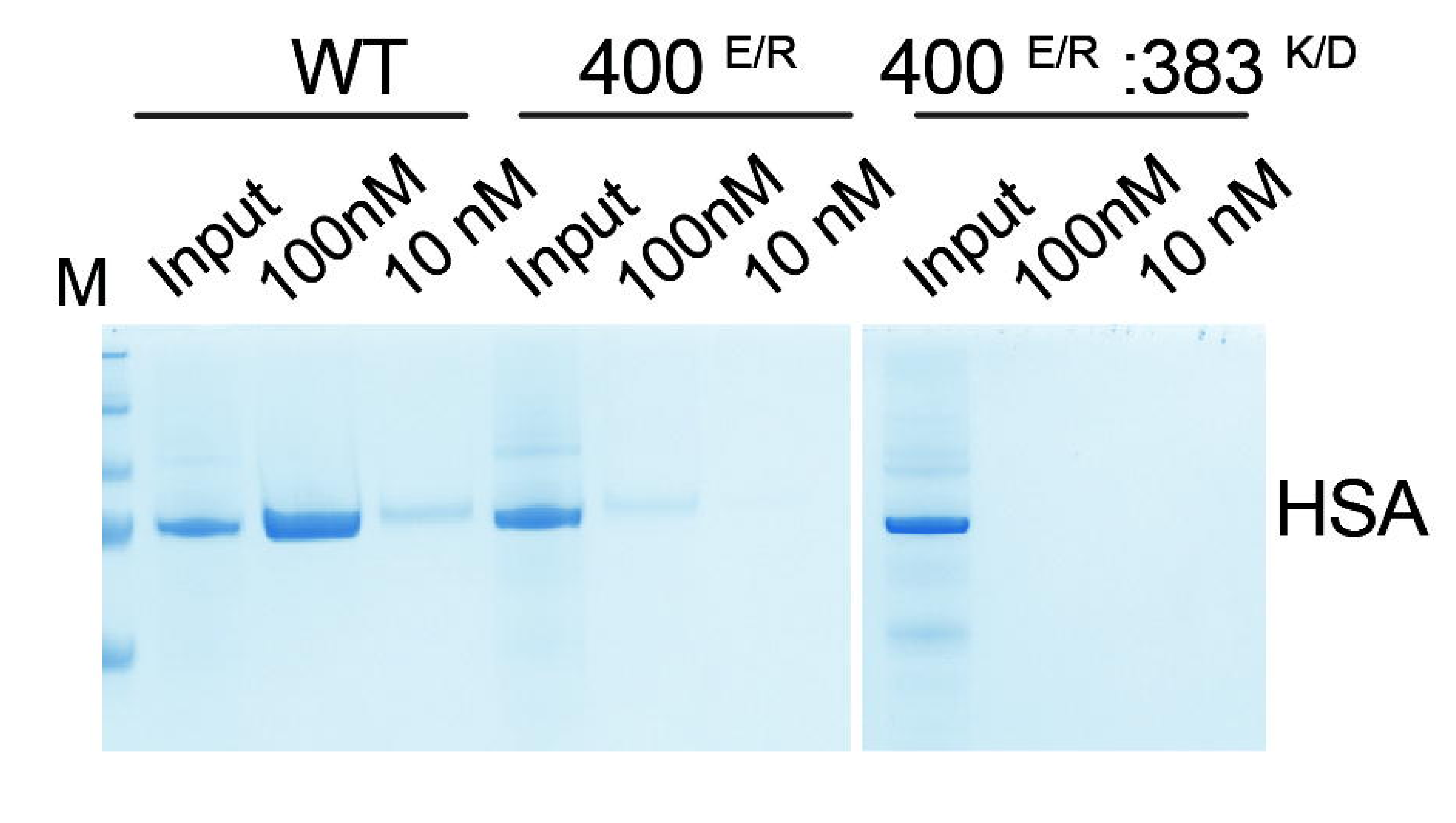


Figure 4

a

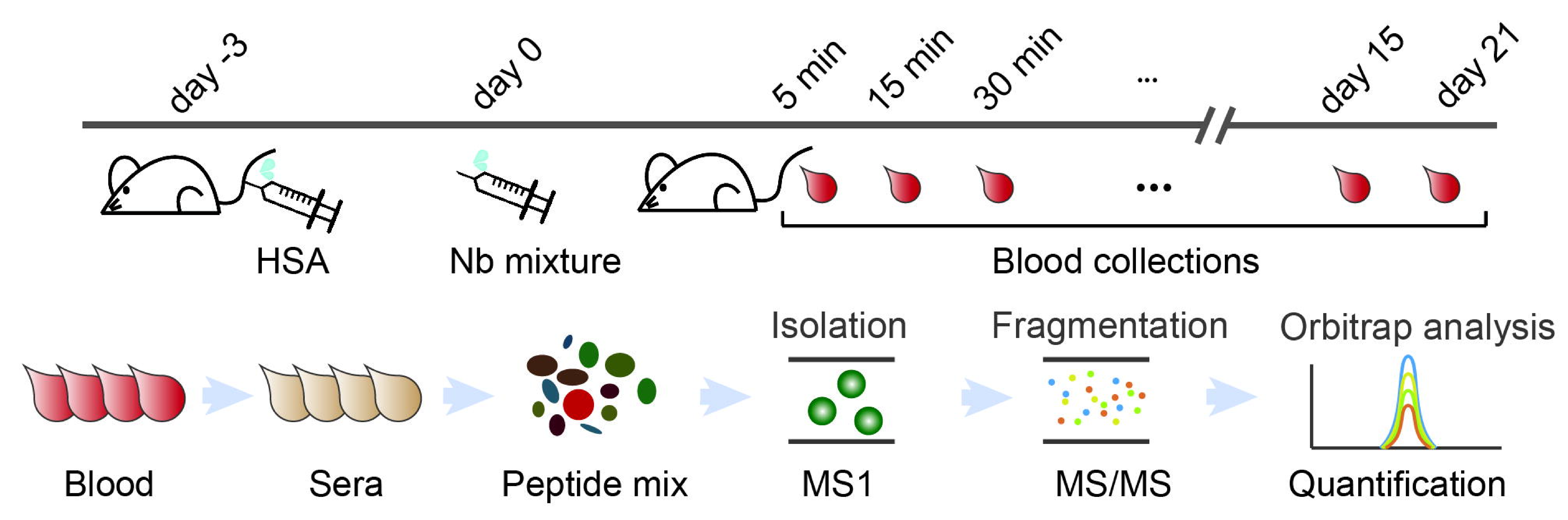

b
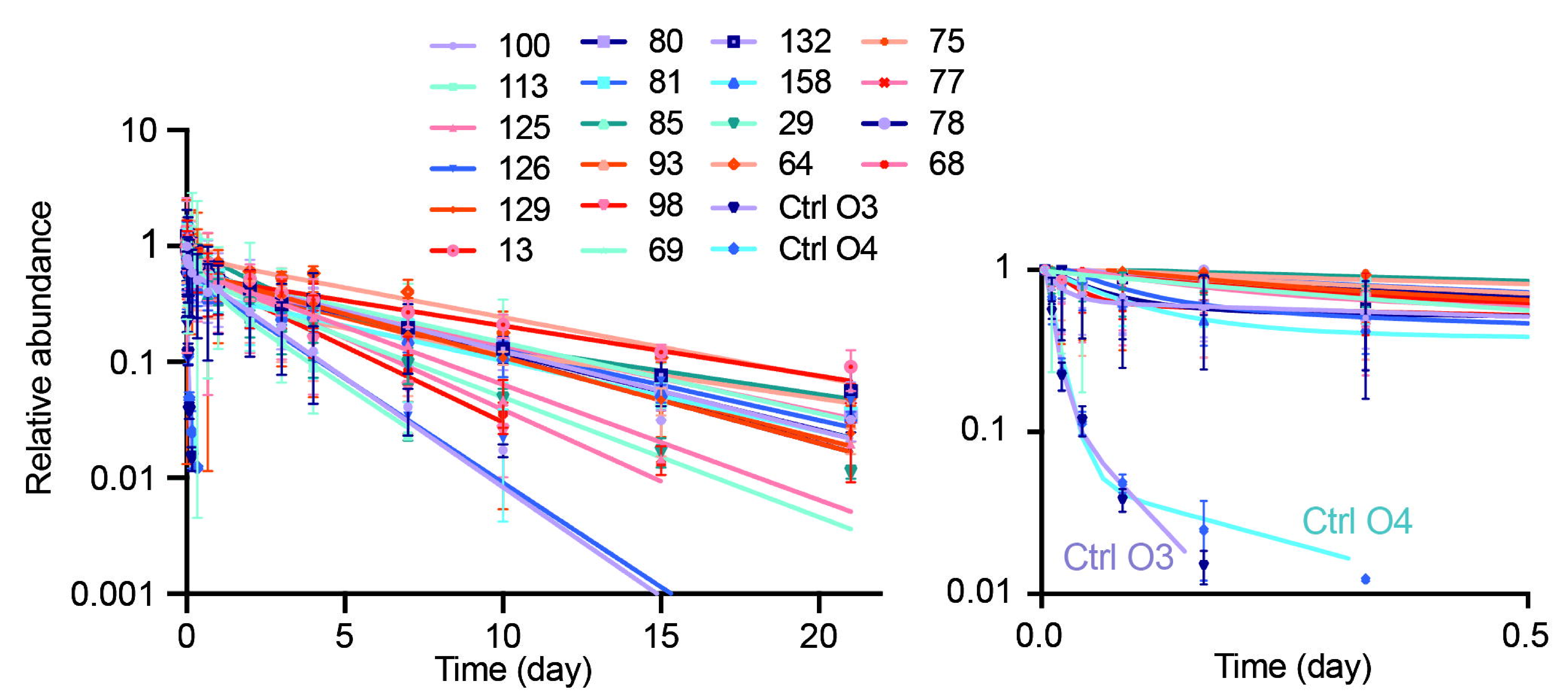

C

Distribution

Elimination

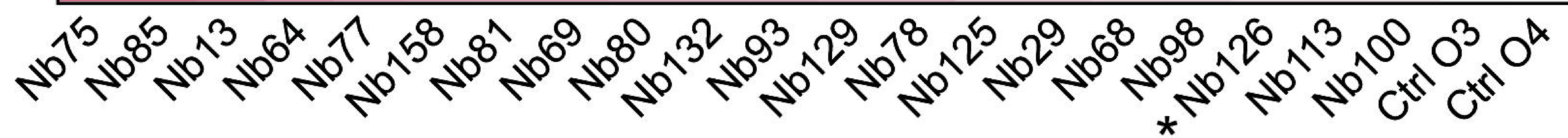

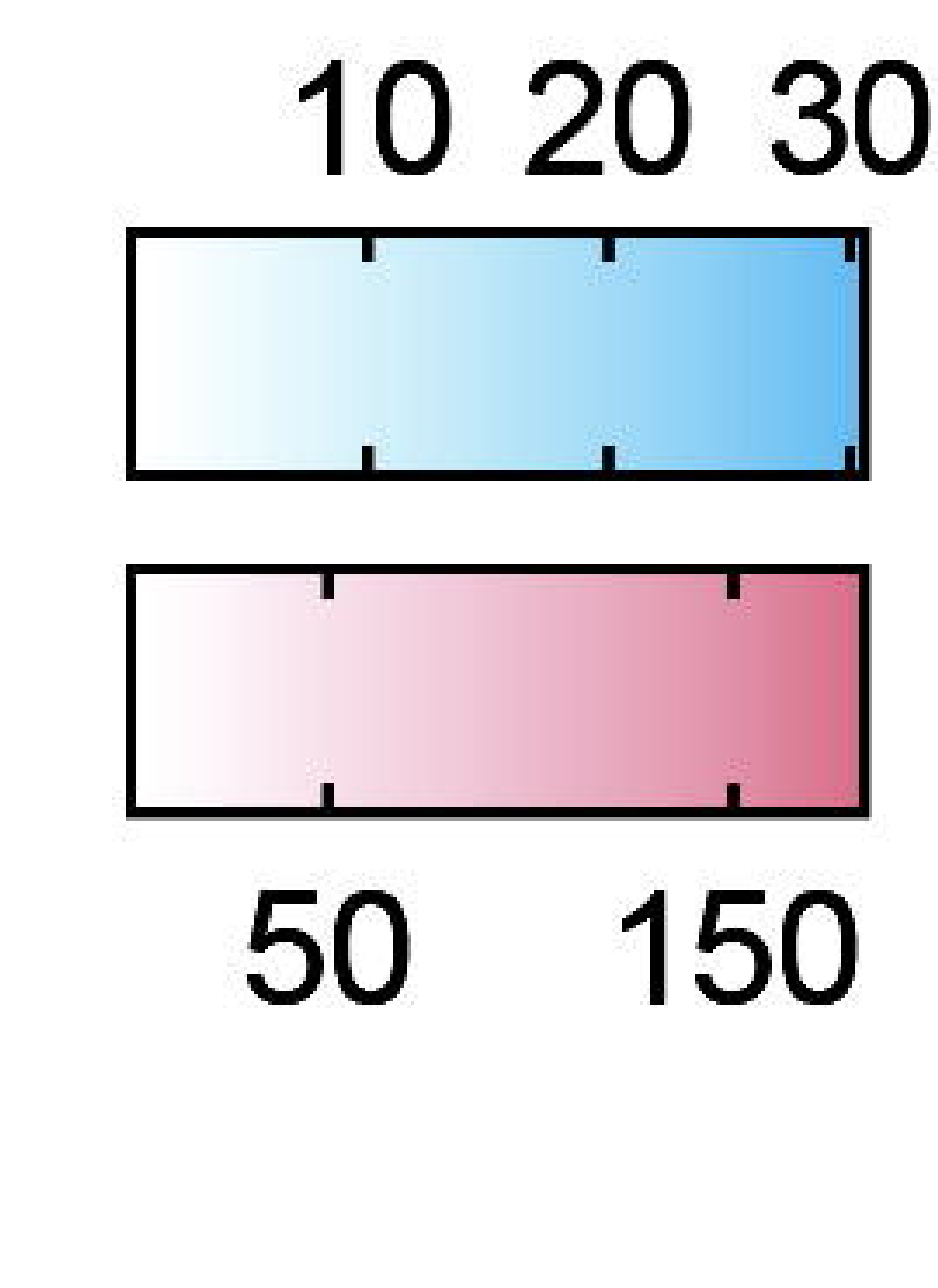

d

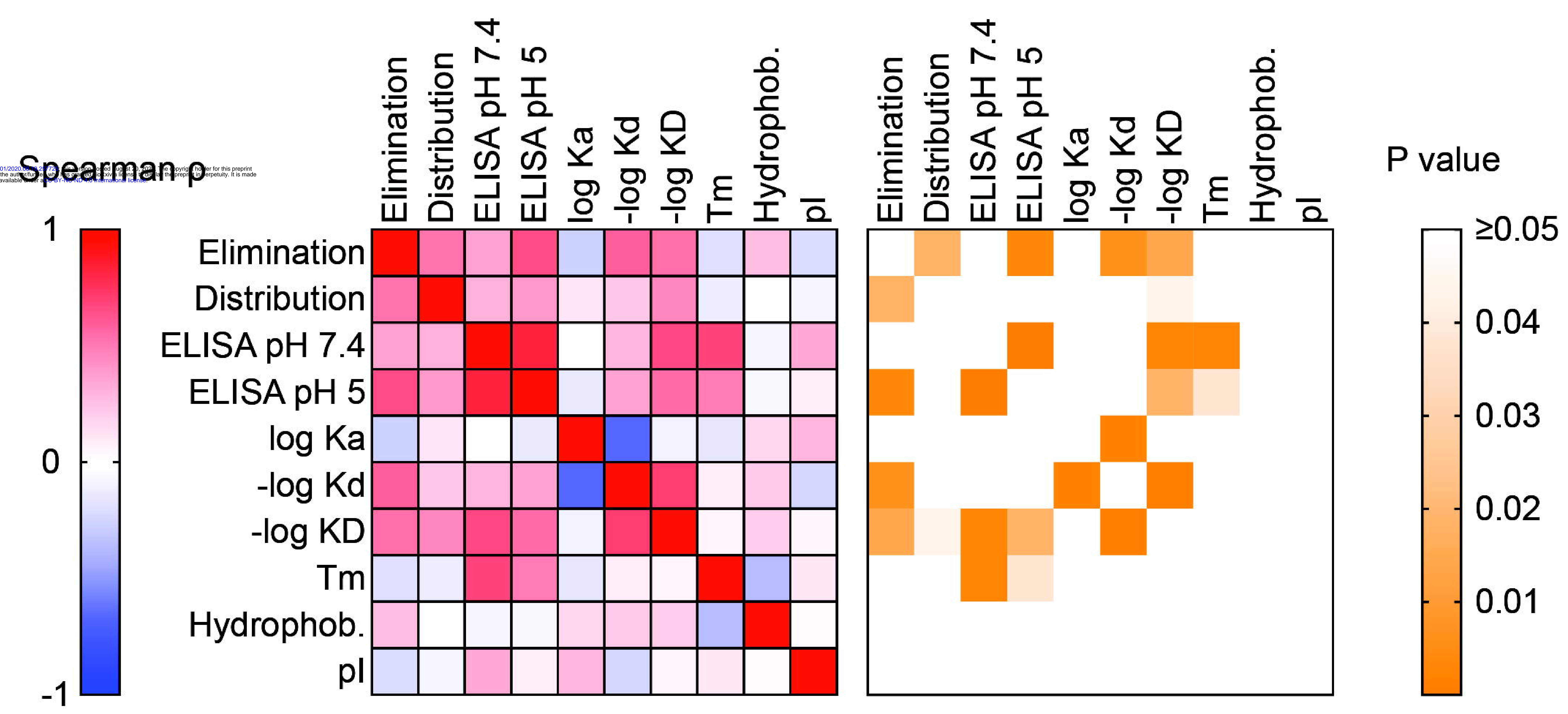


Figure 5

a

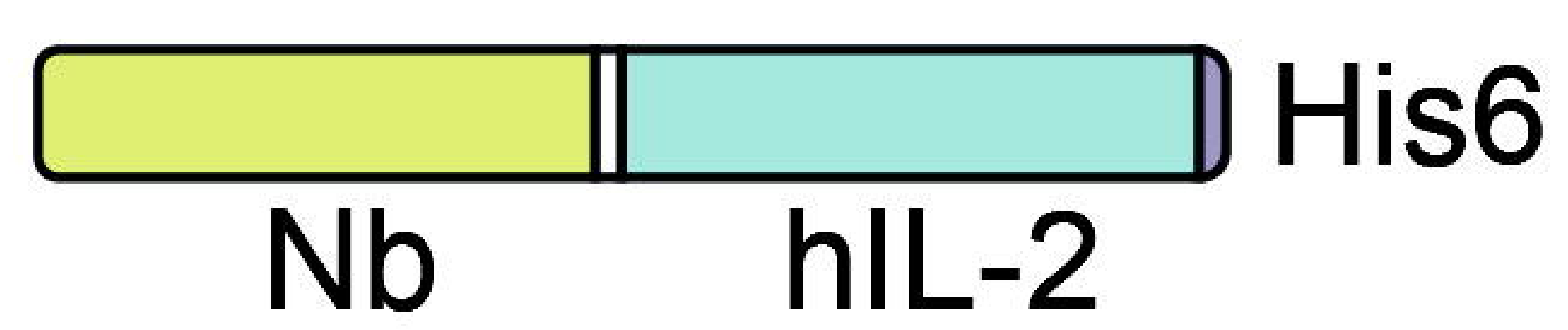

b

E. coli Culture

Harvest

Cell Pellet

Detergent

Wash

Water

Wash

Inclusion Body Denatured Protein d

$6 \mathrm{M} \mathrm{GuHCl}$

Folded Protein

His-tag

Purification

Refolding

\section{$S$ IB $F T$ E PBS}

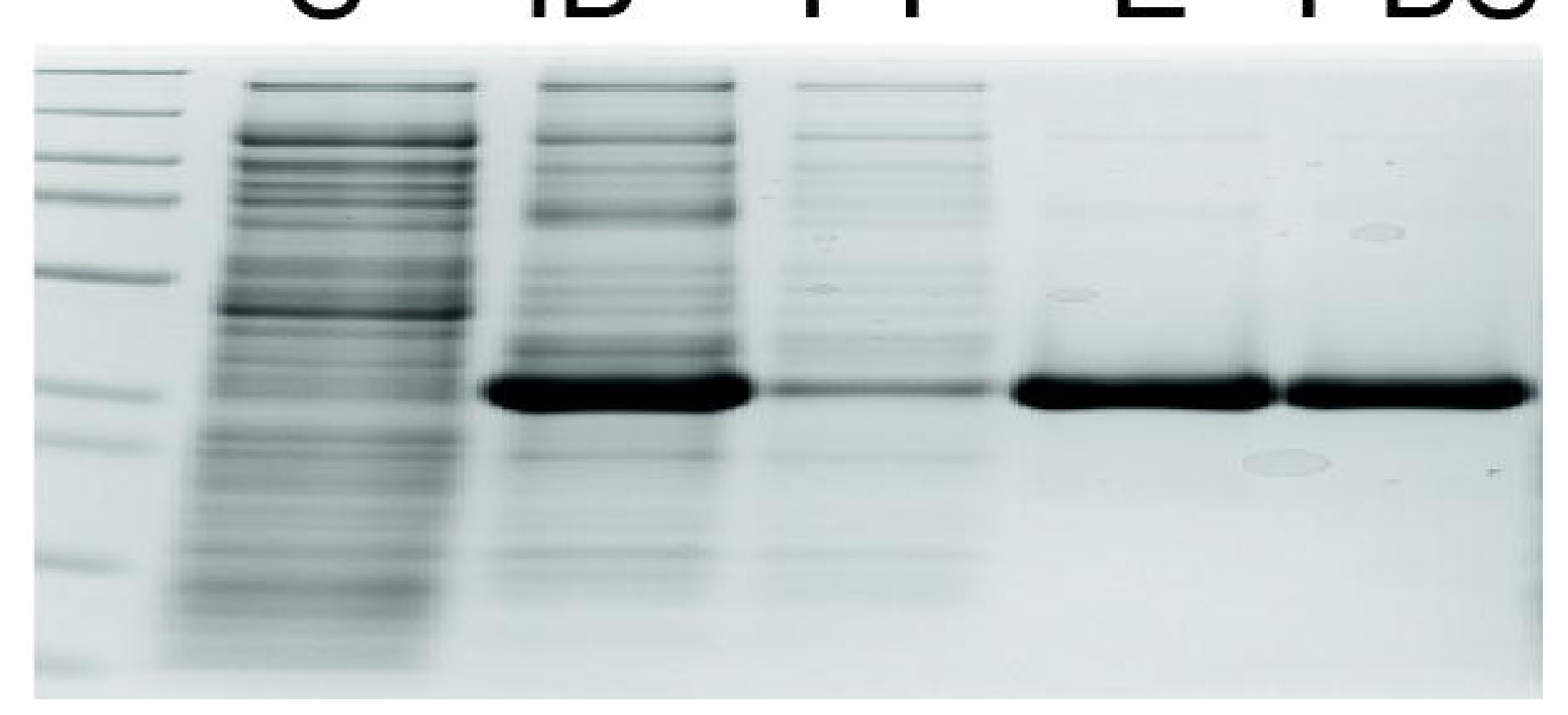

e

Duraleukin

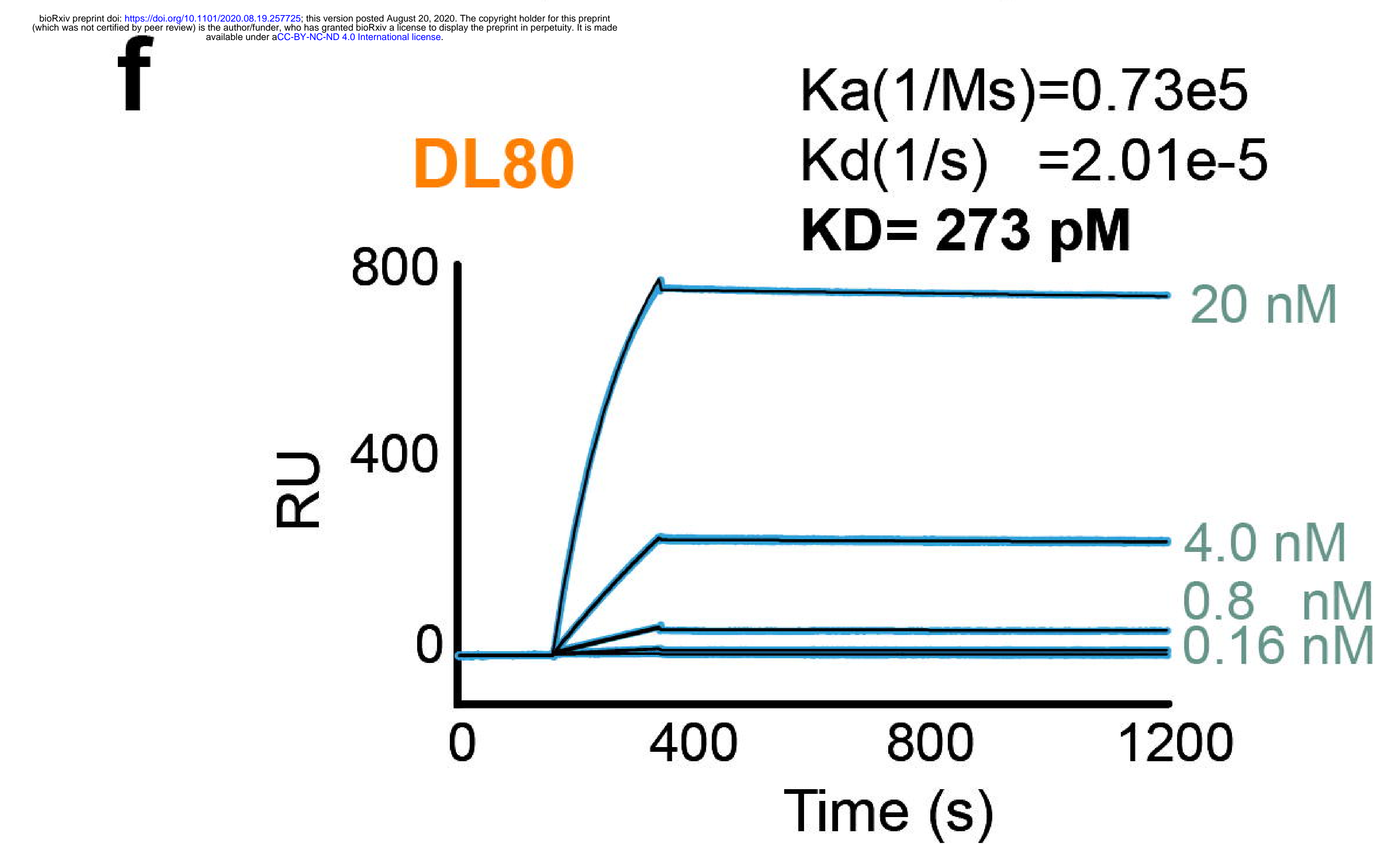

C

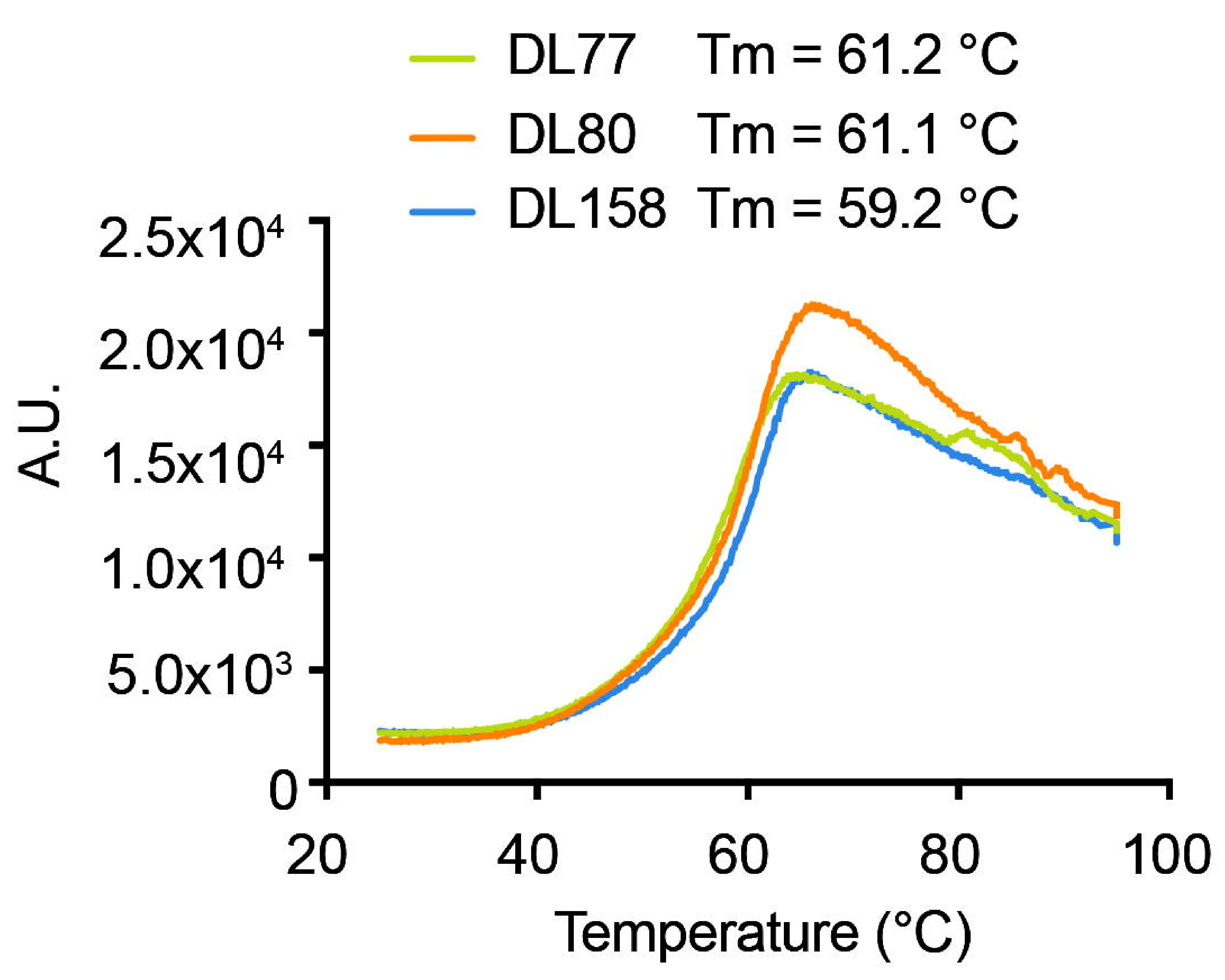

CTLL-2 IL-2

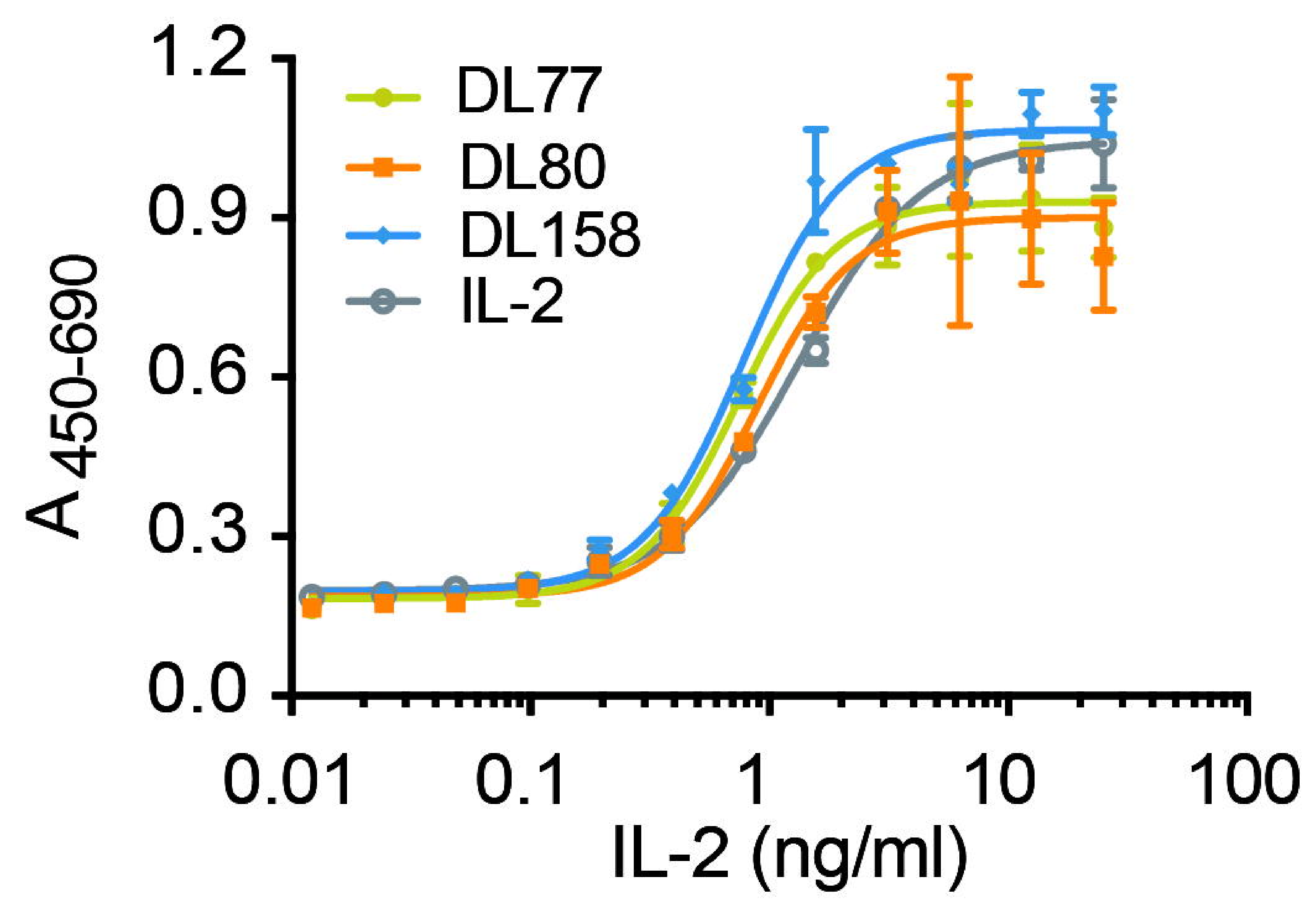

g

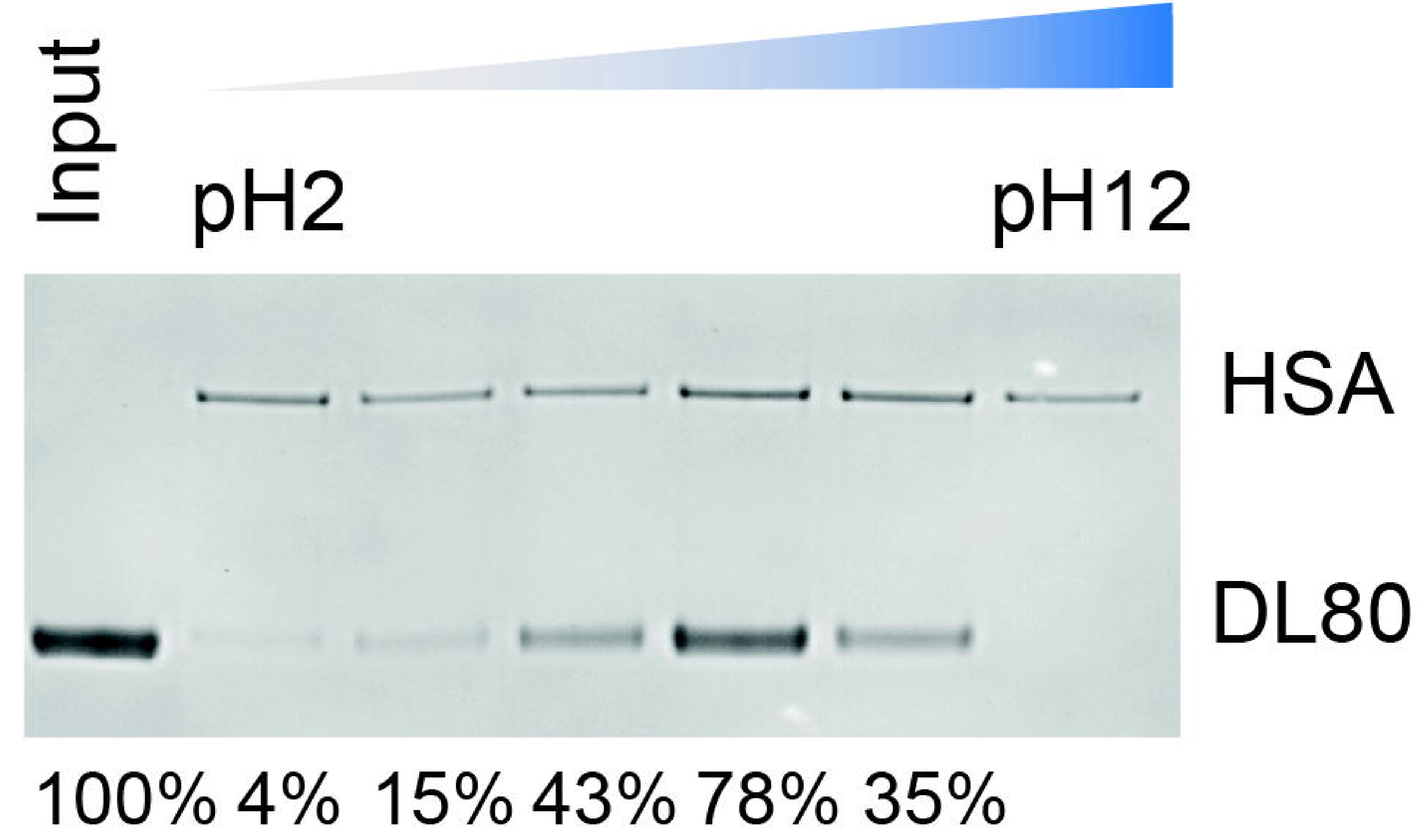


Figure 6

a

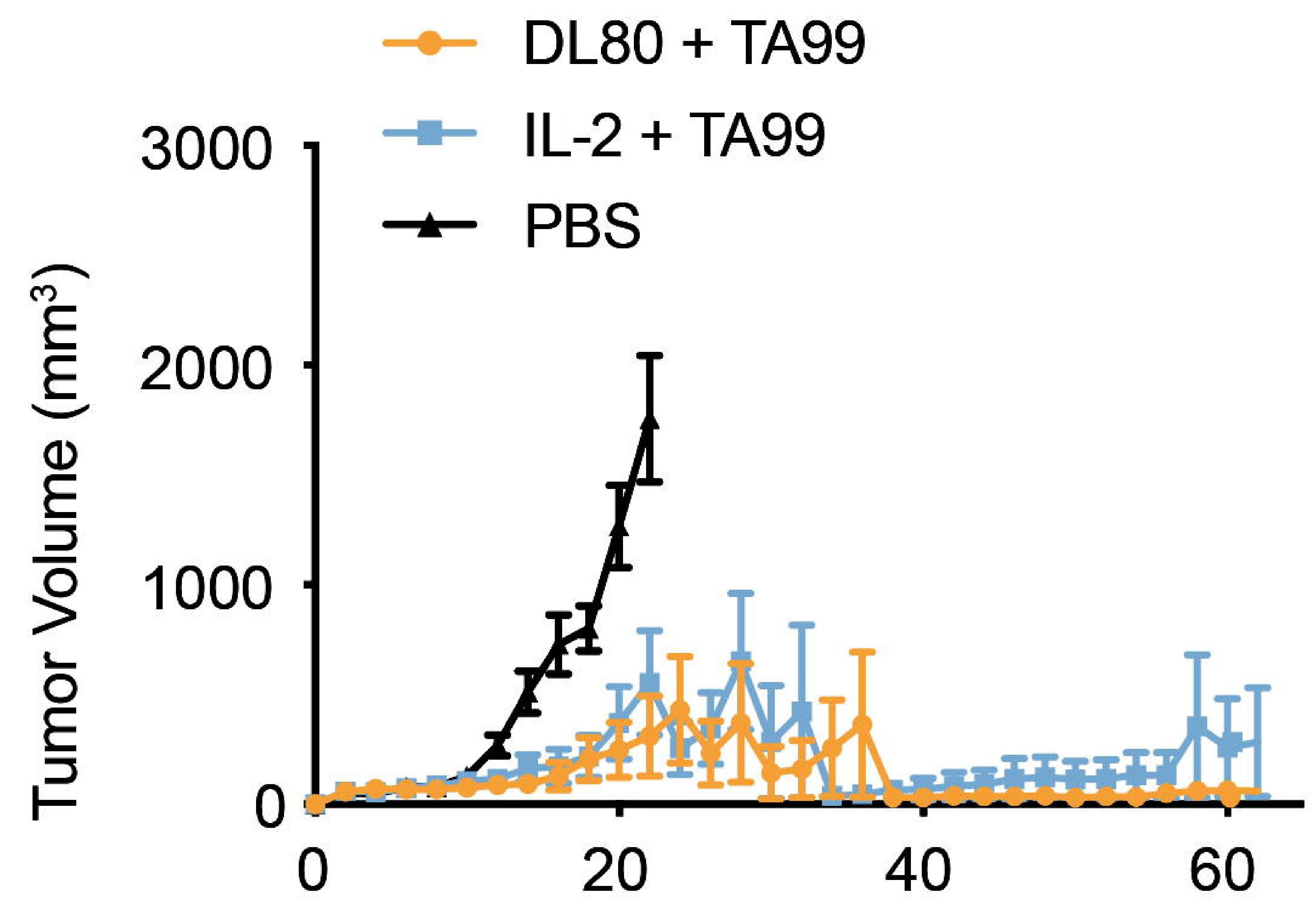

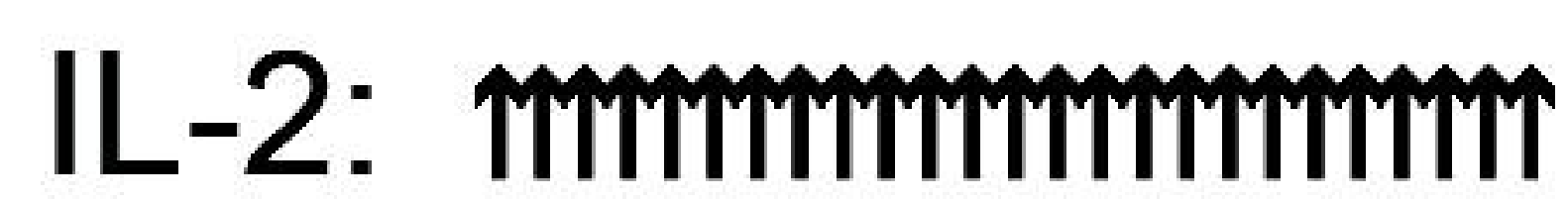

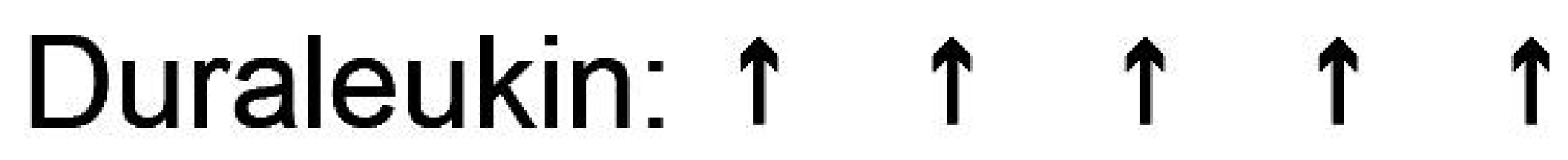

TA99: $\uparrow \quad \uparrow \quad \uparrow \quad \uparrow \quad \uparrow$

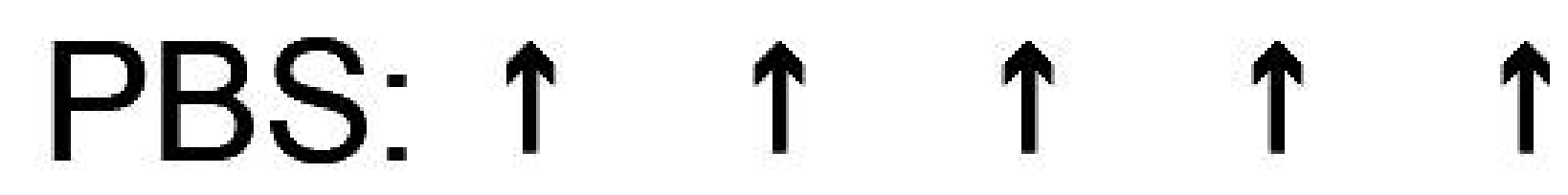

Time after tumor inoculation (days)

C

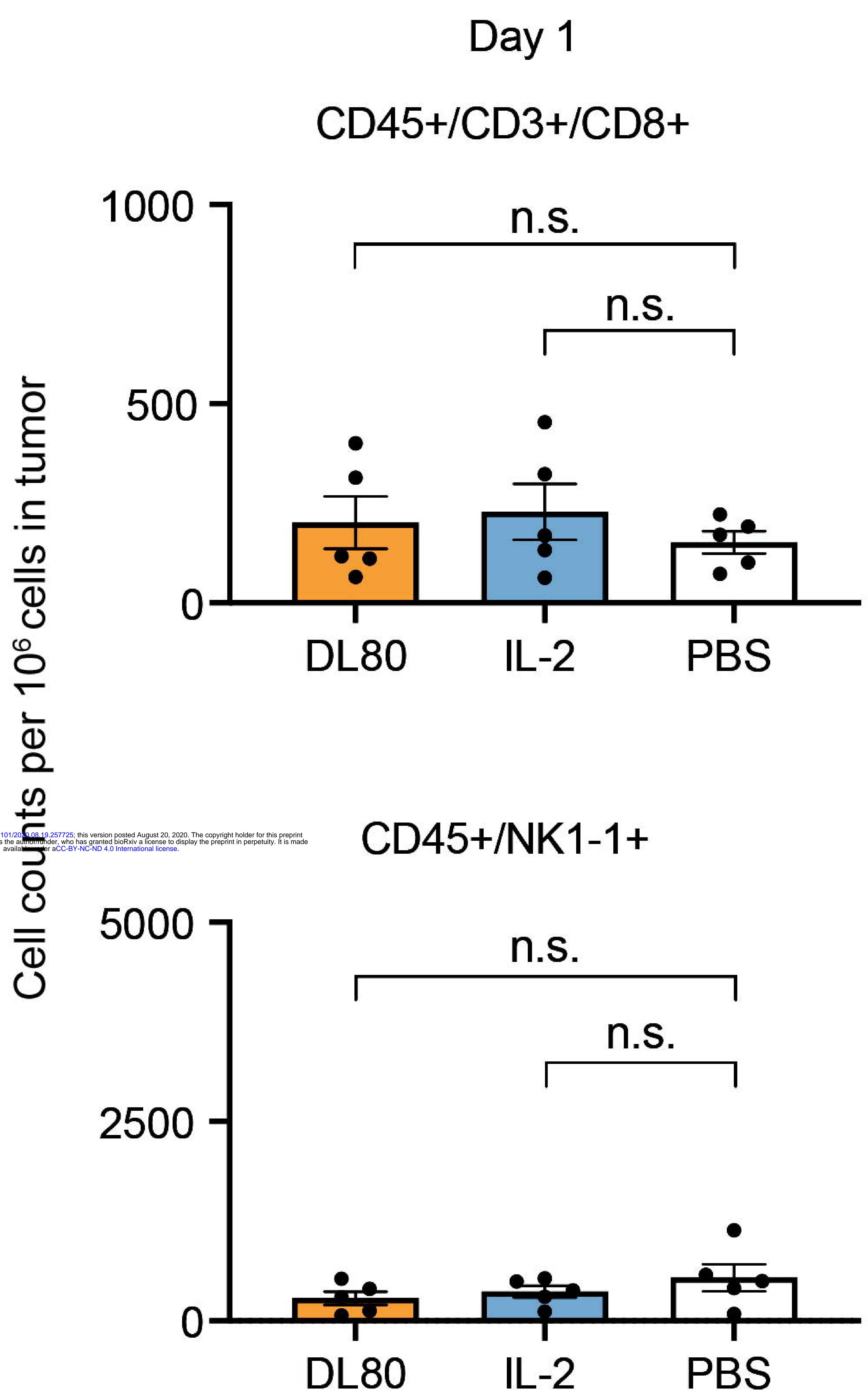

b

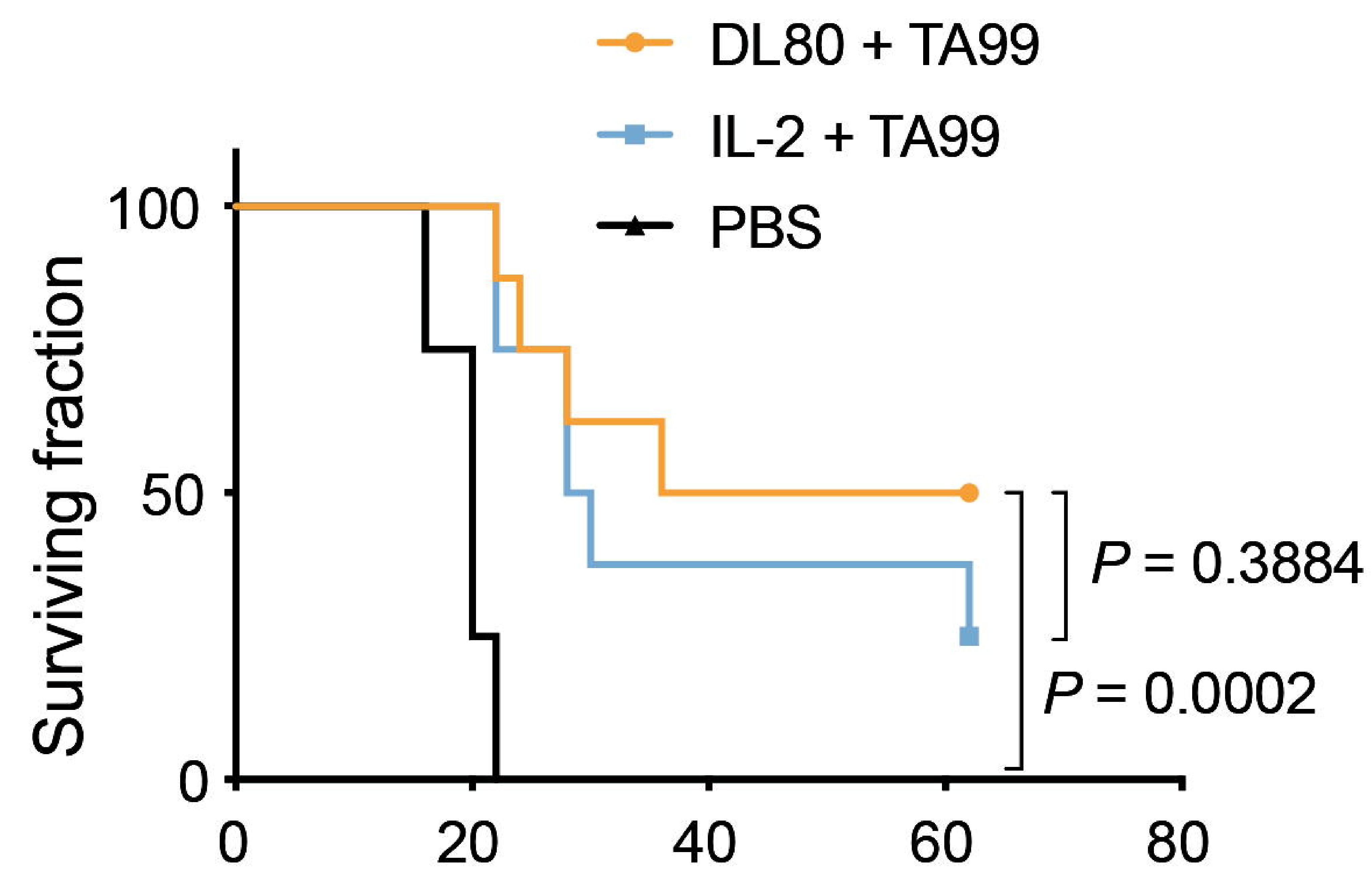

Time after tumor inoculation (days)

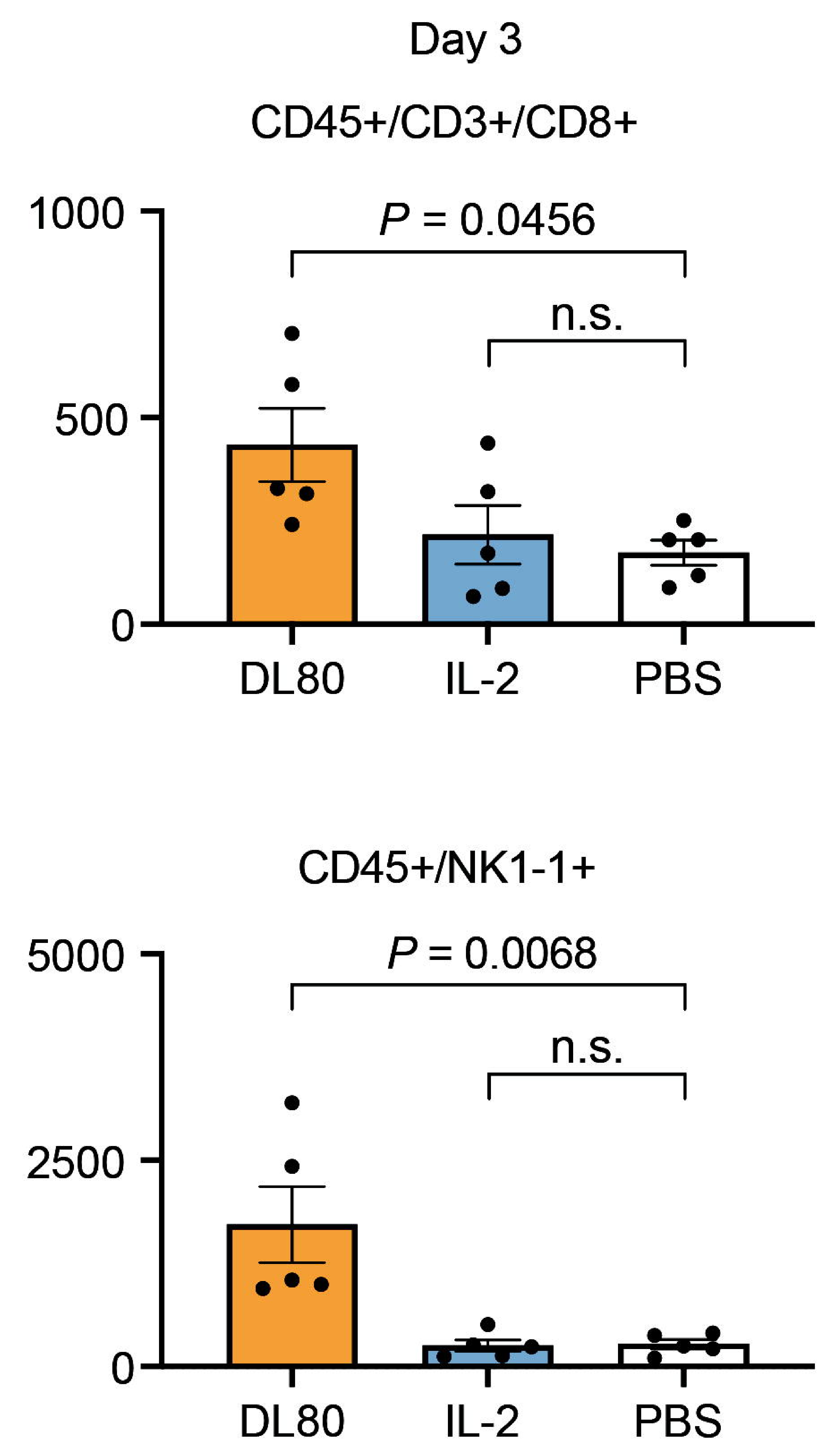

